Florida International University FIU Digital Commons

FIU Electronic Theses and Dissertations

University Graduate School

$11-5-2013$

\title{
Three Essays on the Microstructure of Exchange Traded Funds
}

Samique March

smarch01@fiu.edu

DOI: $10.25148 /$ etd.FI13121202

Follow this and additional works at: https://digitalcommons.fiu.edu/etd

Part of the Finance and Financial Management Commons

\section{Recommended Citation}

March, Samique, "Three Essays on the Microstructure of Exchange Traded Funds" (2013). FIU Electronic Theses and Dissertations. 1011.

https://digitalcommons.fiu.edu/etd/1011

This work is brought to you for free and open access by the University Graduate School at FIU Digital Commons. It has been accepted for inclusion in FIU Electronic Theses and Dissertations by an authorized administrator of FIU Digital Commons. For more information, please contact dcc@fiu.edu. 


\section{FLORIDA INTERNATIONAL UNIVERSITY}

Miami, Florida

THREE ESSAYS ON THE MICROSTRUCTURE OF EXCHANGE TRADED FUNDS

A dissertation submitted in partial fulfillment of the

requirements for the degree of

DOCTOR OF PHILOSOPHY

in

BUSINESS ADMINISTRATION

by

Samique March

2013 
To: $\quad$ Dean David R. Klock

College of Business Administration

This dissertation, written by Samique March, and entitled Three Essays on the Microstructure of Exchange Traded Funds, having been approved in respect to style and intellectual content, is referred to you for judgment.

We have read this dissertation and recommend that it be approved.

Arun J. Prakash

Robert Daigler

Suchismita Mishra, Major Professor

Date of Defense: November 5, 2013

The dissertation of Samique March is approved.

$\begin{array}{r}\text { Dean David R. Klock } \\ \text { College of Business Administration } \\ \hline \begin{array}{r}\text { Dean Lakshmi N. Reddi } \\ \text { University Graduate School }\end{array}\end{array}$

Florida International University, 2013 


\section{ACKNOWLEDGMENTS}

The African proverb starts with "It takes a village..." and I would end it with "...to get through a dissertation process." This dissertation has certainly been a group effort and I would be remiss if I did not acknowledge those that have played an important role in my completion. My family, especially my mother, Joan Richards, my husband, Donovan Dallas, and my daughter, Sariah Dallas, have provided immeasurable amounts of support and understanding throughout this journey; so, to them, I owe a plethora of thanks and appreciation - I could not have made it without you! Additionally, to my 'PhD baby', Sariah, thanks for constantly cheering me on, “Go, Mommy Go!"; you have provided much motivation to finish this project.

I gratefully acknowledge the Florida Education Fund in the granting of the McKnight Doctoral Fellowship and the mentorship, assistance, and support from them that made this dissertation possible. I also graciously acknowledge the support and mentorship provided by the Department of Finance at Florida International University through its professors and administrative staff. My committee led by Dr. Mishra has stood behind me in pushing to get this dissertation defended and approved, so to them I owe my absolute gratitude. Furthermore, the $\mathrm{PhD}$ Project has been a source of new friends and support when I needed it most, so I want to extend a heartfelt thanks to them as well. 


\section{ABSTRACT OF THE DISSERTATION \\ THREE ESSAYS ON THE MICROSTRUCTURE OF EXCHANGE TRADED FUNDS}

by

Samique March

Florida International University, 2013

Miami, Florida

Professor Suchismita Mishra, Major Professor

Exchange traded funds (ETFs) have increased significantly in popularity since they were first introduced in 1993. However, there is still much that is unknown about ETFs in the extant literature. This dissertation attempts to fill gaps in the ETF literature by using three related essays. In these three essays, we compare ETFs to closed ended mutual funds (CEFs) by decomposing the bid-ask spread into its three components; we look at the intraday shape of ETFs and compare it to the intraday shape of equities as well as examine the co-integration factor between ETFs on the London Stock Exchange and the New York Stock Exchange; we also examine the differences between leveraged ETFs and unleveraged ETFs by analyzing the impact of liquidity and volatility. These three essays are presented in Chapters 1,2 , and 3, respectively.

Chapter one uses the Huang and Stoll (1997) model to decompose the bid-ask spread in CEFs and ETFs for two distinct periods - a normal and a volatile period. We show a higher adverse selection component for CEFs than for ETFs without regard to volatility. However, both ETFs and CEFs increased in magnitude of the adverse selection component in the period of high volatility. Chapter two uses a mix of the Werner and Kleidon (1993) and the Hupperets and Menkveld (2002) methods to get the intraday shape of ETFs and analyze co-integration between London and New York trading. We find two different shapes for New York and London ETFs. There also appears to be evidence of co-integration in the overlapping two-hour trading period but not over the entire trading day for the two locations. The third chapter discusses the new class 
of ETFs called leveraged ETFs. We examine the liquidity and depth differences between unleveraged and leveraged ETFs at the aggregate level and when the leveraged ETFs are classified by the leveraged multiples of $-3,-2,-1,2$, and 3 , both for a normal and a volatile period. We find distinct differences between leveraged and unleveraged ETFs at the aggregate level, with leveraged ETFs having larger spreads than unleveraged ETFs. Furthermore, while both leveraged and unleveraged ETFs have larger spreads in high volatility, for the leveraged ETFs the change in magnitude is significantly larger than for the unleveraged ETFs. Among the multiples, the -2 leveraged ETF is the most pronounced in its liquidity characteristics, more so in volatile times. 


\section{TABLE OF CONTENTS}

CHAPTER

PAGE

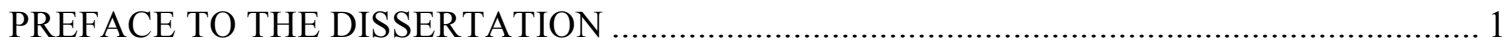

CHAPTER 1: ADVERSE SELECTION AS DEPICTED BY ETFS AND CEFS ....................... 5

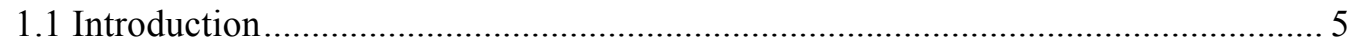

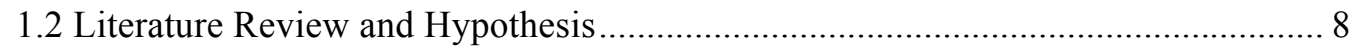

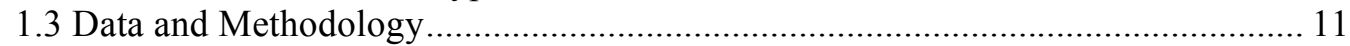

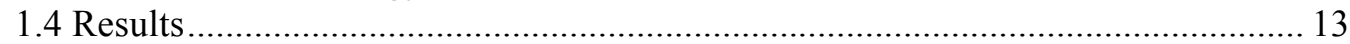

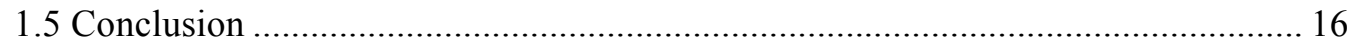

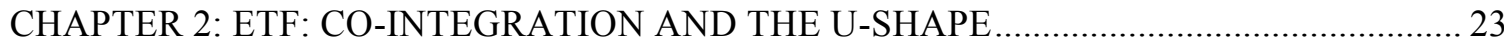

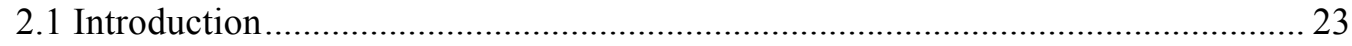

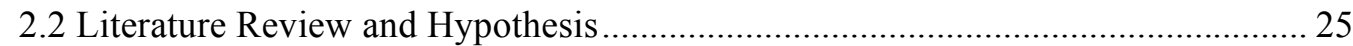

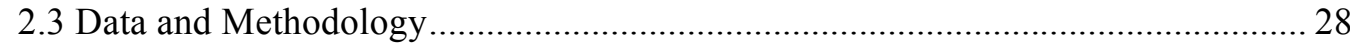

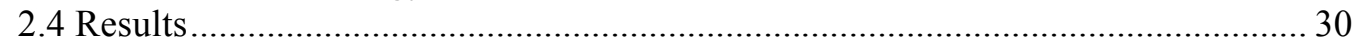

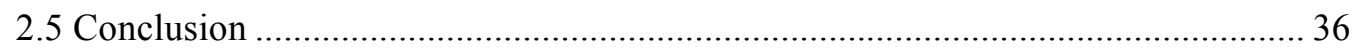

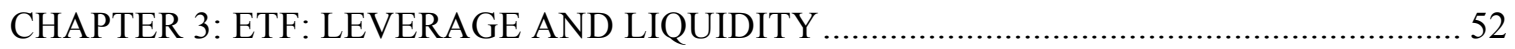

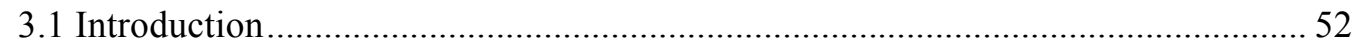

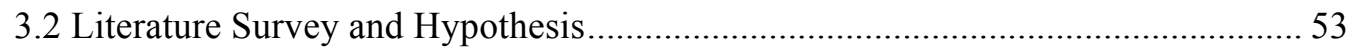

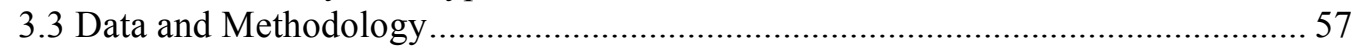

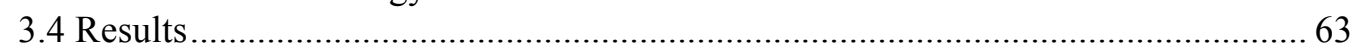

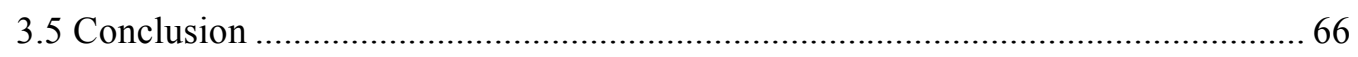

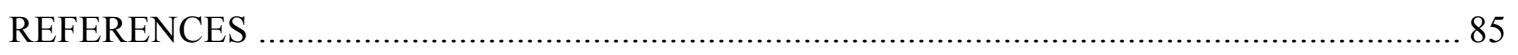

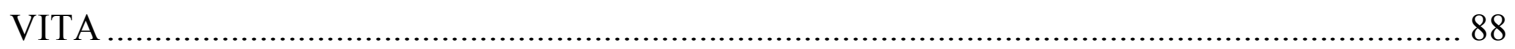




\section{LIST OF TABLES}

TABLE

PAGE

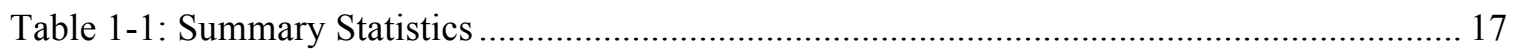

Table 1-2: Traded Spread and Order Processing Component................................................... 18

Table 1-3: Traded Spread and Order Processing Component by Trade Size ............................... 19

Table 1-4: Restricted Models of Traded Spread and Order Processing Component by Trade Size

Table 1-5: Components of the Bid-Ask Spread based on Serial Correlation in Trade Flows

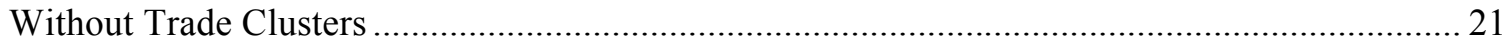

Table 1-6: Components of the Bid-Ask Spread based on Serial Correlation in Trade Flows with

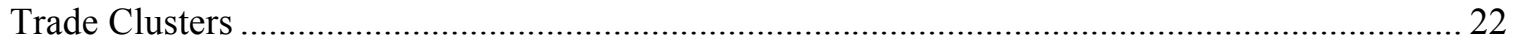

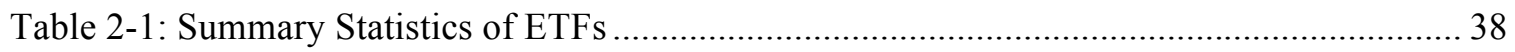

Table 2-2: Summary Statistics in the Two-Hour Overlap Period for ETFs ................................... 39

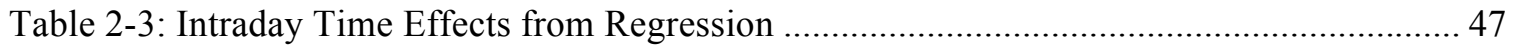

Table 2-4: Correlations of trade price returns during the overlapping two-hour period................ 50

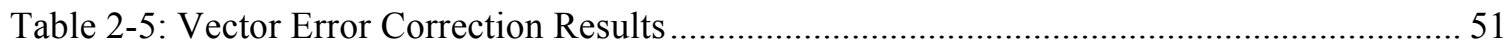

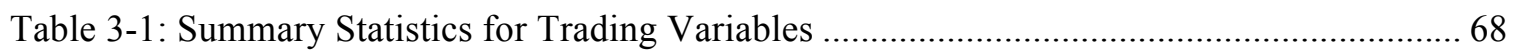

Table 3-2: Summary Statistics for Trading Variables by Leveraged Multiple ............................. 73

Table 3-3: Difference of Means Test Results .......................................................................... 79

Table 3-4: Jonckheere-Terpstra Test Results for Spreads, Ask Size (AS) and Bid Size (BS) in

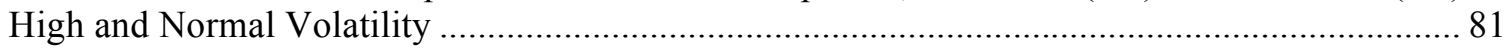

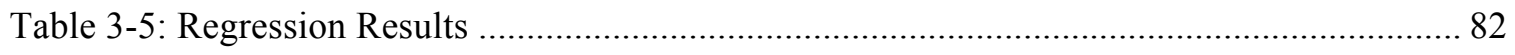

Table 3-6: Z statistic for Comparing Regression Coefficients in High Volatility ........................ 83

Table 3-7: Z statistic for Comparing Regression Coefficients in Normal Volatility ..................... 84 


\section{LIST OF FIGURES}

\section{FIGURE}

PAGE

Figure 2-1: The stylized U-shape for integrated markets.

Figure 2-2: Intraday patterns for all New York ETFs for 2008 and 2010. 40

Figure 2-3: Intraday patterns for all New York iShares ETFs for 2008 and 2010. 41

Figure 2-4: Intraday patterns for all London iShares ETFs for 2008 and 2010 ............................ 42

Figure 2-5: Intraday patterns for dual listed New York iShares ETFs for 2008 and 2010_.......... 43

Figure 2-6: Intraday patterns for dual listed Londn iShares ETFs for 2008 and 2010 ................ 44

Figure 2-7: Intraday patterns for all dual-listed New York iShares ETFs in the overlapping period for 2008 and 2010. 45

Figure 2-8: Intraday patterns for all dual-listed London iShares ETFs in the overlapping period

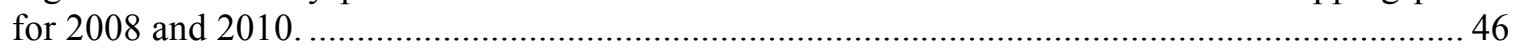

Figure 3-1: All, Leveraged, and Unleveraged ETFs in High Volatility .................................... 71

Figure 3-2: All, Leveraged, and Unleveraged ETFs in Normal Volatility ................................. 72

Figure 3-3: Leveraged ETFs by Leverage Multiple in High Volatility ...................................... 77

Figure 3-4: Leveraged ETFs by Leveraged Multiple in Normal Volatility .................................. 78 


\section{PREFACE TO THE DISSERTATION}

An Exchange Traded Fund (ETF) is a portfolio of stocks, bonds, options and other instruments that trade as one stock on a stock exchange within a trading day. They are designed to closely follow an underlying asset like an index, sector or group. The SPDRs - the ETF on the S\&P500 - were the first ETFs to be manufactured in the USA and were launched in 1993. They have led to about 845 ETFs as of December 2010 being traded in the marketplace according to Masterdata.com. ETF Magazine reported that the asset under management in these funds would reach one trillion dollars by the end of 2011, and they have surpassed that.

ETFs are traded both on the primary and secondary markets. In the primary market, investors called authorized participants - normally large institutional investors - are allowed to trade in creation units. Creation units vary by ETFs but typically range from 25,000 to 200,000 shares. Authorized participants are allowed to redeem or create new ETF shares by exchanging one ETF share for a correctly proportioned basket of the underlying portfolio of assets. In a secondary market, any investor can buy shares of the ETF from an authorized participant who decides to be a market maker for that ETF.

The authorized participant acting as a market maker would then correct the supply and demand of ETF shares in the secondary market by creating and redeeming ETF shares in the primary market as needed. This mechanism allows the market maker to effectively control how close the ETF trades to its Net Asset Value(NAV) - a fund's total net assets divided by the number of outstanding shares. All the market participants in the secondary market trade at the market price depicted by the market makers and the laws of supply and demand but not at the NAV. However, market makers do tend to keep the market price close to the NAV by efficiently managing their creations and redemptions. If the market price gets above or below the NAV, the 
market maker would reduce or increase the amount of shares outstanding, which would then adjust both the market price and the NAV.

ETFs are structured in one of three ways, either as an Exchange Traded Open End Index Mutual Fund, an Exchange Traded Unit Investment Trust or an Exchange Traded Grantor Trust. Both Exchange Traded Open End Index Mutual Funds and Exchange Traded Unit Investment Trusts are registered under the Investment Company Act of 1940. Exchange Traded Open End Index Mutual Funds allow for the use of derivatives in fund construction and securities lending. Dividends are also allowed to be reinvested immediately. They are then paid out quarterly to investors. This arrangement results in less cash holdings than with the Exchange Traded Unit Investment Trust. Exchange Traded Unit Investment Trusts have to wholly replicate the underlying portfolio while limiting investments made in a single issue to $25 \%$ or less. The major difference in comparison to the Open End Index Mutual Fund is that the Unit Investment Trusts are not allowed to reinvest their dividends immediately but must still payout the dividends quarterly. Exchange Traded Grantor Trusts are slightly different in that the investor is an actual owner of the shares in the companies that constitute the ETF's underlying portfolio and, therefore, has all the rights of a shareholder including voting rights. Dividends are not reinvested and are paid directly to the shareholders and not the Trust. In addition, the shares are bought and sold in 100 share increments and do not have creation units like other ETFs.

There are several different types of ETFs. ETFs can be decomposed based on the portfolio that they follow. In that case, according to Masterdata, there would be five different categories of ETFs: US equity ETFs, global equity ETFs, fixed income ETFs, commodity ETFs, and Asset Allocation ETFs. However, ETFs can be broken down into other type formats. There are leveraged ETFs, Currency ETFs, Index ETFs, Hedge Fund ETFs, Exchange Traded Commodities (ETCs), and Exchange Traded Notes (ETNs). 
A Closed End Mutual Fund (CEF) is a type of mutual fund that issues a particular amount of shares and rarely issues new shares after the original issuance. Unlike an Open End Mutual Fund, CEFs trade within a trading day on the secondary market at a market price determined by supply and demand. After the fund is launched, transactions rarely occur in the primary market as share issuance is closed. Therefore, most of the transactions occur in the secondary market. In the secondary market, investors acquire shares at the market price and not the NAV price from the market maker. Closed End funds have been shown historically to deviate from the NAV and trade at either a premium or a discount. These funds tend to trade more at discounts to their NAV, which has spawned much academic research into the "closed end fund puzzle." Lee, Shliefer, and Thaler (1990) describe the four part anomaly of the CEFs that are quite puzzling. CEFs tend to start trading at or close to NAV but pretty soon start trading at a discount to the NAV. These deviations from the NAV tend to be time-varying and differ based on the fund. If CEFs are converted to open ended funds, these deviations tend to rapidly converge with the NAV.

CEFs are actively managed, and thus the management charges a fee that can be based on the common asset base or the total asset base of the fund. In addition to management fees, there are other administrative fees that are incurred by the fund, which reduce the amount of investor returns. The net asset values for CEFs are typically reported on a weekly basis so that investors can mark to market their portfolio.

There are several differences and similarities between these two funds. Both ETFs and CEFs differ from Open End Mutual Funds in that they are traded on a stock exchange on an intraday basis. CEFs are actively managed while most ETFs are passively managed. ETFs are more transparent as the exact portfolio that constitutes the fund is publicly known whereas with the CEFs, the portfolio construction is not known most of the time as CEF portfolios are not required to have continual disclosure. Investors can complete a short sell of an ETF on a 
downtick whereas with the CEF, a short sell can only be completed on an uptick. Capital gains taxation might also be a concern for customers who invest in CEFs rather than in ETFs.

Advantages of ETFs over CEFs are that they are transparent, exhibit low expense ratio (thus are extremely cost-effective), tax-efficient (capital gains do not need to be redistributed but are reinvested instead), and they tend to trade closer to their Net Asset Value. ETFs are priced in short intervals throughout the day in accordance with the underlying portfolio. Therefore, the net asset value is made available every 15 seconds throughout the day. Because the portfolios are actively managed, most CEF managers rebalance them once a month or at least once a quarter. However, with the ETF, since most are passively managed, rebalancing occurs infrequently. Leveraged ETFs are one example of the exception as these are balanced on a daily basis to maintain the exposure in the correct multiple.

This dissertation is comprised of three essays that focus on three topics related to exchange traded funds. The first essay will discuss the disparity exhibited between ETFs and CEFs in the equities market when the adverse selection component of the bid-ask spread is analyzed. Here we use the Huang and Stoll(1997) model to decompose the bid-ask spread for two distinct periods - one of normal volatility and the other of abnormally high volatility. The decomposed spread shows a higher adverse selection component for CEFs than for ETFs. However both ETFs and CEFs increased in magnitude of the adverse selection component in high volatility. The second essay looks at the co-integration factor on the London Stock Exchange in comparison to the New York Stock Exchange as it relates to the ETFs as well as the impact of the U-shape. We find two different shapes for New York and London. There also appears to be evidence of co-integration in the overlapping two-hour trading period but not over the entire trading day. The third essay discusses the new class of ETFs called leveraged ETFs while looking at unleveraged versus leveraged ETFs at the aggregate level as well as the decomposed leveraged ETF into the leveraged multiples of $-3,-2,-1,2$, and 3 . We find distinct differences between 
leveraged and unleveraged ETFs at the aggregate level. When the leveraged ETFs are decomposed into multiples, the -2 leveraged ETFs stand out the most.

The three essays are interlinked based on the subject of the study: ETFs. However, they are each independently presented and each chapter is comprised of individual sections dedicated to introduction, literature review and hypothesis, data and methodology, results, and conclusion.

\section{CHAPTER 1: ADVERSE SELECTION AS DEPICTED BY ETFS AND CEFS}

\subsection{Introduction}

The adverse selection component from spread decomposition is analyzed for both ETFs and CEFs in order to ascertain the information asymmetry differences between these two similar basket securities. It is interesting to see if the adverse selection component drives the spread more in CEFs than in ETFs and thus can explain why two instruments that are so similar happen to behave so differently. Also, does the adverse selection component in periods of excess volatility, increase dramatically and widen between the two assets? This chapter attempts to address both of these issues. We add to the information asymmetry literature in the selection of the financial assets that are being studied and compared.

The efficient market hypothesis (Fama, 1970) has directly and indirectly helped to produce countless research papers as researchers seek to find unequivocal evidence to support or attack the hypothesis (Malkiel, 2003). The efficient market hypothesis is closely related to the random walk model of price series. In a random walk model, the future price changes are independent of past price changes. The random walk process is defined as a special martingale where independent and identically distributed zero-mean random variables are summed (Ross, 1996). This random walk process should be distinctly reflected in a basket of securities such as the financial assets of exchange traded funds (ETFs) and closed end funds (CEFs). These two securities are very similar to each other but differ on how much they trade relative to their net 
asset values. This is a direct result of the construction of ETFs that allow the creation or redemption of additional shares, unlike its counterpart, the CEF. Due to the construction of these seemingly similar products, information asymmetry ought to be reflected more pronouncedly in the CEFs than in the ETFs. There should exist a larger adverse selection component in the CEFs than in the ETFs, which may be as a result of the difference in transparency between the two types of funds. The existence of information asymmetry refutes the existence of strong form market efficiency.

One of the mediums that has been used to attack the validity of the efficient market hypothesis is market microstructure theoretical and empirical research. The main mode of attack in market microstructure is that of spread decomposition. Beginning with Roll (1984), there has been an increased push to provide information regarding spread decomposition of financial assets. Spread decomposition has three components, namely adverse selection cost, inventory holding cost and order processing cost (Stoll, 1989; Huang \& Stoll, 1997; Glosten \& Harris, 1988). This effort in explanation has introduced us to the information asymmetries that face the dealer who has to interface with informed traders, plus the uninformed traders who then have to interact with these dealers. Information asymmetry implies the existence of arbitrage opportunities made available to traders with more information than the casual/uninformed/liquidity trader. Adverse selection has been studied as one of the required costs incurred by a dealer in his role of managing the bid-ask spread, which is his trading cost (Holden \& Avanidhar, 1992; Easley \& O'Hara, 1987; Glosten \& Milgrom, 1985; Copeland \& Galai, 1983).

Studies on adverse selection agree on its existence, but the actual degree of adverse selection based on each study suffers from severe disparity (Chelley-Steeley \& Park, 2008). Studies on ETFs are few, but combination studies with closed end funds are even rarer. Adverse selection can account for the existence of a bid-ask spread (Glosten \& Milgrom, 1985); therefore, 
evaluation of the bid-ask spread for both ETFs and closed end funds leads to an indication of the level of adverse selection in each type of asset. The methodology proposed in Huang and Stoll (1997) is used to evaluate the adverse selection component that is present in each of these assets. The Huang and Stoll methodology fully decomposes the spread into its three components simultaneously: an order processing component, an adverse selection component, and an inventory component. Moreover, Huang and Stoll (1997) successfully demonstrate how other bid-ask spread models are all related to the general form model by adding constraints. Once decomposed, the adverse selection component is compared for both ETFs and CEFs to ascertain how much of a role adverse selection plays in these two instruments. In a comparison between the adverse selection costs, the ETFs should have a smaller adverse selection component than the CEFs as premiums tend to be smaller for ETFs. This finding is synonymous with the findings in Engle and Sarkar (2002).

Neal and Wheatley (1998), as well as Clarke and Shastri (2001) look at the adverse selection components using CEFs and the stocks that comprise their index, but this study compares the adverse selection component in both CEFs and ETFs simultaneously. This result will be of interest because ETFs have become quite popular, particularly in the last decade. As a result of this popularity, it becomes a necessity to learn more about these instruments. Can these instruments truly co-exist together because they have their own niche market? Since ETFs were introduced, what is the impact on the adverse selection component of matched CEFs? Guedj and Huang (2008) have investigated the replacement possibilities of ETFs and Open Ended Mutual Funds (OEFs), primarily because of this popularity. They find that OEFs are beneficial to a select sect that wants insurance for future liquidity purposes while ETFs are beneficial when it comes to less liquid assets. Therefore, the co-existence of both the CEFs and ETFs is based on supplying the niche of the market that is most benefitted by these two types of funds (Barnhart \& Rosenstein, forthcoming). 
We find that the order processing component of both CEFs and ETFs is the biggest component of the bid ask spread irrespective of volatility. We also find that CEFs exhibit a higher adverse selection component than ETFS irrespective of volatility. However, in higher volatility, the adverse selection component of both CEFs and ETFS is larger in magnitude compared to normal volatility.

The rest of the chapter is divided into the following sections: $1.2-$ literature review and hypothesis, 1.3 - data and methodology, 1.4 - results, and 1.5 - conclusion.

\subsection{Literature Review and Hypothesis}

Market microstructure models have been prevalent that analyze the difference between the bid and ask quotes, called the spread. Roll (1984) was the first to introduce a covariance type model to decompose the spread. Glosten and Harris (1988) introduced a new way to decompose the spread by using a trade indicator type model. All of the other spread decomposition models can either be described as one of these two types of models (Stoll, 1989; Lin, Sanger, \& Booth, 1995; Huang \& Stoll, 1997; George, Kaul, \& Nimalendran, 1991; Choi, Salandro, \& Shastri, 1988; Madhavan, Richardson, \& Roomans, 1997; Hasbrouck, 1991; Huang \& Stoll, 1994). Furthermore, Huang and Stoll (1997) showed that both types of models can be derived from one basic trade indicator model, given specific assumptions. The research has shown that there are three components of the spread with the order processing cost being the largest component followed by two other costs, namely the inventory holding cost and the adverse selection cost.

Huang and Stoll (1997) decomposed the bid-ask spread into its three distinct components using a simple trade indicator model. This model has the advantage over other models in that each component can be distinctly derived without overlapping each other. Unlike the Huang and Stoll (1997) model, other spread decomposition models do not have informed trader variables as their only significant relations, which lend added support to the superiority of the model to fully decompose the spread and measure adverse selection (Van Ness, Van Ness, \& Warr, 2001). 
Kyle (1985) introduced the importance of the adverse selection component as it affects dealers and uninformed liquidity traders by informed traders. Further research has been conducted to show that adverse selection is an important component to consider when decomposing the spread (Easley \& O'Hara, 1987; Glosten \& Milgrom, 1985; Copeland \& Galai, 1983). These researchers analyzed the impact of having informed traders in a market setting, where liquidity/uninformed traders and the market maker are the other players. Informed trading has been shown to create a considerable impact on the market maker, who sets the bid and ask quotes, therefore adversely affecting the uninformed/liquidity traders who have to pay the penalty to the market maker. Glosten and Milgrom (1985) proposed three main reasons for adverse selection. They attribute the existence of adverse selection to the level of accurate information available to the informed traders, the amount of informed trading relative to the amount of liquidity trading, and the expectation that the liquidity trader has regarding future supply and demand. The importance of adverse selection has led to a number of studies as we seek to analyze the effect of adverse selection (Neal \& Wheatley, 1998; Van Ness, Van Ness, \& Warr, 2001; Clarke \& Shastri, 2001).

ETFs and CEFs are both basket securities. Researchers Neal and Wheatley (1998) and Clarke and Shastri (2001) focus on closed end funds while measuring the impact of adverse selection models. Both sets of scholars cite the transparency of these funds as a basis for their choice of instruments to analyze. While it has been contended that ETFs and CEFs have a level of transparency, ETFs are certainly more transparent than CEFs. The composition of the ETF portfolio can easily be obtained at a moment's notice while most CEF portfolio composition is unknown. In addition, the NAV for ETFs are reportedly throughout the day and updated at 15second intervals whereas CEFs have their NAVs reported often at the minimum of a week. Furthermore, ETFs allow the authorized participants (APs) to create and redeem shares. These Aps then act as market makers in the ETF shares, thus effectively playing the role of a dealer, 
enhancing liquidity and diffusing the persistence of adverse selection. The persistence in the CEFs has no such diffusing partner and thus would persist longer. Therefore, by this mere fact of transparency, there is an asymmetric level of information for investors interested in CEFs and ETFs.

Neal and Wheatley (1998) found a significantly large adverse selection component in the decomposed bid-ask spreads of the CEFs under study. In comparison to Neal and Wheatley (1998), Clarke and Shastri (2001) enlarged the number of CEFs, and included a more universal scope of the types of CEFs by also analyzing bond and international equity CEFs in addition to the domestic equity CEFs. Clarke and Shastri found a significantly lower adverse selection component embedded in the bid-ask spread of the CEFs than in their corresponding underlying portfolio of stocks. Chelley-Steeley and Park (2008) observed a significant adverse selection component for ETFs when examined using the spread decomposition models. Based on this rationale, we make the following hypothesis.

Hypothesis One: The adverse selection component embedded in the spread of the ETFs is considerably lower than the adverse selection component embedded in the spread of the CEFs.

In periods of high volatility, like the fall of 2008, information asymmetry should be more pronounced than in periods of lower volatility. High volatility implies decreased liquidity. This dynamic should also translate into the spread decomposition component of adverse selection for both ETFs and CEFs. Therefore, we develop hypothesis two.

Hypothesis Two: The magnitude of the adverse selection component of both CEFs and ETFs increases significantly in periods of high volatility, but CEFs have a larger magnitude than ETFs that increases linearly with volatility. 


\subsection{Data and Methodology}

The Bloomberg terminal provides data for ETFs and CEFs. This dataset was manipulated based on filters to select the ETFs and CEFs that are traded in the United States. ETFs have recently branched into a further innovation of leveraged ETFs, which purport to return two to three times the return of the index directly or one to three times of the return of the index inversely. In order not to compound leverage effects into the results, these ETFs are also removed from the analysis. In order to remain a part of the sample, both CEFs and ETFs had to have remained liquid for one year before the date of study and one year after in similarity to Neal and Wheatley (1998).

The periods of focus are April 2006 to June 2006 and September 2008 to December 2008. The year 2006 was a relatively normal year in terms of volatility, while the fall of 2008 was extremely volatile. These two periods give interesting and comparative results for a volatile and a non-volatile time frame. The bids, asks, and trades of the ETFs and CEFs were obtained from TAQ data. Screening methodologies, normally used in intraday studies, were employed. All observations before market open at 9:30 a.m. and market close at 4 p.m. were removed to exclude any overnight positions. If the ask or bid or size was equal to zero or negative, then the quote was deleted. If the bid-ask spread was greater than $\$ 5$ or negative, then the quote was also deleted. If the price of volume was equal to zero or negative, then the trade was deleted.

Quotes and Trades are not automatically matched in the database. Hence, quotes were matched to trades that took place five seconds later as dealers usually place quotes before trades are executed. TAQ data does not explicitly identify buys and sells; therefore, the commonly used tick test by Lee and Ready (1991) was utilized. The midpoint of the bid and ask quote was used as a benchmark. If the trade was transacted above the midpoint, then that was considered a buy and the variable $Q$ was assigned a value of 1 . However, if the trade was transacted below the 
midpoint, then it was considered a sell, and the variable Q was assigned a value of -1 . If the trade transacted was at the midpoint, then Q was assigned a value of 0 .

The Huang and Stoll (1997) model is implemented by first establishing a basic trade indicator model then using two extensions to distinguish between all three spread components. It is a regression procedure that uses the generalized method of moments to provide consistent estimates of the non-linear parameters directly. The basic trade indicator model makes no assumption about the conditional probability of trades - hence its easy implementation. The two extensions to the basic model are facilitated through the assumption of negative serial correlation and portfolio trading pressure. They simultaneously estimate two equations that capture the evolution of conditional expectations about the direction of trades and changes in the midpoint price, respectively. Since we are using the universe of ETFs and CEFs and it would be difficult to make assumptions about how many securities of each type dealers have in their portfolio, we only look at the extended model with induced serial correlation.

The basic model follows from substituting observable values into the unobservable price, $\mathrm{V}_{\mathrm{t}}$, which gives rise to

$$
\Delta P_{t}=\frac{S}{2}\left(Q_{t}-Q_{t-1}\right)+\lambda \frac{S}{2} Q_{t-1}+e_{t}
$$

$\mathrm{S}$ is the estimated traded spread; $\mathrm{Q}$ is the trade indicator that takes the values of $-1,0,1$ depending on whether the trade occurs at the ask, midpoint, or bid, respectively; $\lambda=\alpha+\beta$, where $\alpha$ is the adverse selection component and $\beta$ is the inventory holding component of the bid-ask spread. From this equation we can compute the component of the spread that is not due to either adverse selection or inventory holding, $(1-\lambda)$, which represents the order processing component of the spread. We also look at the effect that size could have on the components of the spread, and the basic model is adjusted to reflect that

$$
\Delta P_{t}=\frac{S^{s m}}{2} D_{t}^{s m}+\left(\lambda^{s m}-1\right) \frac{S^{s m}}{2} D_{t-l}^{s m}+\frac{S^{m}}{2} D_{t}^{m}+\left(\lambda^{m}-1\right) \frac{S^{m}}{2} D_{t-l}^{m}+
$$




$$
\frac{s^{l g}}{2} D_{t}^{l g}+\left(\lambda^{l g}-1\right) \frac{s^{l g}}{2} D_{t-l}^{l g}+e_{t}
$$

where $D_{t}^{S}=Q_{t}$ if share volume at $t \leq 1,000$ shares; 0 otherwise

$$
\begin{aligned}
& D_{t}^{m}=Q_{t} \text { if } 1000 \text { shares }<\text { share volume at } t<10,000 \text { shares; } 0 \text { otherwise } \\
& D_{t}^{l g}=Q_{t} \text { if share volume at } t \geq 10,000 \text { shares; } 0 \text { otherwise }
\end{aligned}
$$

The basic model is extended by using the conditional expectation of trade, where the trade that happened before the current one is known. Once a dealer makes a trade, then the revision of the quote occurs following that trade, and hence subsequent trades are dependent on the trade that occurred before. This assessment gives rise to a probability estimator, $\pi$, which is defined as the probability that the current trade is opposite in sign to the trade that occurred just before. Using this probability with the precept that negative serial correlation in trades, $Q_{t}$, and in quote revisions, $\Delta \mathrm{M}_{\mathrm{t}}$, varies from negative serial correlation in transaction price changes, $\Delta \mathrm{P}_{\mathrm{t}}$, gives rise to the extended model where all three components of the spread are distinctly identified.

$$
\begin{aligned}
& E\left(Q_{t-1} \mid Q_{t-2}\right)=(1-2 \pi) Q_{t-2} \\
& \Delta M_{t}=(\alpha+\beta) \frac{S_{t-1}}{2} Q_{t-1}-\alpha(1-2 \pi) \frac{S_{t-2}}{2} Q_{t-2}+\epsilon_{t}
\end{aligned}
$$

where, $Q_{t}$ is the buy-sell indicator for the transaction price, $P_{t}$, and $\pi$ is the probability that the trade at time $t$ is opposite in sign to the trade at $t-1 . M_{t}$ is the midpoint of the quote that prevails just before the transaction at time $t . \mathrm{S}_{\mathrm{t}}$ is the posted spread immediately prior to the transaction at time $t . \alpha$ and $\beta$ are proportions where $\alpha$ represents the percentage of the half spread attributable to adverse selection costs, and $\beta$ represents the portion attributable to the inventory cost. The remainder of the half spread corresponds to the order processing component and is equivalent to $(1-\alpha-\beta)$.

\subsection{Results}

For the two periods that are analyzed, Table 1-1 reports the summary statistics. The first item of note is that while both CEFs and ETFs from 2006 to 2008 have increased in transactions, 
as evidenced by the number of observations, ETFs have seen more exponential growth in 2008 when compared to 2006. This increase is not only a function of volatility and volume, but the number of ETFs that are actively traded has increased significantly over this period. Based on mean price, CEFs are more affordable to trade than ETFs, but ETFs offer more liquidity in narrower mean spreads over both periods. Spread and price decrease for CEFs and ETFs between 2006 and 2008. For both fund groups, the small size seems to be the driving force behind the mean spread and price. Notably, large size CEFs are the only group that records an increase in mean spread from 2006 to 2008 . These results highlight that volatility does make a difference in ETFs' and CEFs' spreads but the impact is more pronounced for CEFs; hence, underscoring the importance of analyzing the impact of volatility.

Table 1-2 reports the findings from estimating equation 1 using the generalized method of moments. Here again we see that the estimate for traded spread is larger in 2006 than in 2008. However, the traded spread in CEFs is larger than that of ETFs regardless of the year. Equation one distinctly identifies the order processing component as $1-\lambda$ but sums the inventory holding and adverse selection components together into the parameter, $\lambda$. We observe that the order processing component is the largest in magnitude of the three spread components for both CEFs and ETFs. ETFs have a bigger order processing component than CEFs, so this scenario implies that there is a smaller adverse selection component for ETFs even though it is not uniquely distinct in the combined parameter, $\lambda$. The parameter, $\lambda$, is smaller in 2006 than in 2008 for CEFs, but the converse is true for ETFs, which exhibit a larger $\lambda$ in 2008 versus 2006 . We take this trend as an indication that the adverse selection component for CEFs grew from 2006 to 2008 and that there is a positive correlation between the increase in volatility and the adverse selection component of CEFs.

To get an understanding of how different size trades may be impacted by volatility in CEFs and ETFs, equation 2 uses the generalized method of moments to decompose 
equation one into size categories. Table 1-3 reports the findings of equation 2 . The traded spread estimate shows a linear growth for CEFs in 2006 where the large size is greater than medium size, and the medium size is greater than the small size. In 2008, there is some reversal of this linear relationship as the small size has the largest traded spread and the medium size has the smallest traded spread for the CEFs. In 2006, the ETFs with the largest traded spread are the large size while the medium size has the smallest traded spread. In 2008, the order switches up with the small size having the smallest traded spread and the large size retains the largest traded spread. Overall, the CEFs have the larger traded spread in comparison to the ETFs. The order processing component is still the largest component of the spread for all the three sizes. Generally, CEFs have a smaller order processing component than the ETFs when comparing sizes. The ETFs remained fairly stable in spread component magnitude between periods from 2006 to 2008 despite the volatility in the market, but the CEFs exhibited a large change in the component size to the tune of $30 \%$.

Robustness checks using over-identifying restrictions were imposed on equation 2 to examine the estimate variation. Two constraints were used to this end. The first constraint restricts the traded spread so that it does not vary with size, but order processing costs vary with size. The equation estimated under this constraint is

$$
\Delta P_{t}=\frac{s}{2}\left(D_{t}^{s m}+D_{t}^{m}+D_{t}^{l g}\right)+\left(\lambda^{s m}-1\right) \frac{s^{s m}}{2} D_{t-l}^{s m}+\left(\lambda^{m}-1\right) \frac{s^{m}}{2} D_{t-l}^{m}+\left(\lambda^{l g}-\right.
$$

1) $\frac{S^{l g}}{2} D_{t-l}^{l g}+e_{t}(5)$

The second constraint restricts both the traded spread and the order processing costs, so they do not vary with size. Table 1-4 reports the result of the over-identifying restrictions. The results are similar to the results in Table 1-3, except in magnitude.

To further decompose the spread into the three distinct components, negative serial correlation is taken into account. The extended model identifies each component of the spread 
distinctly, and the results are reported in Table 1-5. The adverse selection component comes out negative for both CEFs and ETFS. Huang and Stoll (1997) attribute this dynamic to trade clustering. Trade clustering occurs when sequential orders that might be part of a large order are recorded independently. To address this issue, the data are reorganized to cluster these sequential orders that do not cause quote revision into one order. Clustering the trades and rerunning the extended model are reported as the findings in Table 1-6. The adverse selection component is now positive and a significant portion of the three components of the spread. The CEFs have a bigger adverse selection component than the ETFs.

\subsection{Conclusion}

Previous research has shown the existence of a significant adverse selection component for the basket securities, ETFs and CEFs independently. However, both types of basket securities were not compared to analyze the level of information asymmetry between the two. Here we observed two different periods, one of normal volatility and the other of abnormally high volatility. We found that the order processing component of both CEFs and ETFs was the biggest component of the bid ask spread irrespective of volatility. We also found that CEFs exhibit a higher adverse selection component than ETFS irrespective of volatility. However, in higher volatility, the adverse selection component of both CEFs and ETFS was larger compared to normal volatility. This result makes economic sense as informed traders would have more transactions in which to hide their trades behind the uninformed traders as volume also increases with volatility. As a consequence, dealers need to assess their quotes revision practices in volatile times compared to normal times in order to ensure adequate pricing for information asymmetry. 
Table 1-1: Summary Statistics

The descriptive statistics for trade price and traded spread for closed ended funds (CEF) and exchange traded funds (ETF) by trade size for April - June 2006 and September - December 2008. The trade size is based on volume such that small size is less than 1,000 shares, medium size is between 1,000 and 10,000 shares, and large size is at least 10,000 shares.

\begin{tabular}{|c|c|c|c|c|c|c|}
\hline & Trade Size & \# of Observations & Mean Price & Std. Dev. Price & Mean Spread & Std. Dev Spread \\
\hline \multicolumn{7}{|l|}{2006} \\
\hline \multirow[t]{4}{*}{ CEF } & ALL & 2259758 & 18.6517 & 13.5160 & 0.1690 & 0.3211 \\
\hline & SMALL & 1935427 & 19.4352 & 13.9667 & 0.1754 & 0.3295 \\
\hline & MEDIUM & 318799 & 14.0125 & 9.1057 & 0.1295 & 0.2593 \\
\hline & LARGE & 5532 & 11.8889 & 9.8824 & 0.1908 & 0.4112 \\
\hline \multirow[t]{4}{*}{ ETF } & ALL & 22118888 & 77.4495 & 38.1065 & 0.0487 & 0.1888 \\
\hline & SMALL & 19816539 & 78.0214 & 38.0065 & 0.0487 & 0.1896 \\
\hline & MEDIUM & 2166290 & 73.0269 & 38.4717 & 0.0478 & 0.1777 \\
\hline & LARGE & 136059 & 64.5814 & 39.8793 & 0.0632 & 0.2334 \\
\hline \multicolumn{7}{|l|}{2008} \\
\hline \multirow[t]{4}{*}{ CEF } & ALL & 9784564 & 9.1573 & 239.1925 & 0.1508 & 0.2054 \\
\hline & SMALL & 9039984 & 9.3037 & 248.8452 & 0.1519 & 0.2068 \\
\hline & MEDIUM & 735199 & 7.3903 & 3.8228 & 0.1361 & 0.1862 \\
\hline & LARGE & 9381 & 6.6131 & 4.2617 & 0.2098 & 0.2722 \\
\hline \multirow[t]{4}{*}{ ETF } & ALL & 322110950 & 55.0451 & 32.0174 & 0.0444 & 0.2171 \\
\hline & SMALL & 310834601 & 55.1731 & 31.7886 & 0.0446 & 0.2173 \\
\hline & MEDIUM & 10835763 & 51.7311 & 37.5968 & 0.0393 & 0.2118 \\
\hline & LARGE & 440586 & 46.2458 & 37.6063 & 0.0401 & 0.2115 \\
\hline
\end{tabular}


Table 1-2: Traded Spread and Order Processing Component

The results from estimating $\Delta P_{t}=\frac{S}{2}\left(Q_{t}-Q_{t-1}\right)+\lambda \frac{S}{2} Q_{t-1}+e_{t}$ are reported. The estimated traded spread (S) as well as the proportion of traded spread due to adverse selection and inventory holding $(\lambda)$ is shown. The proportion of the traded spread due to order processing is calculated as $1-\lambda$ and is also shown.

\begin{tabular}{lllll}
\hline & $\mathrm{S}$ & & $\Lambda$ & \\
\cline { 2 - 4 } & Coefficent & Std. Error & Coefficient & \multicolumn{1}{c}{ Std. Error } \\
\hline 2006 & & & & 0.0017 \\
CEF & 0.0331 & 0.0002 & 0.2151 & 0.0068 \\
ETF & 0.0269 & 0.0023 & 0.0379 & 0.7849 \\
& & & & 0.9620 \\
CEF & & & 0.3266 & 0.0275 \\
ETF & 0.1650 & 0.1331 & 0.0358 & 0.0012 \\
\hline
\end{tabular}


Table 1-3: Traded Spread and Order Processing Component by Trade Size

The results from estimating $\Delta P_{t}=\frac{s^{s m}}{2} D_{t}^{s m}+\left(\lambda^{s m}-1\right) \frac{s^{s m}}{2} D_{t-l}^{s m}+\frac{s^{m}}{2} D_{t}^{m}+\left(\lambda^{m}-1\right) \frac{s^{m}}{2} D_{t-l}^{m}+\frac{s^{l g}}{2} D_{t}^{l g}+\left(\lambda^{l g}-1\right) \frac{s^{l g}}{2} D_{t-l}^{l g}+e_{t}$ are reported. The estimated traded spread (S), as well as the proportion of traded spread due to adverse selection and inventory holding $(\lambda)$ is shown. The proportion of the traded spread due to order processing is calculated as $1-\lambda$ and is also shown. The trade size is based on volume such that small size is less than 1,000 shares, medium size is between 1,000 and 10,000 shares, and large size is at least 10,000 shares.

\begin{tabular}{|c|c|c|c|c|c|c|c|c|c|c|c|c|c|c|c|}
\hline & $\begin{array}{l}\mathrm{S} \\
\mathrm{Sm} \\
\end{array}$ & $\mathrm{SE}$ & Med & $\mathrm{SE}$ & $\mathrm{Lg}$ & $\mathrm{SE}$ & $\begin{array}{l}\Lambda \\
\mathrm{Sm} \\
\end{array}$ & $\mathrm{SE}$ & Med & $\mathrm{SE}$ & $\mathrm{Lg}$ & SE & $\begin{array}{l}1-\lambda \\
\text { Sm } \\
\end{array}$ & Med & $\mathrm{Lg}$ \\
\hline \multicolumn{16}{|l|}{2006} \\
\hline $\mathrm{CEF}$ & 0.0327 & 0.0002 & 0.0352 & 0.0002 & 0.0698 & 0.0038 & 0.2040 & 0.0020 & 0.2713 & 0.0042 & 0.3714 & 0.0293 & 0.7960 & 0.7287 & 0.6286 \\
\hline ETF & 0.0268 & 0.0024 & 0.0252 & 0.0016 & 0.0509 & 0.0025 & 0.0396 & 0.0080 & 0.0280 & 0.0109 & 0.0099 & 0.0235 & 0.9604 & 0.9720 & 0.9901 \\
\hline \multicolumn{16}{|l|}{2008} \\
\hline CEF & 0.1726 & 0.1407 & 0.0793 & 0.0480 & 0.1669 & 0.0562 & 0.3456 & 0.0275 & -0.172 & 0.0853 & 0.0536 & 0.0930 & 0.6544 & 1.0172 & 0.9464 \\
\hline ETF & 0.0253 & 0.0008 & 0.0262 & 0.0008 & 0.0525 & 0.0010 & 0.0367 & 0.0013 & 0.0149 & 0.0050 & 0.0025 & 0.0049 & 0.9633 & 0.9851 & 0.9975 \\
\hline
\end{tabular}


Table 1-4: Restricted Models of Traded Spread and Order Processing Component by Trade Size

The results from estimating $\Delta P_{t}$ by imposing over-identifying restrictions are reported for two constraints. The first constraint restricts the traded spread, so it does not vary with size, but order processing costs vary with size. Essentially, we estimate the following equation for the first constraint, $\Delta P_{t}=\frac{s}{2}\left(D_{t}^{s m}+\right.$ $\left.D_{t}^{m}+D_{t}^{l g}\right)+\left(\lambda^{s m}-1\right) \frac{s^{s m}}{2} D_{t-l}^{s m}+\left(\lambda^{m}-1\right) \frac{s^{m}}{2} D_{t-l}^{m}+\left(\lambda^{l g}-1\right) \frac{s^{l g}}{2} D_{t-l}^{l g}+e_{t}$. The second constraint restricts both the traded spread and the order processing costs, so they do not vary with size. The estimated traded spread (S) as well as the proportion of traded spread due to adverse selection and inventory holding $(\lambda)$ is shown. The trade size is based on volume, such that: small size is less than 1,000 shares, medium size is between 1,000 and 10,000 shares, and large size is at least 10,000 shares.

\begin{tabular}{|c|c|c|c|c|c|c|c|c|c|}
\hline & & $\begin{array}{l}\text { S } \\
\text { All Sizes } \\
\text { Coefficient }\end{array}$ & Std. Error & $\begin{array}{l}\Lambda \\
\text { Small } \\
\text { Coefficient }\end{array}$ & Std. Error & $\begin{array}{l}\text { Medium } \\
\text { Coefficient }\end{array}$ & Std. Error & $\begin{array}{l}\text { Large } \\
\text { Coefficient }\end{array}$ & Std. Error \\
\hline \multicolumn{10}{|l|}{ Constraint 1} \\
\hline \multirow[t]{2}{*}{$\mathrm{CEF}$} & 2006 & 0.0332 & 0.0002 & 0.2133 & 0.0019 & 0.2334 & 0.0043 & -0.2790 & 0.0775 \\
\hline & 2008 & 0.1651 & 0.1333 & 0.3213 & 0.0240 & 0.3928 & 0.0639 & 0.00149 & 0.4210 \\
\hline \multirow[t]{2}{*}{ ETF } & 2006 & 0.0268 & 0.0023 & 0.0384 & 0.0078 & 0.0805 & 0.0190 & -0.8496 & 0.1400 \\
\hline & 2008 & 0.0253 & 0.0008 & 0.0387 & 0.0013 & -0.0067 & 0.0054 & -0.9647 & 0.0458 \\
\hline Constraint 2 & & All Sizes & & All Sizes & & & & & \\
\hline \multirow[t]{2}{*}{ CEF } & 2006 & 0.0331 & 0.0002 & 0.2150 & 0.0016 & & & & \\
\hline & 2008 & 0.1650 & 0.1331 & 0.3266 & 0.0275 & & & & \\
\hline \multirow[t]{2}{*}{ ETF } & 2006 & 0.0269 & 0.0023 & 0.0379 & 0.0068 & & & & \\
\hline & 2008 & 0.0253 & 0.0007 & 0.0358 & 0.0012 & & & & \\
\hline
\end{tabular}


Table 1-5: Components of the Bid-Ask Spread based on Serial Correlation in Trade Flows Without Trade Clusters

The results from computing the extended model with induced serial correlation in trade flows is reported. Here, trade order flow clusters are not considered sequential orders thought to be a part of one large order. The extended model distinctly shows the three components of the bid-ask spread - adverse selection $(\alpha)$, inventory holding $(\beta)$, and order processing $(1-\alpha-\beta)$. The extended model simultaneously estimates the equations $E\left(Q_{t-1} \mid Q_{t-2}\right)=(1-2 \pi) Q_{t-2}+\varepsilon_{t}$ and $\Delta M_{t}=(\alpha+\beta) \frac{S_{t-1}}{2} Q_{t-1}-\alpha(1-2 \pi) \frac{S_{t-2}}{2} Q_{t-2}+e_{t}$.

\begin{tabular}{|c|c|c|c|c|}
\hline & $\begin{array}{l}\text { A } \\
\text { Coefficient }\end{array}$ & $\begin{array}{l}\text { B } \\
\text { Coefficient }\end{array}$ & $\begin{array}{l}\pi \\
\text { Coefficient }\end{array}$ & $1-\alpha-\beta$ \\
\hline \multicolumn{5}{|l|}{2006} \\
\hline CEF & -0.0324 & 0.0986 & 0.3139 & 0.9338 \\
\hline ETF & -0.0273 & 0.0952 & 0.1916 & 0.9321 \\
\hline \multicolumn{5}{|l|}{2008} \\
\hline CEF & -0.0569 & 0.1299 & 0.1210 & 0.9269 \\
\hline ETF & -0.0311 & 0.1033 & 0.0231 & 0.9277 \\
\hline
\end{tabular}


Table 1-6: Components of the Bid-Ask Spread based on Serial Correlation in Trade Flows with Trade Clusters

The results from computing the extended model with induced serial correlation in trade flows is reported. Here, trade order flow clusters are considered to be one order - sequential orders without quote revision are thought to be a part of one large order. The extended model distinctly shows the three components of the bid-ask spread - adverse selection $(\alpha)$, inventory holding $(\beta)$, and order processing (1- $\alpha-\beta)$. The extended model simultaneously estimates the equations $E\left(Q_{t-1} \mid Q_{t-2}\right)=(1-2 \pi) Q_{t-2}+\varepsilon_{t}$ and $\Delta M_{t}=(\alpha+\beta) \frac{S_{t-1}}{2} Q_{t-1}-\alpha(1-2 \pi) \frac{S_{t-2}}{2} Q_{t-2}+e_{t}$.

\begin{tabular}{|c|c|c|c|c|}
\hline & $\begin{array}{l}\text { A } \\
\text { Coefficient }\end{array}$ & $\begin{array}{l}\beta \\
\text { Coefficient }\end{array}$ & $\begin{array}{l}\pi \\
\text { Coefficient }\end{array}$ & $1-\alpha-\beta$ \\
\hline \multicolumn{5}{|l|}{2006} \\
\hline CEF & 0.2323 & 0.3936 & 0.9135 & 0.3740 \\
\hline ETF & 0.1293 & 0.2352 & 0.8169 & 0.6354 \\
\hline \multicolumn{5}{|l|}{2008} \\
\hline CEF & 0.3562 & 0.4694 & 0.8216 & 0.1743 \\
\hline ETF & 0.1675 & 0.2981 & 0.7834 & 0.5343 \\
\hline
\end{tabular}




\section{CHAPTER 2: ETF: CO-INTEGRATION AND THE U-SHAPE}

\subsection{Introduction}

The efficient market hypothesis (Fama, 1970) has been a stalwart issue in financial literature for several decades. However, if efficient markets were to truly exist, then arbitrage opportunities would not concurrently exist. Furthermore, there would be no evidence of a lagged relationship between markets, which provides arbitrage opportunities to traders. Trading in different markets that have non-overlapping or a few hours of overlapping trading hours should not result in available arbitrage opportunities, provided that markets are integrated. However, some markets seem to lag behind others and are affected by new revelations from other markets (Werner \& Kleidon, 1996; Hupperets \& Menkveld, 2002; Lin, Engle, \& Ito, 1994).

Therefore, if there is such a lag, or if it takes a significant time interval between trades for prices to coincide when one market opens and another closes, then this time lag would be an instrumental consideration when modeling price movements and evolution. This relationship can best be analyzed by looking at their intraday characteristics and how long it takes for markets to get integrated. This chapter analyzes the intraday shape of volatility, volume, and depth for ETFs on the domestic New York Stock Exchange (NYSE) as well as for iShares ETFs traded on both the NYSE and London Stock Exchange (LSE). The intraday shape for the iShares ETFs grants insight into the market integration of both markets, where market integration is defined as the reflection of the same intrinsic information in prices in both markets.

There has been an observed U-shape in US market equities (Goodhart \& O'hara, 1997; Jain \& Joh, 1988; McInnish \& Wood, 1992) as well as evidence of the U-shape in the London market (Werner \& Kleidon, 1996; Abhyankar, Ghosh, Levin, \& Limmack, 1997). 
Therefore, this backdrop provides good material to examine market integration relationships since in integrated trading there should be one distinct U-shape instead of two. However, we will be using exchange traded funds (ETFs) to observe the market co-integration. Since the ETFs' intraday characteristics have not been documented, we must first ascertain the intraday shape of the volume, volatility, and spread for the ETFs in order to proceed. Studying these basket securities provides us with an insight into the intraday shape of reduced risk securities, where unsystematic risk has been reduced compared to each individual stock in the underlying portfolio. Previous literature has used individual equities to look at the intraday shape and not basket securities.

Since risk is often represented by volatility, does the reduction of risk through diversification play a significant role in the intraday shape of reduced risk securities even though we still observe the U-shape documented for individual stocks? The characteristics of the intraday shape of ETFs in the NYSE are first examined individually. The intraday characteristics of the universe of iShares ETFs in both New York and London are first compared, then the iShares ETFs that are based on the same underlying and traded in both New York and London are compared to see if there is an integrated U-shape or whether there are two distinct U-shapes as previously observed (Hupperets \& Menkveld, 2002; Werner \& Kleidon, 1996). Does the location of trade matter, where trading on one exchange is superior to trading another? Does sequential trading of cross-listed ETFs produce an integrated Ushaped intraday pattern? Does the US macro-economic news affect London more than London's news affects the US as shown in Hupperets and Menkveld (2002) as well as in Lin, Engle, and Ito (1991)?

If markets were perfectly co-integrated, then the shape should transfer from one market to another uniformly. However, if any of the intraday shapes should deviate, particularly between the close of the LSE and the opening of the NYSE, then the markets would suffer from a time lag in integration. If there is such a deviation, is it present every day 
or is it just a fluke that appears in a random fashion? There has been no seminal work done on the intraday shape of exchange traded funds or the co-integration effects between markets of reduced risk basket securities, such as ETFs. This study differs from Werner and Kleidon (1996) since some of the stocks used in their study are traded as ADRs, which have to be converted to observe true arbitrage, and that is not the case with the ETFs. As a result, ETFs do not have the cost of conversion that ADRs have, and neither do they have the same risk level due to the inherent diversification of a fund. Therefore, this chapter fills a void in the literature.

The remainder of the chapter is divided into sections as follows: 2.2 - literature review and hypothesis, 2.3 - data and methodology, 2.4 - results, and 2.5 - conclusion.

\subsection{Literature Review and Hypothesis}

The characteristics of intraday data have piqued the interest of many as they provide a view into price evolution. These characteristics - namely that of volatility, volume, and depth - help to illustrate how prices behave and evolve over time. Analyzing and comparing these characteristics across markets help us to understand how markets relate and react to each other. Hupperets and Menkveld (2002) found that there is a U-shaped difference when looking at cross-listed stocks in Amsterdam and New York, so these two markets are not perfectly integrated. Froot and Dabora (1999), as well as Werner and Kleidon (1996), found evidence that financial markets are not one hundred percent integrated. Lin, Engle, and Ito (1994) found that while markets are not integrated, the US movement affects other markets, but this effect is asymmetric as it does not occur the other way around. The level of market integration is of utmost importance as we live in an ever changing and globalized world.

Before analysis, the market structure of the markets paired for comparative purposes need to have some underlying thread that could explain why these markets would be integrated. In the case of London and New York, both of these exchanges are open trading 
environments with virtually complete access for foreign investors. There are no regulatory constraints to prevent cross-border arbitrage in dual listed stocks, and the markets are heavily arbitraged by institutional investors. In particular, the LSE has a higher amount of institutional investors (Cai, Hudson, \& Keasey, 2004). Dual listed stocks are liquid in both London and New York trading. Dealers in dual listed stocks potentially face considerable cross-Atlantic competition for order flow. London stocks trade on the LSE SETS system, which was introduced in 1997. The trading day typically runs from 8:00 a.m. to 4:30 p.m. London time. However, there is no rigid starting and ending time as trading can begin anytime between 8 a.m. and 8:30 a.m. and end anytime between 4 p.m. and 4:30 p.m. This time frame translates to 3:00 a.m. to 11:30 a.m., New York time. The NYSE operates from 9:30 a.m. to 4:00 p.m., New York time. There is a two-hour overlap - 9:30 a.m. to 11:30 a.m., New York time - in the trading times for these two exchanges. This overlap allows for testing of the impact of macro-economic news and the effects of contagion. In Werner and Kleidon (1996), London was not affected by the news from the US, but in a more vertically integrated globalised world, the news effect in cross-border relationships ought to be significant as shown in Hupperets and Menkveld (2002) as well as in Lin, Engle, and Ito (1991)

Another aspect that has to be taken into account is the frequency of the data. Previously, much research used to be done with low frequency data, such as monthly and weekly data. However, much information is left out when using low frequency data as opposed to intraday data (Goodhart \& O'hara, 1997). Since financial markets operate, during their opening hours, on a continuous, high frequency basis, then it makes perfect sense that studies done on these markets should utilize as high as possible frequency data. It is, therefore, only by looking at the highest frequency continuous time series that one could observe temporal interrelationships between markets connected by such (arbitrage) interrelationships. The intraday pattern is also important to know for traders in these markets. 
This pattern helps to guide traders when it comes to correct timing to place trades, as well as the modeling of price movements, in financial markets.

Issue one looks at the characteristics of reduced risk basket securities, which trade on the domestic NYSE market, by examining ETFs. Diversification reduces risk in a basket of securities so that their shape exhibits less volatility than the individual assets that make up their portfolios. Therefore, this risk reduction may also be exhibited in the observed intraday pattern, and a deviation from the U-shape may occur. This issue is analyzed by considering the subsequent question: How much different from stocks is the intraday shape of ETFs when characterizing volatility, volume, and depth? I hypothesize that the intraday shapes of volume, volatility, and depth of ETFs differ from that of stocks, due to the diversification benefits inherent in ETFs.

Issue two looks at the intraday characteristics of iShares ETFs that are listed on both the NYSE and the LSE. If these two were perfectly co-integrated, then they would exhibit a stylized shape like the one shown in Figure 2-1. This issue is analyzed by considering the questions: Does location of trade matter? Is one market more liquid or volatile than the other? Are markets integrated for the overlapping trading period based on their shape? If there is a time lag in integration, is it persistent every day, or does it appear randomly? How much does US macroeconomic news affect ETF prices in London and vice versa? This series of questions leads to the following hypotheses: I hypothesize that markets are not integrated over the whole day but show integration in their overlapping period, so location of trade does matter. In addition, the lag in integration does not appear randomly, but it is present every day in the same interval of time. Furthermore, there is a more powerful effect of economic news from the New York to London but not vice versa. 


\subsection{Data and Methodology}

ETFs would provide a good database for studying integration because they are basket securities and through diversification have eliminated much of the individual stock risk. Therefore, any lapse in integration would represent market specific factors and not those of individual stocks. The two markets to be looked at are the London Stock Exchange (LSE) and the New York Stock Exchange (NYSE) for nine months of data: September to November 2008 and June to November 2010. These two markets provide much ETF volume and are a good fit for a study on ETFs. The iShares group of ETFs is touted as having the most ETFs under management. There are over 300 iShares ETFs being traded in the US while there are over 250 being traded in London. Thus, there is a good amount of ETFs to conduct the research. Of that number, 37 are dual listed ETFs.

ETFs' intraday data for the US were readily available on TAQ. TAQ provided the bids, asks, and trades of the US ETFs. ETFs' intraday data for London were available from the LSE. The CRSP data files were accessed through WRDS to get an accounting of all the US ETFs that were being traded. This list was cross referenced with the TAQ database in order to filter out ETFs from the universe of daily traded equities. Additionally, the Bloomberg terminal was used to get a list of all iShares ETFs that were traded on the LSE and the NYSE. These two lists were merged based on the underlying ETF to result in a list depicting iShares ETFs that were traded both in London and in New York (dual listing). Concentrating on the intraday activity required excluding any overnight positions. Therefore, all observations before the opening of the market - 9:30 a.m. in New York and 8:00 a.m. in London - and after the closing of the market at 4:00 p.m. in New York and at 4:30 p.m. in London were removed. If the price or volume was equal to zero or negative, then the trade was deleted. The data were separated into 15-minute intervals for the analysis. The first interval for the New York data was 9:30:01 to 9:44:59 while for the British data, it was 
8:00:01 to 8:14:59. This time frame resulted in 36,15 -minute intervals for the LSE data and 27 for the NYSE data.

Integration is assessed both directly and indirectly - indirectly through the study of intraday patterns, which builds on Werner and Kleidon (1996), and directly by modeling price discovery during the two overlapping trading hours. For separate markets to be viewed as an integrated one, there should be a fusing of their U-shaped pattern instead of two distinct U-shapes for each market, so this approach provides a way to indirectly test for integration (see Figure 2-1). If markets are not integrated on a whole-day basis, as evidenced by a fused U-shape, are they integrated for the two-hour overlapping period? If both price series are cointegrated, then this finding would be a direct modeling of price discovery.

The trading variables explored are trade price volatility, volume, and depth. The interval return is calculated as log difference between the trade price prevailing at the start of the interval as is inferred from the last trade and the prevailing price at the end of the interval. The total number of shares traded in each interval is summed up to give the interval trading volume. The number of trades in each trading interval is the depth of trades. Intraday patterns for volatility, volume, and depth are estimated using ordinary least squares regression. The trading variables for each specific day and minute intervals are scaled by the daily mean. Similar to Werner and Kleidon (1996), these scaled variables are used in a cross-sectional regression in order to arrive at the intraday patterns.

$$
\frac{Y_{f, d, t}}{\delta_{f, t}}=\sum_{i=t_{0}}^{T} J^{i}(t) \alpha_{i}+\left(\sum_{i=t_{0}}^{T}\left(J^{i}(t) \sigma_{i}\right)\right) \varepsilon_{f, d, t}
$$

$\mathrm{Y}$ is either volume, volatility or spread, and $\mathrm{f}$ is the ETF, $\mathrm{d}$ is the day, and $\mathrm{t}$ is the time interval. $\delta$ represents the fund specific, day specific mean. The dummy vector of $J^{\mathrm{i}}(\mathrm{t})$ is a $\{0,1\}$ vector with value of one only when $i=t$. The error term, $\varepsilon_{f, d, t}$ is iid with a mean of zero and variance of one. The $\sigma$ vector represents the intraday variance and can be heteroskedastic. 
Price differences should be transient for arbitrage reasons and, therefore, stationary. The null hypothesis of market integration for price discovery during the overlap is tested by evaluating whether or not both price series are co-integrated. The Dickey-Fuller Test is used to test for market integration. If there is high volume and high volatility, there are typically large spreads and integrated price discovery. This dynamic suggests that we can discover a causal relationship. The vector error correction model proposed by Hasbrouck (1995) is a valuable tool to help determine from where this relationship originates.

The model involves solving the following system of equations

$$
\begin{aligned}
& r_{t}^{L}=\Delta \log \left(P_{t}^{L}\right) \\
& r_{t}^{N}=\Delta \log \left(P_{t}^{N}\right) \\
& r_{t}^{L}=\alpha^{L}\left(\log \left(P_{t-1}^{L}\right)-\log \left(P_{t-1}^{N}\right)\right)+\sum_{i=1}^{4} \gamma_{i}^{L, L} r_{t-i}^{L}+\sum_{i=1}^{4} \gamma_{i}^{L, N} r_{t-i}^{N}+\varepsilon_{t}^{A} \\
& r_{t}^{N}=\alpha^{N}\left(\log \left(P_{t-1}^{L}\right)-\log \left(P_{t-1}^{N}\right)\right)+\sum_{i=1}^{4} \gamma_{i}^{N, L} r_{t-i}^{L}+\sum_{i=1}^{4} \gamma_{i}^{N, N} r_{t-i}^{N}+\varepsilon_{t}^{N}
\end{aligned}
$$

$\mathrm{L}$ is London and $\mathrm{N}$ is New York

\subsection{Results}

After data collection, the data were summarized to get a general view. Summary statistics for both the 2008 and 2010 periods are reported in Table 2-1 for the entire day while Table 2-2 depicts the overlapping two-hour period between the NYSE and the LSE. Panel A of each table represents the trading in the New York market while Panel B represents the trading in the London market. ${ }^{1}$ The New York panel provides a summary for three different groups: all ETFs (ETFs that are actively being traded, regardless of issuer), all iShares ETFs (ETFs that are actively traded and issued by iShares) and dual-listed iShares ETFs (ETFs that are issued by iShares and traded both in New York and London). The London panel provides

${ }^{1}$ Werner and Kleidon (1996) adjust for the impact of exchange rates on the trading variables. However, they find that stock prices and exchanges would need to be perfectly negatively correlated in order for the impact of exchange rates to skew the results. Since perfect negative correlation has not been observed between exchange rates and stock prices, I do not expect any change in results and I do not account for the impact of exchange rates. 
a summary for two groups: all iShares ETFs and dual-listed iShares ETFs. Both markets are very liquid as observed by the average volume across all groups.

Table 2-1 illustrates that New York has more ETFs being traded, and that the NYSE has more volume and more depth than London. This circumstance may be due to the fact that ETFs started to be traded at an earlier date in New York than in London. This observation is consistent with the higher average volume per trade in New York that was observed by Werner and Kleidon (1996). Regardless of location, the average volume and average depth of trade was larger in 2008 than in 2010. In New York, the average trade price volatility was larger for the group, all ETFs, in 2010 versus 2008. Conversely, the groups, all iShares ETFs and dual-listed iShares ETFs, had more trade price volatility in 2008 than in 2010. For London, the average trade price volatility for all iShares ETFs was larger in 2010 than in 2008, but the opposite was true for the dual-listed iShares ETFs. The amounts traded of these shares were larger in 2008 than in 2010. Therefore, it is reasonable to conclude that volatility is higher when volume is higher as more volume means more trading and more opportunities for the deviations of trade prices from the mean.

Table 2-2 shows similar results to Table 2-1. There is more volume and depth in the New York market than in the London market for ETFs in the two-hour overlapping period. There are also more volume and depth in both New York and London in 2008 compared to 2010 for the two-hour overlap. Also, trade price volatility is large in 2008 than in 2010 for all of the three groups for the New York market. Regarding trade price volatility in London, there is the same relationship in the two-hour overlap as in the whole day, where for the group, all iShares ETFs, there is a larger trade price volatility in 2010 compared to 2008. For the group, dual-listed iShares ETFs, trade price volatility in 2008 is larger than in 2010. It is interesting to note that in comparison to the whole trading day, the two-hour overlapping period in both 2008 and 2010 shows that both volume and depth increased across all groups regardless of location. Volatility varies slightly as the increase for the overlap compared to 
the whole day is shown for all groups except all ETFs in New York, where the volatility for the day as a whole is larger than the volatility in the two-hour overlap. This observation support the hypothesis that the two-hour overlapping period is distinguished from the entire day and creates an ideal time and place for arbitrageurs to trade.

Panel C of Tables 2-1 and 2-2 reports the t-statistics from the Welch's difference of means test, ${ }^{2}$ which tests the hypothesis that the means of trade price volatility, volume and, depth for New York and London are equal. During the day as a whole, there is generally a statistically significant difference in both 2008 and 2010 for all three variables. Trade price volatility shows a negative significant difference while volume and depth show a positive significant difference in both 2008 and 2010. In other words, the volatility in the London market is typically larger than the volatility in New York, but volume and depth are larger in the New York market, which translates from Panel A. During the two hour-overlap, the variables have the same sign as during the whole day. While volume and depth retain a general positive statistical significance, volatility has a statistically significant difference for all iShares ETFs but not for the dual-listed iShares ETFs, where there is no significance in 2008 while there is a weak $10 \%$ significance level for 2010 .

The empirical intraday pattern for stocks in the US has been shown to reflect a Ushape. However, taking into consideration that ETFs are basket securities and thus benefit from reduced risk through diversification based on their construction, it is important to first construct the intraday patterns for all ETFs in the US to verify that they also follow the Ushaped intraday patterns recorded for US stocks. The intraday patterns for all ETFs traded on the New York market are first established by using the double pass regression from Werner and Kleidon (1996). This intraday pattern is shown in Figure 2-2 for both 2008 and 2010. All

\footnotetext{
${ }^{2}$ A non-parametric test, the Wilcoxon rank sum test, was also conducted, and it verifies the results of the t-test, rejecting the null hypothesis in favor of the alternative where true location shift was not equal to 0 - hence it was not reported here.
} 
three variables show a distinct U-shaped pattern in 2008. There are more jumps seen for volatility resulting in a departure from the pure U-shape than for the other two variables. In 2010, while volume and depth show the conceived U-shape, volatility takes a dive in the last half hour of trading, and the U-shape becomes slightly distorted.

Figures 2-3 and 2-4 show the intraday patterns for all iShares ETFs traded in New York and London, respectively. Figure 2-3 illustrates that the iShares ETFs follow a very similar intraday pattern to all the ETFs traded in the New York market, validating this group as a good choice as vehicle for this study. The pattern shows jumps in similar positions when compared to Figure 2-2, although some of these jumps are a tad sharper. The London iShares ETFs, on the other hand, in Figure 2- 4 tell a very different story. This pattern resembles more of a sideways $\mathbf{J}$ shape for volatility and somewhat for volume and depth. The highest point seems to be at the end of the day, with oscillations occurring from when trade starts to when trade ends. This uptick in trading could be attributed to the opening of the markets in New York that occurs in the last two hours of trading in London. However, there are many jumps throughout the day to get to the uptick at the end of the day. With the knowledge that trading starts in London at 3:30 a.m. (New York time) then transitions to US trading at 9:30 a.m. (New York time), and then to close at 4:30 p.m. (New York time), these patterns show evidence of a non-integrated market as stylized by the disconnected markets in Figure 2-1. There is progression throughout the day from 3:30 a.m. (New York time) to 11:30 a.m. (New York time) in the London market, but at around 9:30 a.m. (New York time) - when the New York market opens - there is an uptick in the patterns. This uptick flows into the New York market from the time it opens to a decline in trading during the middle of the day, followed by an increase at the end of the day, to close out trading at 4:30 p.m. Therefore, it is immensely important to look at the occurrences during the overlapping two-hour period to see how these two markets transition. 
Figures 2-5 and 2-6 report the pattern attributed to the dual-listed iShares ETFs that trade both in New York and London. The New York market shows an adherence to the established U-shaped pattern that was presented in Figure 2-2 with more pronounced deviations/jumps. It can still clearly be observed that there is an uptick at the beginning of trading which is larger than the trading in the middle of the day followed by another uptick at the end of the day. The London market shows a significant increase in the number of jumps throughout the day, especially in 2008. The pattern from Figure 2-6 showing 2008 depicts the contribution of increased panic in the worldwide markets through the distortion of the patterns. However, 2010 shows a reversion to what looks like the norm for the London market.

Figures 2-7 and 2-8 illustrate the pattern for the dual-listed ETFS that are traded in the overlapping two-hour window between the New York and London markets. For the New York market, there is a clear decline from the beginning of the period to the end of the period for volatility, volume, and depth in both 2008 and 2010. For London in 2008, there is a general increase from the beginning of the period to the end of the period for volatility, volume, and depth. However, in 2010, volume and depth show a steady increase over the period while volatility reverts back to its starting point with several jumps between the beginning and the end of the period. In the London market, there appear to be quite a few jumps throughout the day and in the overlapping period. This dynamic renders it difficult to ascertain the cause of these jumps, thus measuring the impacts from US news and the opening of a new market in the overlap hours.

It would seem that the US market and the UK market are more integrated or less sensitive to one another as compared to, for instance, the Amsterdam market (see Hupperets \& Menkveld, 2002). Price discovery does not appear to be as distinctive or as easily placed when looking at the US and the UK market together because as there no distinctions to ascribe to price movements when particular events occur. However, the hypothesis that the 
US and the UK markets are integrated on a whole-day basis can be rejected as the intraday patterns point otherwise. In order to delve deeper into integration, the overlapping period is considered for market integration. The vector error correction model used by Hasbrouck (1995) is used to further detail the relationship between these two markets. First, the price series for the US and the UK are tested for co-integration. The augmented Dickey-Fuller test is conducted, and this shows that both price series are co-integrated of order one and the first difference is stationary in the overlapping period at a $99 \%$ confidence level. This finding implies that both markets are integrated for each stock.

Table 2-5 presents the results of the vector error correction model. The error term and the adjusted $\mathrm{R}^{2}$ for the London market are larger than the error term and the adjusted $\mathrm{R}^{2}$ for the New York market. This observation suggests that the London market is more dependent on historical information and thus is more impacted by news, such as macro-economic information, than the New York market. The magnitude of the $\mathrm{R}^{2}$ is larger in 2010 than in 2008 for London while remaining relatively constant for the New York market. This observation could be an indication of the recovery from the whirlwind of financial activity as a result of the worldwide panic in 2008 back to the normal level of activity at the London market in 2010. Hence, London is more likely to be impacted by historical events in the US than New York is affected by events in the UK. In 2008, the error correction term is statistically significant at the $10 \%$ level for both New York and London, but in 2010, the statistical significance disappears. The returns are significantly positive for London while there are significantly negative returns for New York in 2008. Again, this observation seems to be a result of the financial meltdown in 2008. In 2010, there appears to be a recovery where market information is assimilated within two lags or 30 minutes as this finding is statistically significant in both London and New York. The vector error correction results imply that there was a rapid adjustment to prices in 2008, which would explain why there was wide spread contagion between these two markets. However, in 2010, with the markets 
stabilized again, the vector error correction estimate is no longer significant, and price discovery is not relegated to any one market but moves across both markets accordingly.

\subsection{Conclusion}

Microstructure research has shown the existence of a U-shape in stocks traded on the US market. However, no research has looked at the intraday shape of reduced risk basket securities like ETFs. Here, we show that although ETFs provide the benefit of reduced risk in every share, there still exists the intraday U-shape pattern for ETFs that are traded in New York similar to that of stocks for trade price volatility, volume, and depth. Focusing on the iShares group of ETFs to analyze integration between markets is fruitful. The New York iShares ETFs exhibit a similar U-shape pattern for New York ETFs while the London ETFs have a shape that is consistent with what is found in Werner and Kleidon (1996).

The US and the UK markets are not integrated across the day as a whole, and in the

overlapping period there seems to be evidence of integration here with limited price discovery outside of the financial meltdown of 2008. 


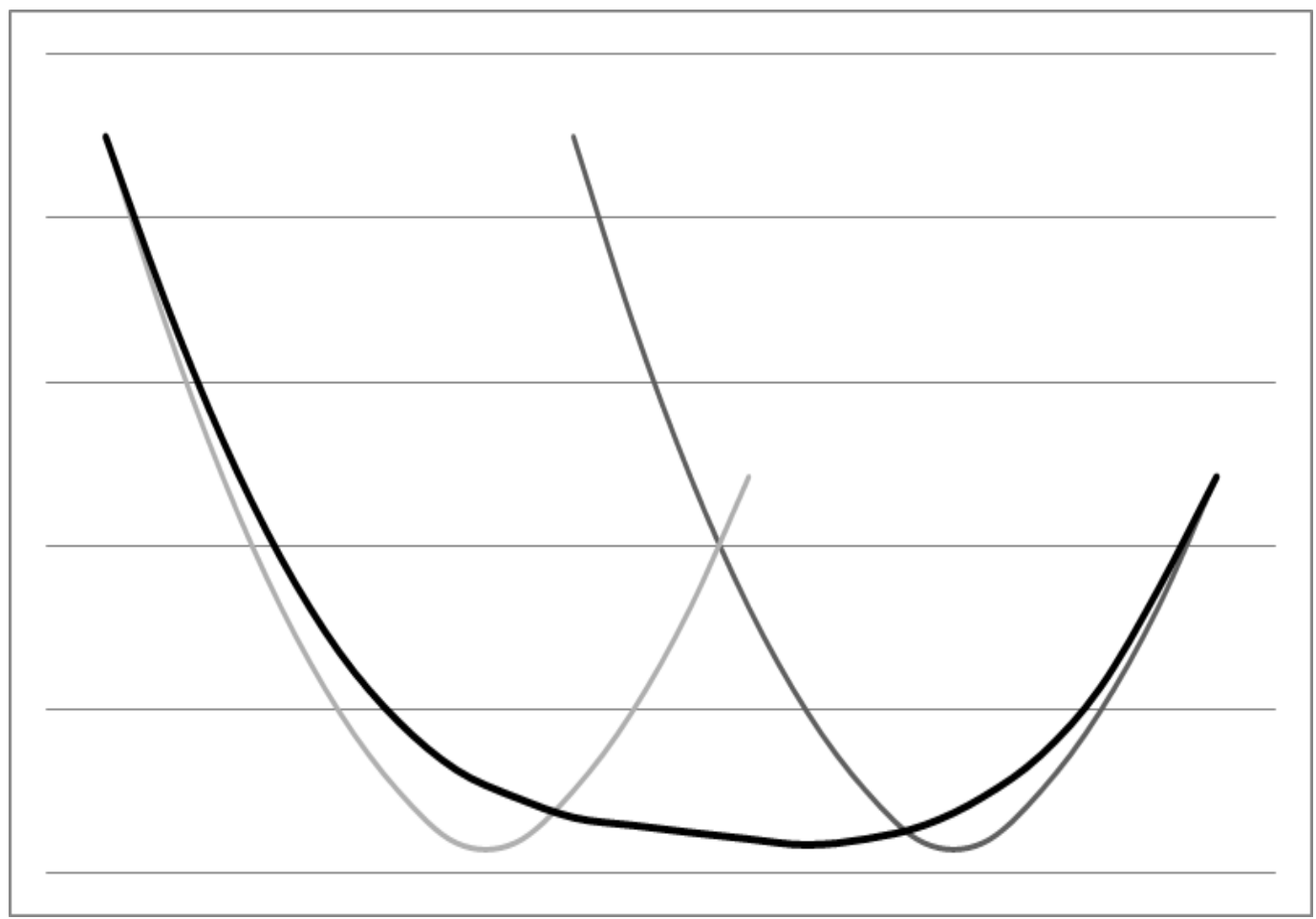

Figure 2-1: The stylized U-shape for integrated markets.

The thin lines represent the two individual markets while the thick line represents the hypothesized integrated markets. 
Table 2-1: Summary Statistics of ETFs

The dates for analysis are September through November 2008 and June through November 2010.

\begin{tabular}{|c|c|c|c|c|c|c|}
\hline & \multicolumn{3}{|c|}{2008} & \multicolumn{3}{|c|}{2010} \\
\hline & Volatility & Volume & Depth & Volatility & Volume & Depth \\
\hline \multicolumn{7}{|c|}{ Panel A: New York Trading (NY) } \\
\hline \multicolumn{7}{|c|}{ All ETFS } \\
\hline Mean & $5.14 \mathrm{e}-04$ & 87148 & 258.9 & $5.76 \mathrm{e}-04$ & 42519 & 115.1 \\
\hline Std Deviation & $1.13 \mathrm{e}-02$ & 525362 & 1035.5 & $2.61 \mathrm{e}-02$ & 216924 & 420.5 \\
\hline First Quartile & $1.73 e-06$ & 900 & 4 & 0 & 624 & 3 \\
\hline Median & $1.08 \mathrm{e}-05$ & 4140 & 14 & $1.11 \mathrm{e}-06$ & 3300 & 12 \\
\hline Third Quartile & $4.81 \mathrm{e}-05$ & 23413 & 100 & $5.02 \mathrm{e}-06$ & 18757 & 68 \\
\hline \#of ETFs & 768 & 768 & 768 & 675 & 675 & 675 \\
\hline \multicolumn{7}{|l|}{ All iShares ETFS } \\
\hline Mean & $4.21 \mathrm{e}-05$ & 75108 & 264.2 & $3.15 \mathrm{e}-06$ & 35085 & 99.2 \\
\hline Std Deviation & $2.65 \mathrm{e}-04$ & 635742 & 982.7 & $9.52 \mathrm{e}-06$ & 142654 & 319.1 \\
\hline First Quartile & $1.16 \mathrm{e}-06$ & 1300 & 6 & $9.95 \mathrm{e}-08$ & 837 & 4 \\
\hline Median & $7.46 \mathrm{e}-06$ & 6300 & 26 & $6.58 \mathrm{e}-07$ & 3500 & 15 \\
\hline Third Quartile & $3.12 \mathrm{e}-05$ & 27400 & 131 & $2.77 \mathrm{e}-06$ & 14749 & 55 \\
\hline \# of ETFs & 174 & 174 & 174 & 175 & 175 & 175 \\
\hline \multicolumn{7}{|l|}{ Dual-listed iShares ETFS } \\
\hline Mean & $3.64 \mathrm{e}-05$ & 312714 & 842.7 & $2.19 \mathrm{e}-06$ & 127310 & 239.1 \\
\hline Std Deviation & $1.47 \mathrm{e}-04$ & 886648 & 2268 & $5.83 e-06$ & 330086 & 87.7 \\
\hline First Quartile & $1.08 \mathrm{e}-06$ & 7274 & 33 & $5.42 \mathrm{e}-08$ & 394 & 13 \\
\hline Median & $6.85 \mathrm{e}-06$ & 32100 & 113 & $3.89 \mathrm{e}-07$ & 17632 & 52 \\
\hline Third Quartile & $2.83 e-05$ & 218846 & 473 & $1.81 \mathrm{e}-06$ & 92751 & 169 \\
\hline \# of ETFs & 31 & 31 & 31 & 31 & 31 & 31 \\
\hline \multicolumn{7}{|c|}{ Panel B: London Trading (LN) } \\
\hline \multicolumn{7}{|c|}{ All iShares ETFS } \\
\hline Mean & $5.03 \mathrm{e}-04$ & 60528 & 5.23 & $9.06 \mathrm{e}-04$ & 25513 & 4.12 \\
\hline Std Deviation & $1.85 \mathrm{e}-02$ & 230918 & 10.31 & $8.27 \mathrm{e}-02$ & 155283 & 7.75 \\
\hline First Quartile & $2.14 \mathrm{e}-07$ & 556 & 1 & 0 & 280 & 1 \\
\hline Median & $4.12 \mathrm{e}-06$ & 3500 & 2 & $1.01 \mathrm{e}-06$ & 1373 & 2 \\
\hline Third Quartile & $2.55 \mathrm{e}-05$ & 21171 & 4 & $3.08 \mathrm{e}-06$ & 8598 & 4 \\
\hline \# of ETFS & 109 & 109 & 109 & 171 & 171 & 171 \\
\hline Dual-listed & & & & & & \\
\hline \multicolumn{7}{|l|}{ ETFS } \\
\hline Mean & $3.66 \mathrm{e}-04$ & 29253 & 3.02 & $1.27 \mathrm{e}-04$ & 15424 & 3.27 \\
\hline Std Deviation & $1.05 \mathrm{e}-02$ & 164917 & 3.07 & $7.91 \mathrm{e}-03$ & 115923 & 3.82 \\
\hline First Quartile & $4.26 \mathrm{e}-07$ & 395 & 1 & 0 & 250 & 1 \\
\hline Median & $4.33 \mathrm{e}-06$ & 2675 & 2 & $5.01 \mathrm{e}-07$ & 1100 & 2 \\
\hline Third Quartile & $3.85 \mathrm{e}-05$ & 15034 & 4 & $2.51 \mathrm{e}-06$ & 6124 & 4 \\
\hline \# of ETFs & 28 & 28 & 28 & 42 & 42 & 42 \\
\hline \multicolumn{7}{|c|}{ Panel C: Student T-test of Means $(N Y-L N=0)$} \\
\hline All iShares ETFs & $-3.02 * * *$ & $6.96 * * *$ & $108.22 * * *$ & $-2.40 * * *$ & $12.60 * * *$ & $151.14 * * *$ \\
\hline Dual-listed iShares ETFs & $-2.31 * *$ & $37.44 * * *$ & $45.40 * * *$ & $-2.14 * *$ & $51.72 * * *$ & $66.70 * * *$ \\
\hline
\end{tabular}


Table 2-2: Summary Statistics in the Two-Hour Overlap Period for ETFs

The dates for analysis are September through November 2008 and June through November 2010.

\begin{tabular}{|c|c|c|c|c|c|c|}
\hline & \multicolumn{3}{|c|}{2008} & \multicolumn{3}{|c|}{2010} \\
\hline & Volatility & Volume & Depth & Volatility & Volume & Depth \\
\hline \multicolumn{7}{|c|}{ Panel A: New York Trading (NY) } \\
\hline \multicolumn{7}{|c|}{ All ETFS } \\
\hline Mean & $1.16 \mathrm{e}-04$ & 93741 & 290.7 & $9.18 \mathrm{e}-06$ & 53877 & 160.31 \\
\hline Std Deviation & $4.91 \mathrm{e}-03$ & 486648 & 1127.8 & $2.91 \mathrm{e}-05$ & 206657 & 543.37 \\
\hline First Quartile & $2.03 \mathrm{e}-06$ & 1000 & 4 & $2.96 \mathrm{e}-07$ & 1000 & 4 \\
\hline Median & $1.41 \mathrm{e}-05$ & 4556 & 14 & $1.79 \mathrm{e}-06$ & 4800 & 17 \\
\hline Third Quartile & $5.73 e-05$ & 25601 & 104 & $7.30 \mathrm{e}-06$ & 26626 & 98 \\
\hline \multicolumn{7}{|l|}{ All iShares ETFS } \\
\hline Mean & $5.75 \mathrm{e}-05$ & 83276 & 290.2 & $4.99 \mathrm{e}-06$ & 45736 & 128.41 \\
\hline Std Deviation & $4.51 \mathrm{e}-04$ & 340324 & 1029.3 & $1.06 \mathrm{e}-05$ & 170585 & 393.66 \\
\hline First Quartile & $1.56 \mathrm{e}-06$ & 1473 & 6 & $1.96 \mathrm{e}-07$ & 1100 & 5 \\
\hline Median & $9.74 \mathrm{e}-06$ & 7110 & 26 & $1.28 \mathrm{e}-06$ & 4660 & 18 \\
\hline Third Quartile & $3.87 \mathrm{e}-05$ & 30645 & 137.8 & $5.05 \mathrm{e}-06$ & 19394 & 71 \\
\hline \multicolumn{7}{|l|}{ Dual-listed iShares ETFS } \\
\hline Mean & $4.49 \mathrm{e}-05$ & 356933 & 975 & $3.43 e-06$ & 178631 & 338.73 \\
\hline Std Deviation & $2.12 \mathrm{e}-04$ & 830968.5 & 2412.2 & $7.52 \mathrm{e}-06$ & 395108 & 755.79 \\
\hline First Quartile & $1.56 \mathrm{e}-06$ & 9386 & 39 & $1.01 \mathrm{e}-07$ & 5048 & 17 \\
\hline Median & $8.94 \mathrm{e}-06$ & 43698 & 140 & $7.45 \mathrm{e}-07$ & 30500 & 86 \\
\hline Third Quartile & $3.53 e-05$ & 270638 & 542.5 & $3.35 \mathrm{e}-06$ & 145388 & 240 \\
\hline \multicolumn{7}{|c|}{ Panel B: London Trading (LN) } \\
\hline \multicolumn{7}{|l|}{ All iShares ETFS } \\
\hline Mean & $1.23 \mathrm{e}-03$ & 67611 & 5.33 & $1.77 \mathrm{e}-03$ & 25933 & 4.61 \\
\hline Std Deviation & $3.18 \mathrm{e}-02$ & 238697 & 10.81 & $1.15 \mathrm{e}-01$ & 96235 & 9.53 \\
\hline First Quartile & $5.02 \mathrm{e}-07$ & 716 & 1 & 0 & 367.5 & 1 \\
\hline Median & $7.23 \mathrm{e}-06$ & 4030 & 2 & $1.02 \mathrm{e}-06$ & 1903 & 2 \\
\hline Third Quartile & $5.09 \mathrm{e}-05$ & 22873 & 4 & $5.05 \mathrm{e}-06$ & 10000 & 4 \\
\hline \multicolumn{7}{|l|}{ Dual-listed iShares ETFS } \\
\hline Mean & $5.05 \mathrm{e}-04$ & 35587 & 3.44 & $3.04 \mathrm{e}-04$ & 18910 & 3.39 \\
\hline Std Deviation & $1.32 \mathrm{e}-02$ & 125073 & 3.81 & $1.35 \mathrm{e}-02$ & 67062 & 4.576 \\
\hline First Quartile & $1.21 \mathrm{e}-06$ & 558 & 1 & $1.22 \mathrm{e}-07$ & 392 & 1 \\
\hline Median & $7.91 \mathrm{e}-06$ & 4000 & 2 & $9.01 \mathrm{e}-07$ & 1931 & 2 \\
\hline Third Quartile & $5.89 \mathrm{e}-05$ & 25000 & 4 & $4.42 \mathrm{e}-06$ & 10000 & 4 \\
\hline \multicolumn{7}{|c|}{ Panel C: Student T-test of Means $(N Y-L N=0)$} \\
\hline All iShares ETFs & $-2.42 * * *$ & $4.09 * * *$ & $63.79 * * *$ & $-1.93 * *$ & $20.47 * * *$ & $91.11 * * *$ \\
\hline Dual-listed iShares ETFs & -1.51 & $25.84 * * *$ & $27.67 * * *$ & $-1.75^{*}$ & $37.04 * * *$ & $41.48 * * *$ \\
\hline
\end{tabular}


Trade Price Volatility

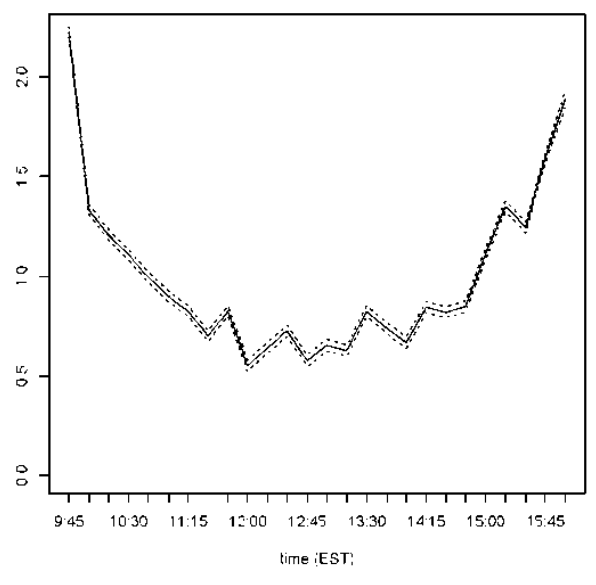

A

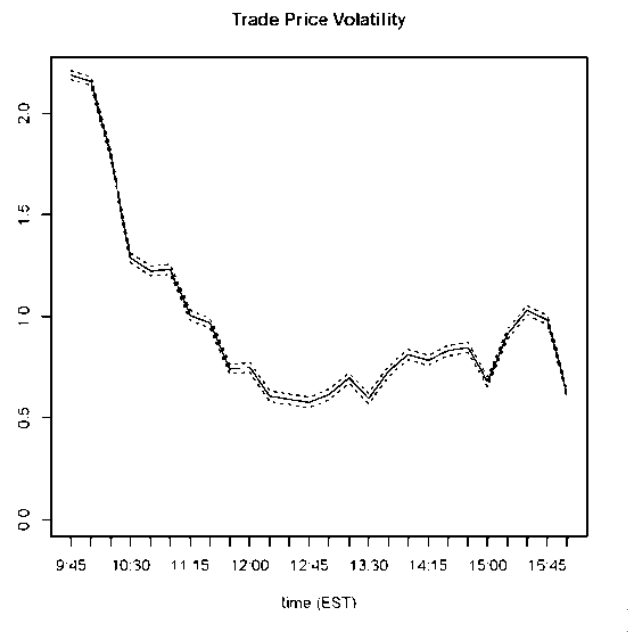

$\mathrm{D}$
Trade Price Volume

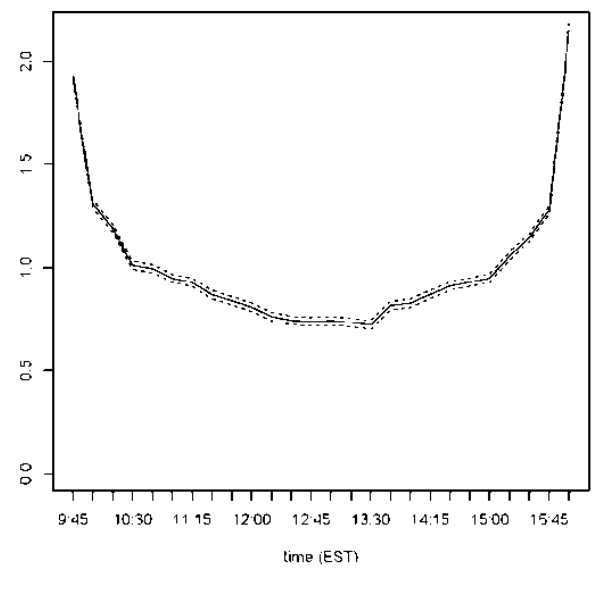

Trade Price Volume

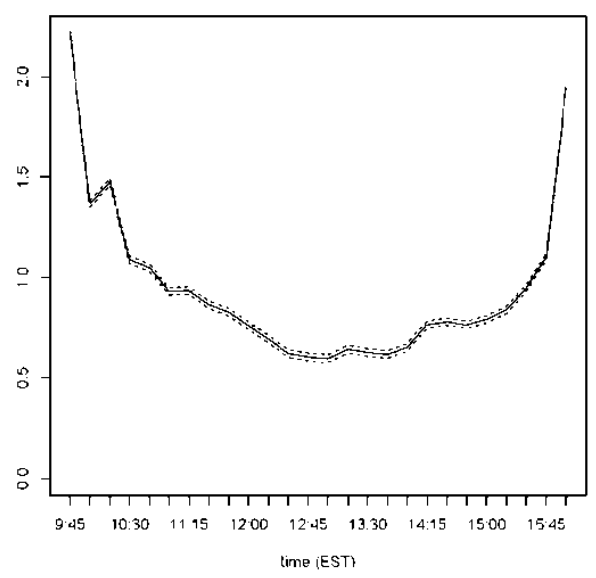

Figure 2-2: Intraday patterns for all New York ETFs for 2008 and 2010.

The top panels, A, B, C, represent September through November 2008 while the bottom panels, D, E, F, represent June through November 2010. These graphs illustrate the results of the regression for the intraday patterns. The dotted line representss the $99 \%$ confidence interval. 
Trade Price Volatility

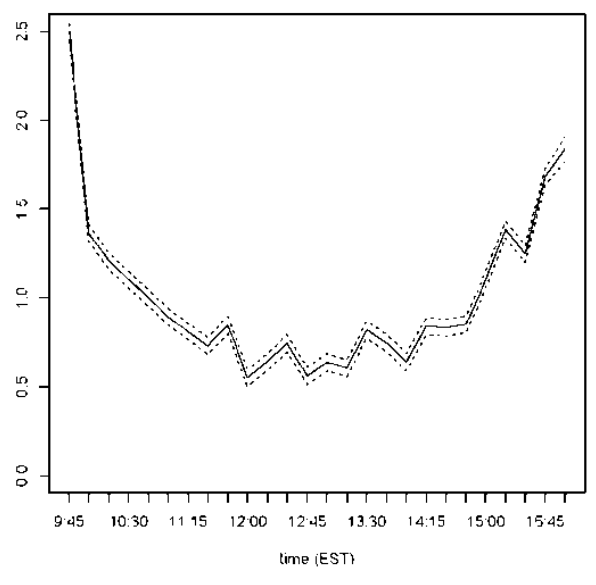

A

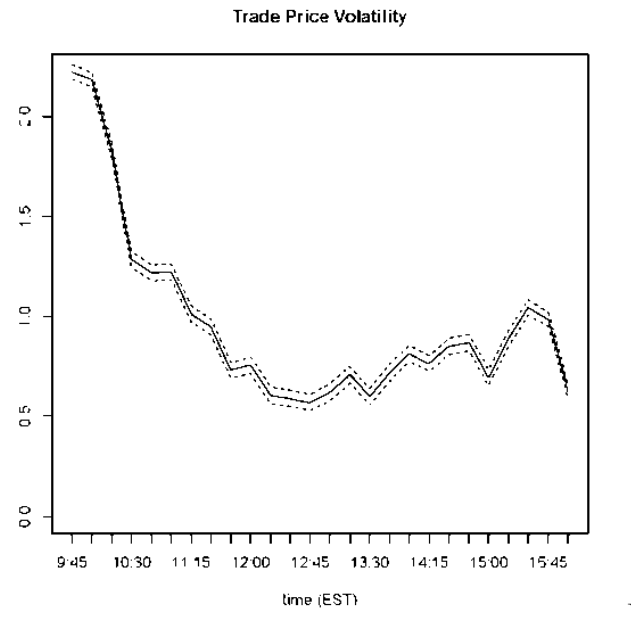

Trade Price Volume

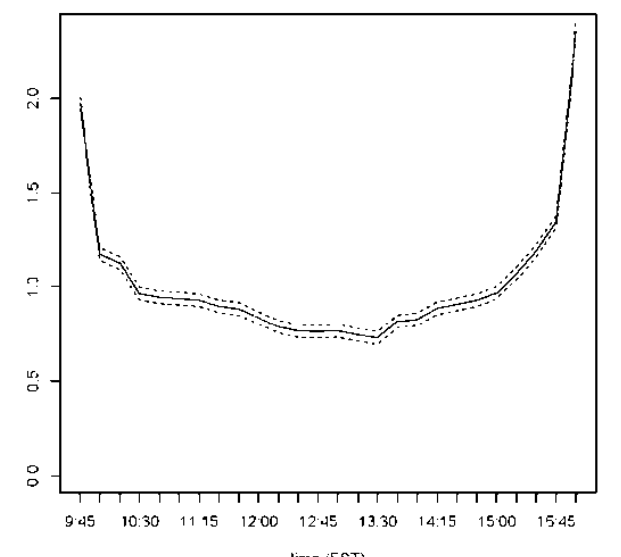

time ESTR

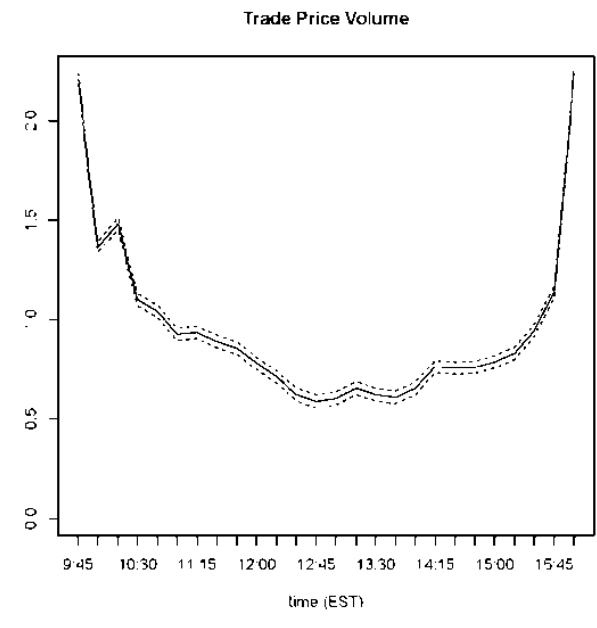

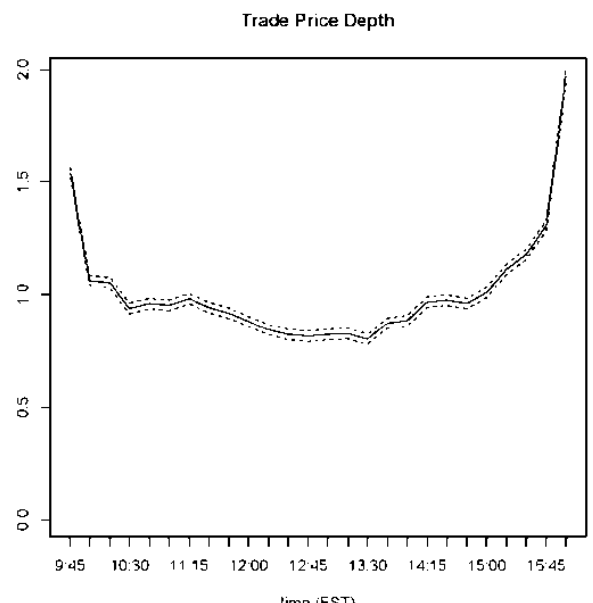

time (EST)

Trade Price Depth

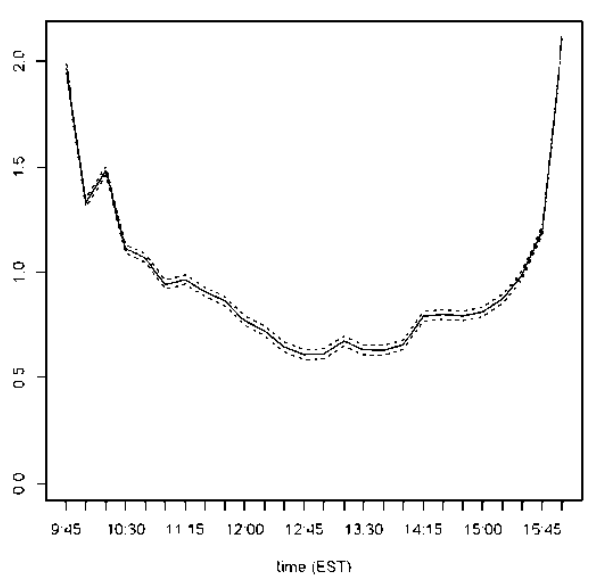

Figure 2-3: Intraday patterns for all New York iShares ETFs for 2008 and 2010

The top panels, A, B, C, represent September through November 2008 while the bottom panels, D, E, F, represent June through November 2010. These graphs illustrate the results of the regression for the intraday patterns. The dotted line represents the $99 \%$ confidence interval. 
Trade Price Volatility

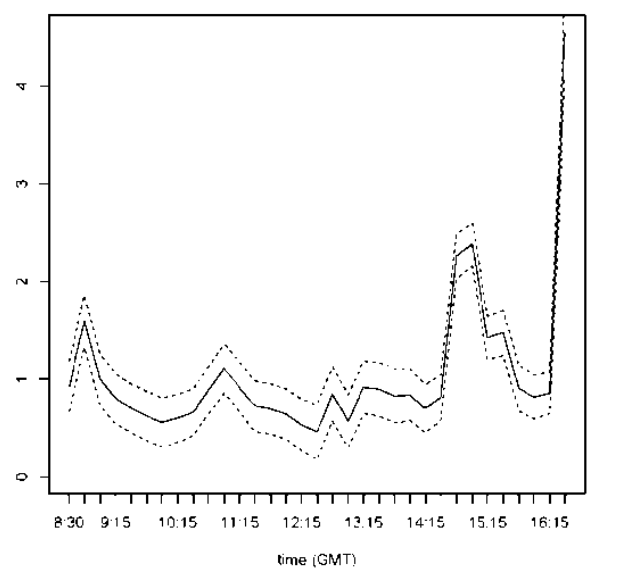

A

Trade Price Volatility

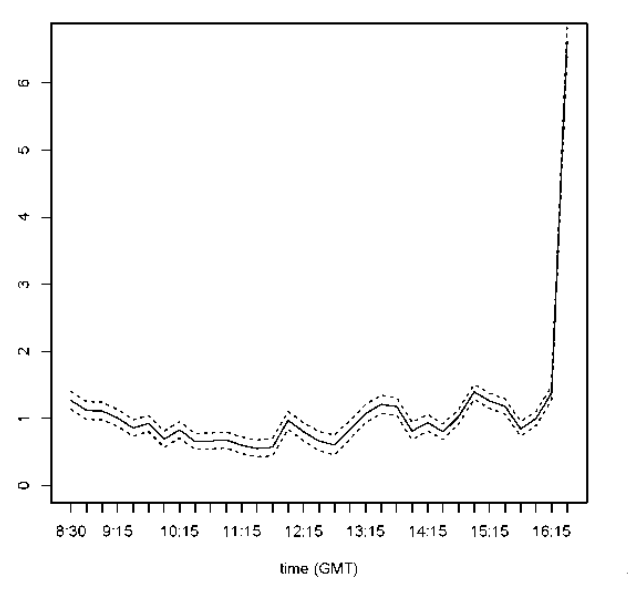

Trade Price Volume

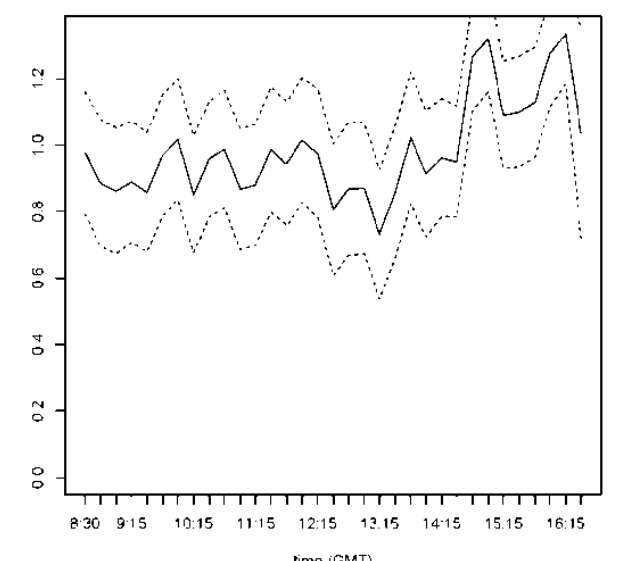

(ime (GMT)

Trade Price Volume

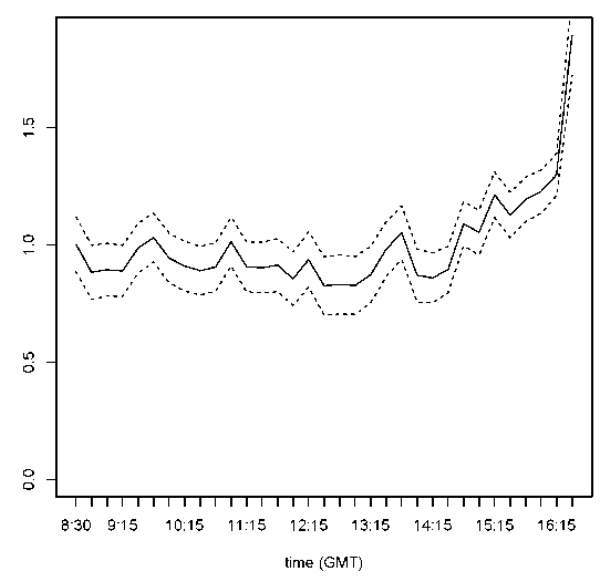

B

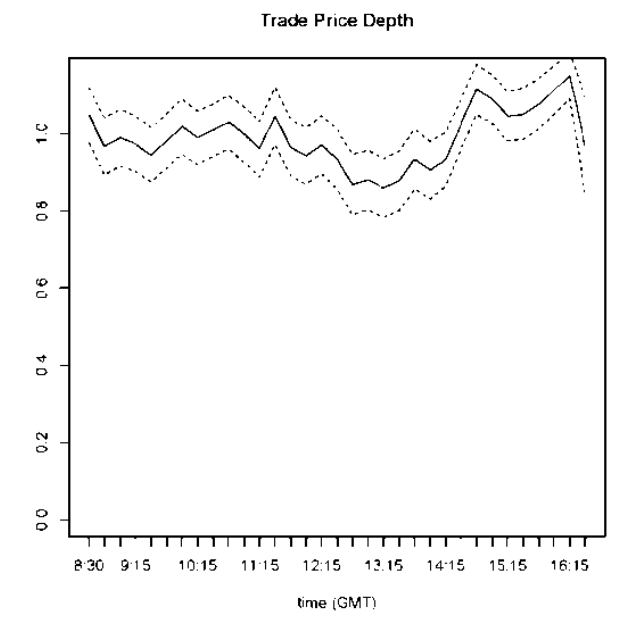

$\mathrm{C}$

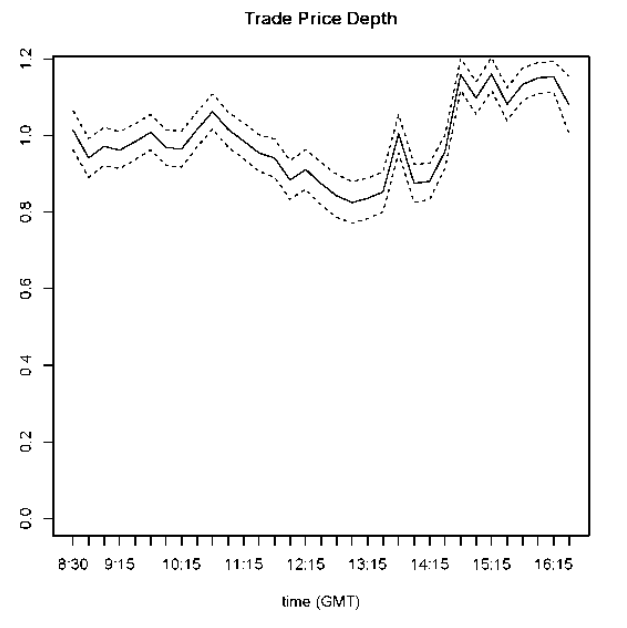

Figure 2-4: Intraday patterns for all London iShares ETFs for 2008 and 2010.

The top panels, A, B, C, represent September through November 2008 while the bottom panels, D, E, F, represent June through November 2010. These graphs illustrate the results of the regression for the intraday patterns. The dotted line represents the $99 \%$ confidence interval. 

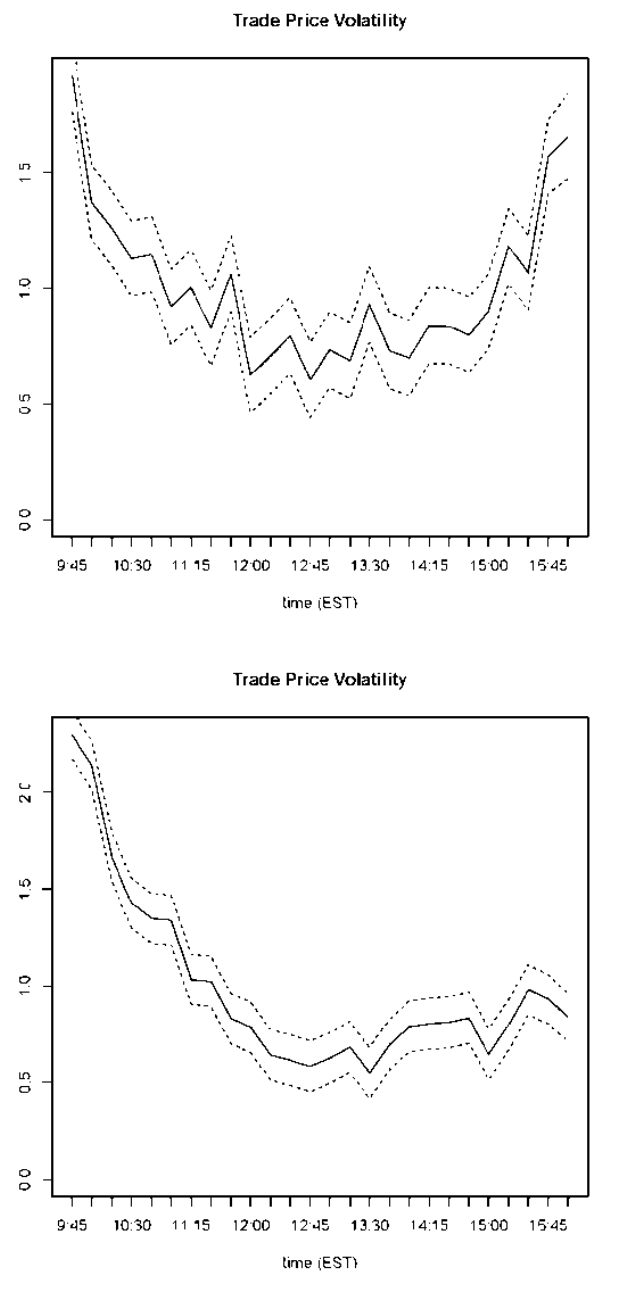

Trade Price Volume

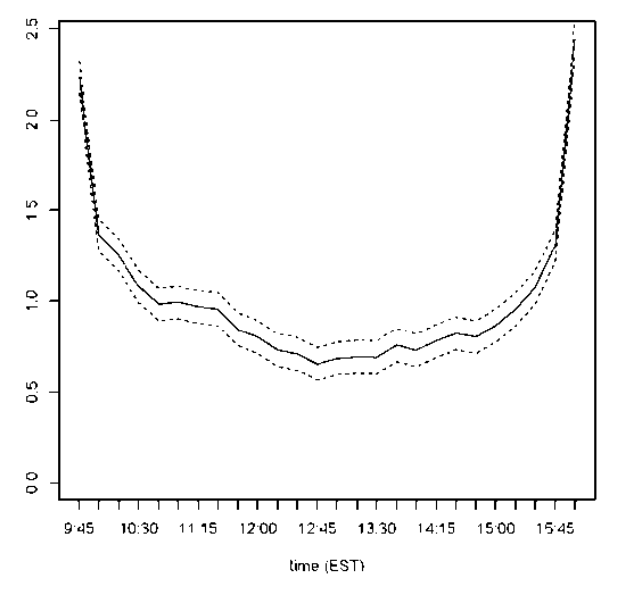

rade Price Volume

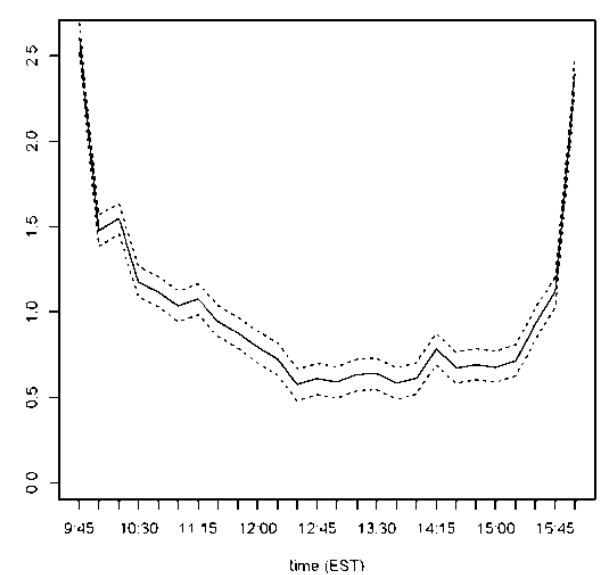

D

Trade Price Depth

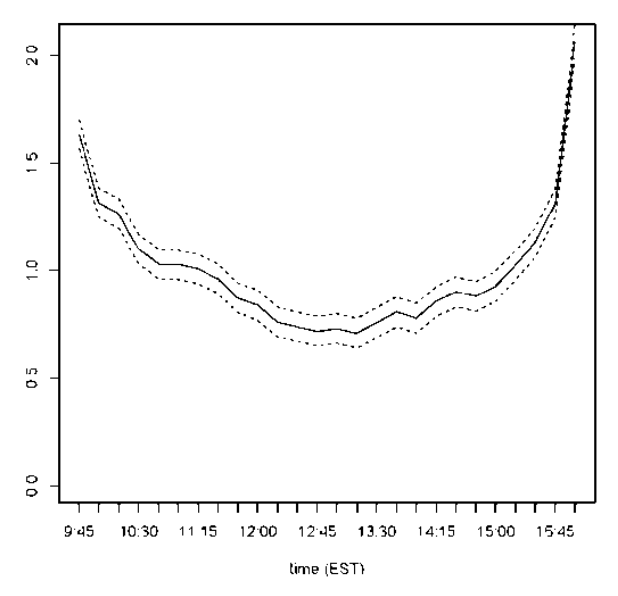

Trade Price Depth

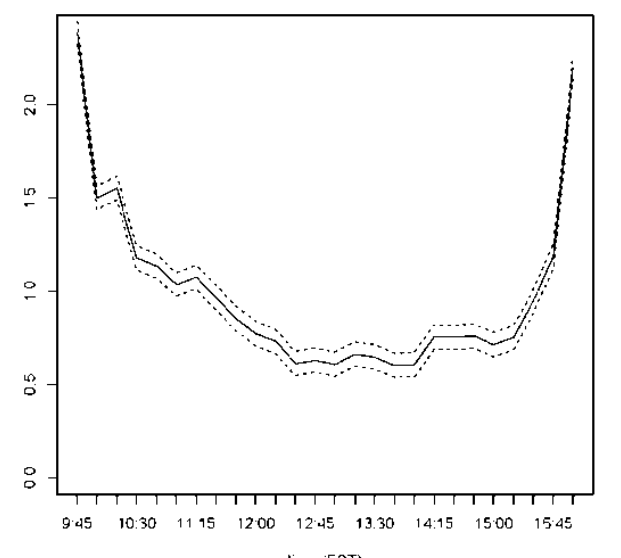

time (EST)

$\mathrm{F}$

Figure 2-5: Intraday patterns for dual listed New York iShares ETFs for 2008 and 2010.

The top panels, A, B, C, represent September through November 2008 while the bottom panels, D, E, F, represent June through November 2010 . These graphs illustrate the results of the regression for the intraday patterns. The dotted line representss the $99 \%$ confidence interval. 


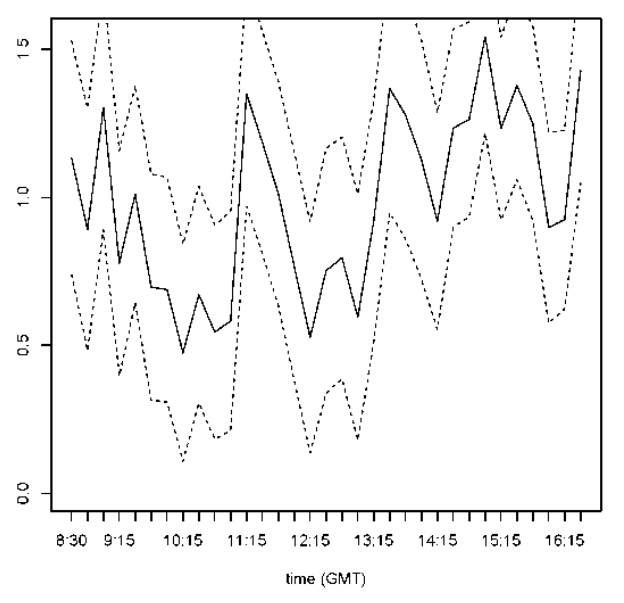

$$
\text { time (GMT) }
$$

Trade Price Volatility

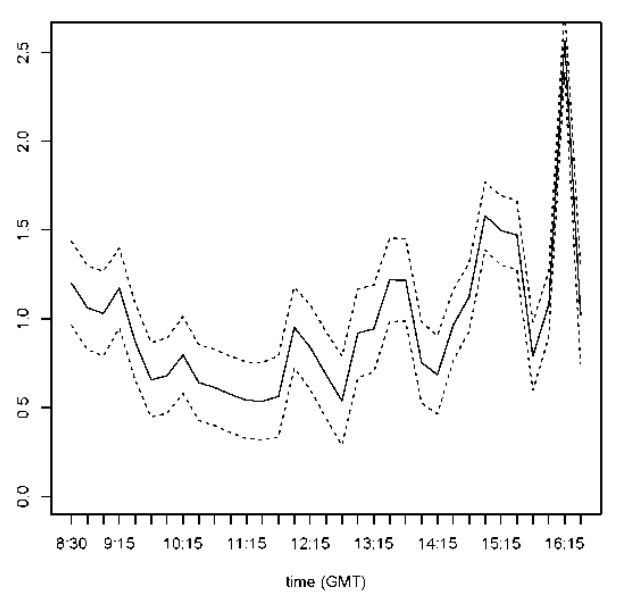

Trade Price Volume

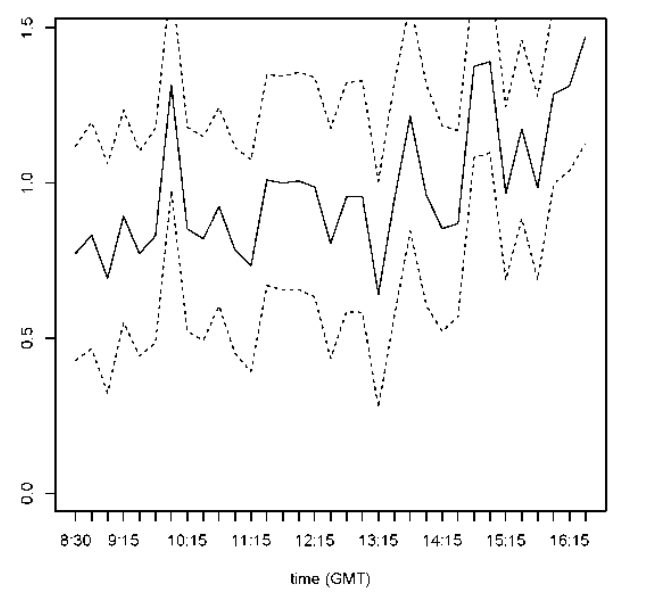

time (GMT)
Trade Price Volume

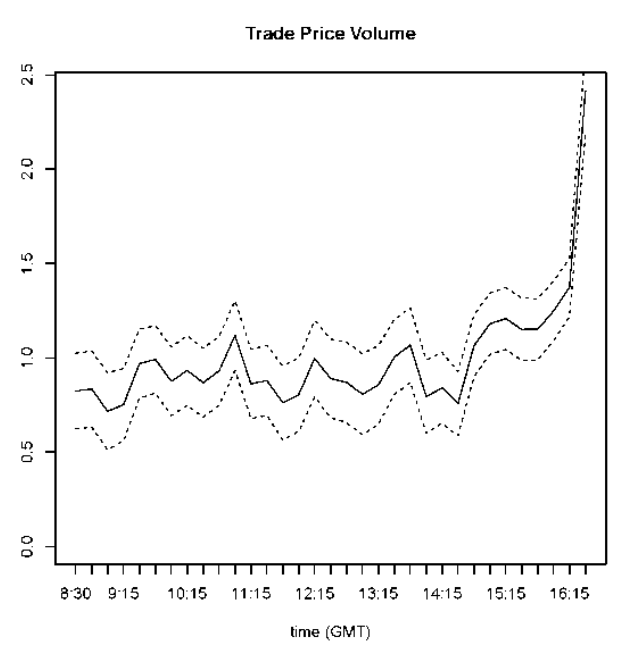

time (GMT)
B

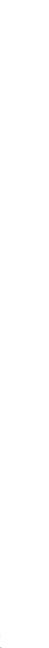

Trade Price Depth

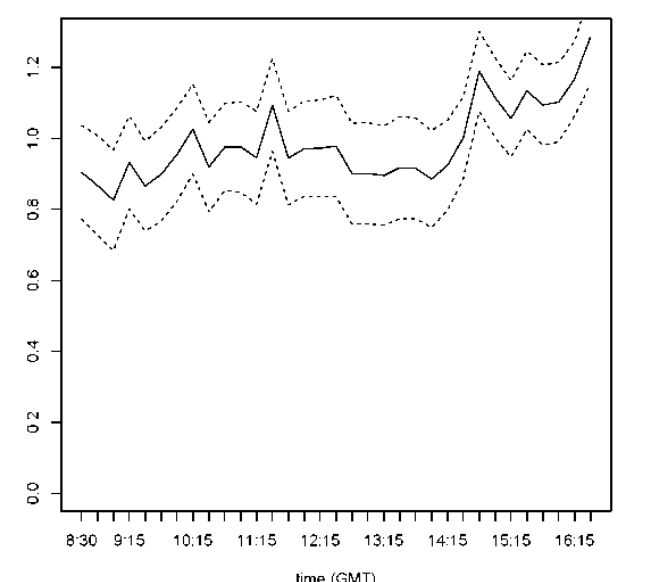

time (GMT)

C

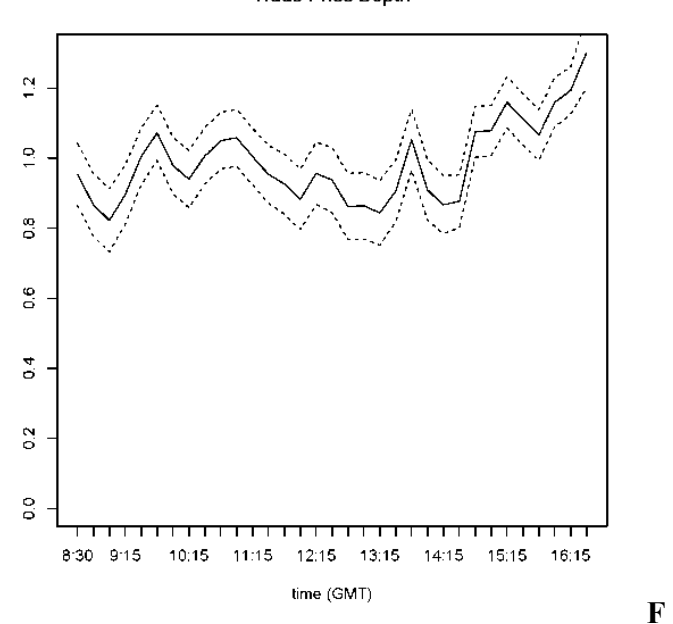

Figure 2-6: Intraday patterns for dual listed Londn iShares ETFs for 2008 and 2010.

The top panels, A, B, C, represent September through November 2008 while the bottom panels, D, E, F, represent June through November 2010. These graphs illustrate the results of the regression for the intraday patterns. The dotted line represents the $99 \%$ confidence interval. 
Trade Price Volatility

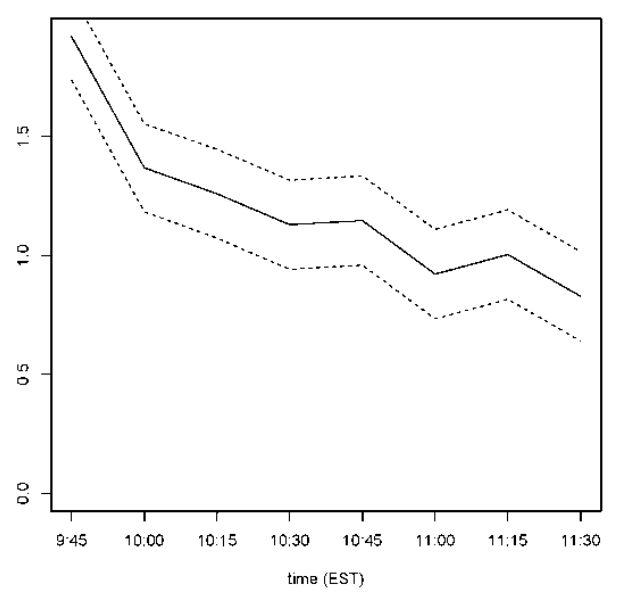

A

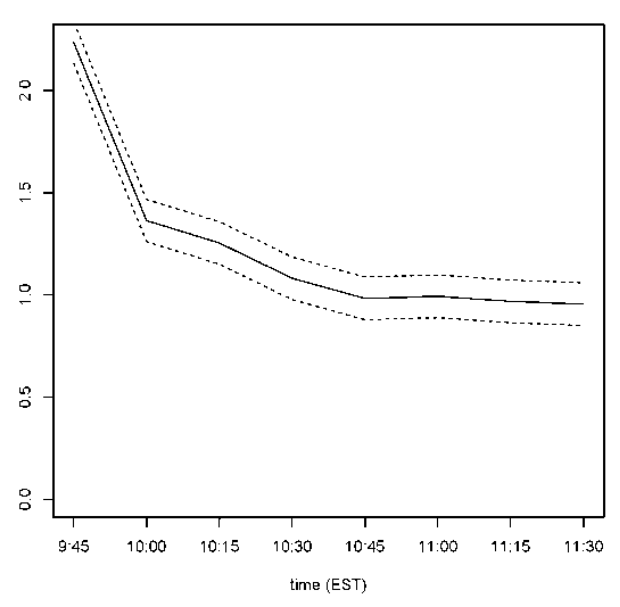

rade Price Volurne

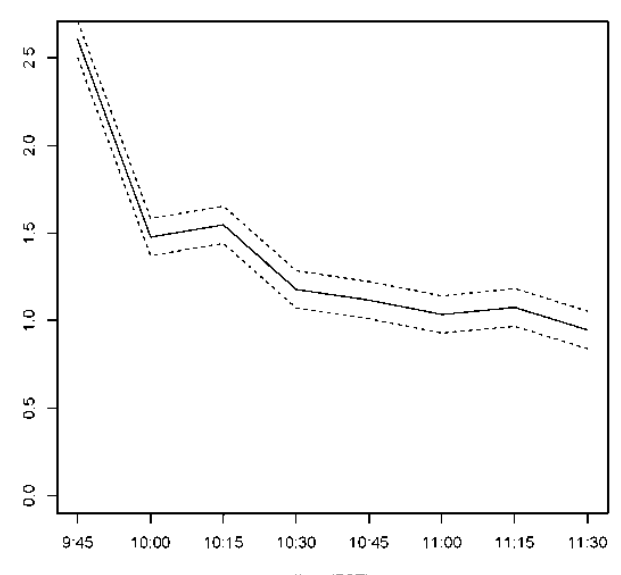

time (EST)

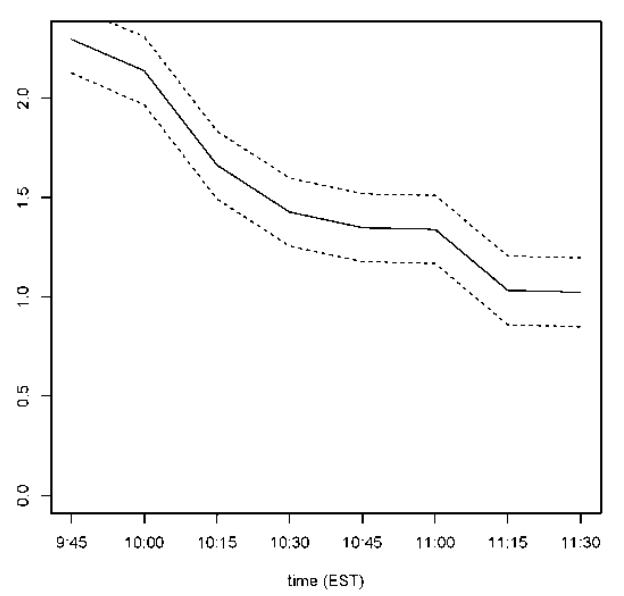

Figure 2-7: Intraday patterns for all dual-listed New York iShares ETFs in the overlapping period for 2008 and 2010.

The top panels, A, B, C, represent September through November 2008 while the bottom panels, D, E, F, represent June through November 2010. These graphs

illustrate the results of the regression for the intraday patterns. The dotted line represents the $99 \%$ confidence interval.
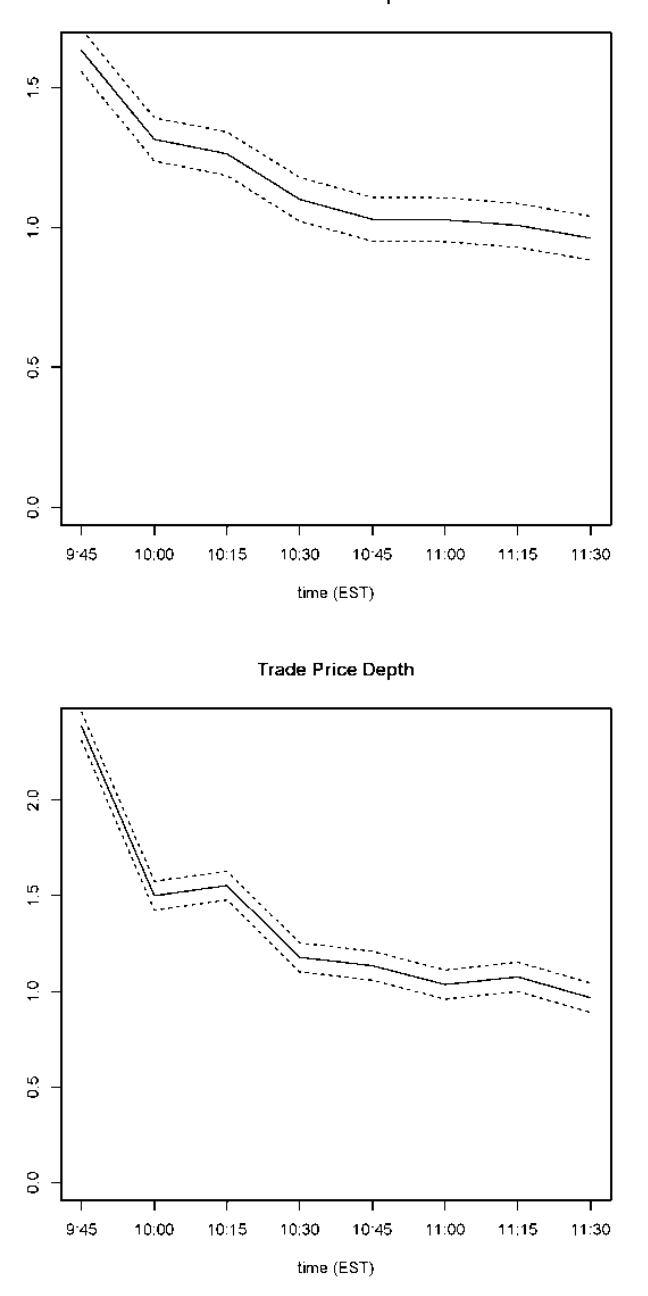

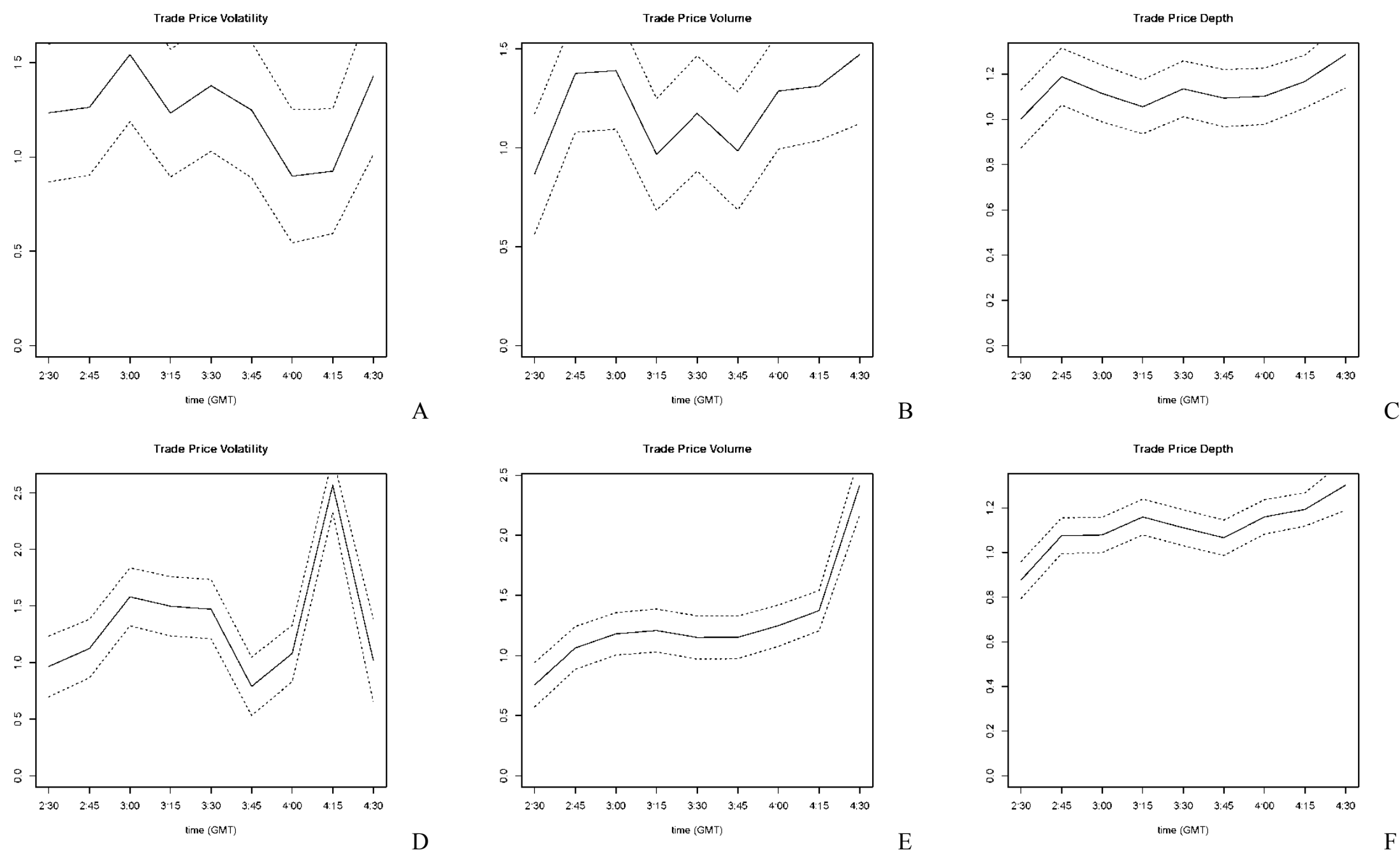

Figure 2-8: Intraday patterns for all dual-listed London iShares ETFs in the overlapping period for 2008 and 2010.

The top panels, A, B, C, represent September through November 2008 while the bottom panels, D, E, F, represent June through November 2010. These graphs illustrate the results of the regression for the intraday patterns. The dotted line represents the $99 \%$ confidence interval. 
Table 2-3: Intraday Time Effects from Regression

The estimates from the regression for the time effect are provided. The parentheses contain the t-statistic that tests whether the estimate is significantly different from zero. The model is computed similar to Werner and Kleidon (1996) where $\frac{Y_{f, d, t}}{\delta_{f, t}}=\sum_{i=t_{0}}^{T} J^{i}(t) \alpha_{i}+\left(\sum_{i=t_{0}}^{T}\left(J^{i}(t) \sigma_{i}\right)\right) \varepsilon_{f, d, t}$

$\mathrm{Y}$ is volume, volatility or spread, and $\mathrm{f}$ is the ETF, $\mathrm{d}$ is the day, and $\mathrm{t}$ is the time interval. $\delta$ represents the fund specific, day specific mean. The dummy vector of $\mathrm{J}^{\mathrm{i}}(\mathrm{t})$ is a $\{0,1\}$ vector with value of one only when $\mathrm{i}=\mathrm{t}$. The error term, $\varepsilon_{\mathrm{f}, \mathrm{d}, \mathrm{t}}$ is iid with a mean of zero and variance of one. The $\sigma$ vector represents the intraday variance, and can be heteroskedastic.

\begin{tabular}{|c|c|c|c|c|c|c|c|}
\hline \multicolumn{8}{|c|}{ Panel A: Dual-listed ETFs for the whole day (2008) } \\
\hline Time & Volatility & Volume & Depth & Time & Volatility & Volume & Depth \\
\hline $9: 30-9: 45$ & $1.92(31.32)$ & $2.23(65.88)$ & $1.63(63.00)$ & $8: 30-8: 45$ & $0.89(5.61)$ & $0.83(5.86)$ & $0.87(15.94$ \\
\hline $9: 45-10: 00$ & $1.37(21.99)$ & $1.36(39.58)$ & $1.31(49.97)$ & $8: 45-9: 00$ & $1.30(8.13)$ & $0.69(4.83)$ & $0.83(15.01)$ \\
\hline 10:00-10:15 & $1.26(20.07)$ & $1.25(36.09)$ & $1.26(47.61)$ & $9: 00-9: 15$ & $0.78(5.26)$ & $0.89(6.72)$ & $0.93(18.31)$ \\
\hline $10: 15-10: 30$ & $1.13(17.92)$ & $1.08(31.01)$ & $1.10(41.32)$ & $9: 15-9: 30$ & $1.01(7.09)$ & $0.77(6.04)$ & $0.87(17.65)$ \\
\hline $10: 30-10: 45$ & $1.15(18.18)$ & $0.98(28.16)$ & $1.03(38.63$ & $9: 30-9: 45$ & $0.70(4.69)$ & $0.83(6.19)$ & $0.90(17.48)$ \\
\hline 10:45-11:00 & $0.92(14.56)$ & $0.99(28.36)$ & $1.03(38.43)$ & $9: 45-10: 00$ & $0.69(4.67)$ & $1.32(9.92)$ & $0.95(18.75)$ \\
\hline 11:00-11:15 & $1.00(15.89)$ & $0.97(27.70)$ & $1.01(37.73)$ & 10:00-10:15 & $0.47(3.34)$ & $0.85(6.68)$ & $1.03(20.99)$ \\
\hline $11: 15-11: 30$ & $0.83(13.11)$ & $0.95(27.32)$ & $0.96(36.03)$ & 10:15-10:30 & $0.67(4.72)$ & $0.82(6.44)$ & $0.92(18.80)$ \\
\hline $11: 30-11: 45$ & $1.06(16.79)$ & $0.84(24.08)$ & $0.87(32.60)$ & $10: 30-10: 45$ & $0.54(3.88)$ & $0.92(7.45)$ & $0.98(20.48)$ \\
\hline $11: 45-12: 00$ & $0.63(09.89)$ & $0.80(22.94)$ & $0.84(31.41)$ & $10: 45-11: 00$ & $0.58(4.06)$ & $0.78(6.07)$ & $0.98(19.72)$ \\
\hline $12: 00-12: 15$ & $0.71(11.19)$ & $0.73(20.80)$ & $0.76(28.33)$ & $11: 00-11: 15$ & $1.35(9.14)$ & $0.73(5.54)$ & $0.95(18.62)$ \\
\hline $12: 15-12: 30$ & $0.79(12.58)$ & $0.71(20.25)$ & $0.74(27.59)$ & $11: 15-11: 30$ & $1.19(8.12)$ & $1.01(7.65)$ & $1.09(21.62)$ \\
\hline $12: 30-12: 45$ & $0.60(09.51)$ & $0.65(18.60)$ & $0.72(26.76)$ & $11: 30-11: 45$ & $1.01(6.89)$ & $1.0(7.49)$ & $0.94(18.42)$ \\
\hline $12: 45-1: 00$ & $0.73(11.54)$ & $0.68(19.42)$ & $0.73(27.18)$ & $11: 45-12: 00$ & $0.77(5.11)$ & $1.01(7.41)$ & $0.97(18.63)$ \\
\hline 1:00-1:15 & $0.69(10.79)$ & $0.69(19.59)$ & $0.71(26.20)$ & $12: 00-12: 15$ & $0.53(3.48)$ & $0.99(7.19)$ & $0.97(18.46)$ \\
\hline $1: 15-1: 30$ & $0.93(14.58)$ & $0.69(19.52)$ & $0.76(28.05)$ & $12: 15-12: 30$ & $0.75(4.67)$ & $0.81(5.59)$ & $0.98(17.70)$ \\
\hline $1: 30-1: 45$ & $0.73(11.49)$ & $0.76(21.52)$ & $0.81(30.07)$ & $12: 30-12: 45$ & $0.80(5.03)$ & $0.96(6.66)$ & $0.90(16.36)$ \\
\hline $1: 45-2: 00$ & $0.70(10.99)$ & $0.73(20.70)$ & $0.78(28.93)$ & $12: 45-1: 00$ & $0.59(3.69)$ & $0.96(6.61)$ & $0.90(16.25)$ \\
\hline $2: 00-2: 15$ & $0.84(13.18)$ & $0.78(22.17)$ & $0.86(31.85)$ & $1: 00-1: 15$ & $0.92(5.82)$ & $0.64(4.53$ & $0.90(16.51)$ \\
\hline $2: 15-2: 30$ & $0.84(13.27)$ & $0.82(23.56)$ & $0.89(33.78)$ & $1: 15-1: 30$ & $1.37(8.40)$ & $0.95(6.50)$ & $0.92(16.42)$ \\
\hline $2: 30-2: 45$ & $0.79(12.56)$ & $0.80(22.84)$ & $0.88(32.79)$ & $1: 30-1: 45$ & $1.28(7.88)$ & $1.21(8.47)$ & $0.92(16.64)$ \\
\hline $2: 45-3: 00$ & $0.90(14.26)$ & $0.86(24.75)$ & $0.93(34.72)$ & $1: 45-2: 00$ & $1.13(7.19)$ & $0.96(6.96)$ & $0.89(16.69)$ \\
\hline $3: 00-3: 15$ & $1.18(08.85)$ & $0.95(27.54)$ & $1.02(38.70)$ & $2: 00-2: 15$ & $0.92(6.47)$ & $0.85(6.65)$ & $0.92(18.78)$ \\
\hline $3: 15-3: 30$ & $1.07(17.03)$ & $1.08(31.11)$ & $1.13(42.81)$ & $2 \cdot 15-2 \cdot 30$ & $123(051)$ & $0.87(745)$ & $1 \cap(2230)$ \\
\hline $3: 30-3: 45$ & $1.57(25.45)$ & $1.31(38.22)$ & $1.31(50.22)$ & $2: 30-2: 45$ & $1.26(9.89)$ & $1.38(12.06)$ & $1.19(27.16)$ \\
\hline $3: 45-4: 00$ & $1.66(23.22)$ & $2.44(61.79)$ & $2.06(68.26)$ & $2: 45-3: 00$ & $1.54(12.23)$ & $1.39(12.21)$ & $1.11(25.52)$ \\
\hline & & & & $3: 00-3 ; 15$ & $1.23(10.28)$ & $0.97(8.90)$ & $1.06(25.36)$ \\
\hline & & & & $3: 15-3: 30$ & $1.38(11.16)$ & $1.17(10.49)$ & $1.14(26.42)$ \\
\hline & & & & $3: 30-3: 45$ & $1.25(9.79)$ & $0.98(8.58)$ & $1.09(24.86)$ \\
\hline & & & & $3: 45-4: 00$ & $0.89(7.17)$ & $1.29(11.4)$ & $1.10(25.48)$ \\
\hline & & & & $4: 00-4: 15$ & $0.92(7.88)$ & $1.31(12.41)$ & $1.16(28.78)$ \\
\hline & & & & $4: 15-4: 30$ & $143(9.69)$ & $1.47(1098)$ & $1.29(25.02)$ \\
\hline F-Statistic & 275.7 & 953.7 & 1514 & F-Statistic & 53.51 & 63.75 & 417.7 \\
\hline Adjusted $\mathrm{R}^{2}$ & 0.3223 & 0.6223 & 0.7235 & Adjusted $\mathrm{R}^{2}$ & 0.2487 & 0.2769 & 0.72 \\
\hline Std. Error & 1.523 & 0.8431 & 0.6438 & Std. Error & 1.797 & 1.642 & 0.63 \\
\hline
\end{tabular}




\begin{tabular}{|c|c|c|c|c|c|c|c|}
\hline \multicolumn{8}{|c|}{ Panel B: Dual-listed ETFs for the whole day (2010) } \\
\hline Time & Volatility & Volume & Depth & Time & Volatility & Volume & Depth \\
\hline 9:30-9:45 & $2.29(47.07)$ & $2.61(75.99)$ & $2.39(97.73)$ & $8: 30-8: 45$ & $1.06(11.57)$ & $0.83(10.67)$ & $0.87(25.02)$ \\
\hline $9: 45-10: 00$ & $2.14(43.20)$ & $1.48(42.44)$ & $1.50(60.58)$ & $8: 45-9: 00$ & $1.03(11.10)$ & $0.72(9.04)$ & $0.82(23.45)$ \\
\hline 10:00-10:15 & $1.66(33.70)$ & $1.55(44.58)$ & $1.55(62.90)$ & $9: 00-9: 15$ & $1.17(13.49)$ & $0.75(10.14)$ & $0.89(27.32)$ \\
\hline 10:15-10:30 & $1.43(28.83)$ & $1.18(33.84)$ & $1.18(47.56)$ & $9: 15-9: 30$ & $0.87(10.42)$ & $0.97(13.64)$ & $1.00(31.95)$ \\
\hline $10: 30-10: 45$ & $1.35(27.32)$ & $1.12(32.17)$ & $1.13(45.91)$ & $9: 30-9: 45$ & $0.66(8.07)$ & $0.99(14.31)$ & $1.07(34.95)$ \\
\hline 10:45-11:00 & $1.34(27.05)$ & $1.03(29.72)$ & $1.04(41.79)$ & $9: 45-10: 00$ & $0.68(8.28)$ & $0.88(12.45)$ & $0.98(31.48)$ \\
\hline 11:00-11:15 & $1.03(20.63)$ & $1.07(30.54)$ & $1.08(42.95)$ & $10: 00-10: 15$ & $0.80(9.51)$ & $0.93(13.01)$ & $0.94(29.62)$ \\
\hline $11 \cdot 15-11 \cdot 30$ & $102(2038)$ & $0.95(2680)$ & $097(3845)$ & $10: 15-10: 30$ & $0.64(7.72)$ & $0.87(12.23)$ & $1.01(32.05)$ \\
\hline $11: 30-11: 45$ & $0.83(16.47)$ & $0.88(24.71)$ & $0.86(33.83)$ & $10: 30-10: 45$ & $0.61(7.37)$ & $0.93(13.13)$ & $1.05(33.48)$ \\
\hline $11: 45-12: 00$ & $0.79(15.51)$ & $0.79(22.26)$ & $0.77(30.38)$ & $10: 45-11: 00$ & $0.57(6.87)$ & $1.12(15.62)$ & $1.06(33.41)$ \\
\hline $12: 00-12: 15$ & $0.64(12.64)$ & $0.72(20.24)$ & $0.73(28.72)$ & $11: 00-11: 15$ & $0.54(6.48)$ & $0.86(12.14)$ & $1.00(32.00)$ \\
\hline $12: 15-12: 30$ & $0.62(12.09)$ & $0.57(16.01)$ & $0.61(23.97)$ & $11: 15-11: 30$ & $0.54(6.34)$ & $0.88(12.20)$ & $0.95(29.89)$ \\
\hline $12: 30-12: 45$ & $0.59(11.49)$ & $0.61(16.97)$ & $0.63(24.73)$ & $11: 30-11: 45$ & $0.56(6.33)$ & $0.76(10.05)$ & $0.93(27.67)$ \\
\hline $12: 45-1: 00$ & $0.63(12.25)$ & $0.59(16.32)$ & $0.61(23.71)$ & $11: 45-12: 00$ & $0.95(10.72)$ & $080(10.60)$ & $0.88(26.27)$ \\
\hline $1: 00-1: 15$ & $0.68(13.32)$ & $0.63(17.48)$ & $0.66(25.76)$ & $12: 00-12: 15$ & $0.84(9.15)$ & $0.99(12.71)$ & $0.96(27.58)$ \\
\hline $1: 15-1: 30$ & $0.55(10.71)$ & $0.64(17.64)$ & $0.65(25.15)$ & $12: 15-12: 30$ & $0.68(7.22)$ & $0.89(10.99)$ & $0.94(26.18)$ \\
\hline $1: 30-1: 45$ & $0.70(13.62)$ & $0.58(16.15)$ & $0.60(23.51)$ & $12: 30-12: 45$ & $0.54(5.55)$ & $0.87(10.51)$ & $0.86(23.55)$ \\
\hline $1: 45-2: 00$ & $0.79(15.46)$ & $0.61(16.96)$ & $0.60(23.63)$ & $12: 45-1: 00$ & $0.92(9.48)$ & $0.81(9.68)$ & $0.86(23.43)$ \\
\hline $2: 00-2: 15$ & $0.80(15.80)$ & $0.78(21.83)$ & $0.75(29.62)$ & 1:00-1:15 & $0.94(9.93)$ & $0.86(10.59)$ & $0.84(23.59)$ \\
\hline $2: 15-2: 30$ & $0.81(15.93)$ & $0.67(18.78)$ & $0.75(29.52)$ & $1: 15-1: 30$ & $1.22(13.37)$ & $1.00(12.97)$ & $0.91(26.45)$ \\
\hline $2: 30-2: 45$ & $0.83(16.40)$ & $0.69(19.36)$ & $0.76(29.82)$ & $1: 30-1: 45$ & $1.22(13.50)$ & $1.01(13.93)$ & $1.05(31.05)$ \\
\hline $2: 45-3: 00$ & $0.65(12.73)$ & $0.68(18.99)$ & $0.71(28.06)$ & $1: 45-2: 00$ & $0.75(8.50)$ & $0.79(10.54)$ & $0.91(27.25)$ \\
\hline $3: 00-3: 15$ & $0.80(15.81)$ & $0.71(20.12)$ & $0.75(29.68)$ & $2: 00-2: 15$ & $0.68(7.99)$ & $0.84(11.55)$ & $0.87(26.93)$ \\
\hline $3: 15-3: 30$ & $0.98(19.56)$ & $0.93(26.36)$ & $0.95(37.76)$ & $2: 15-2: 30$ & $0.97(12.47)$ & $0.76(11.46)$ & $0.88(30.01)$ \\
\hline $3: 30-3: 45$ & $0.93(18.94)$ & $1.12(32.32)$ & $1.19(48.18)$ & $2: 30-2: 45$ & $1.12(15.02)$ & $1.06(16.70)$ & $1.07(38.17)$ \\
\hline $3: 45-4: 00$ & $0.84(17.53)$ & $2.39(71.4)$ & $2.20(92.13)$ & 2:45-3:00 & $1.58(21.35)$ & $1.18(18.70)$ & $1.08(38.62)$ \\
\hline & & & & $3: 00-3 ; 15$ & $1.50(19.77)$ & $1.21(18.89)$ & $1.16(40.98)$ \\
\hline & & & & $3: 15-3: 30$ & $1.47(19.48)$ & $1.15(17.90)$ & $1.11(39.08)$ \\
\hline & & & & $3: 30-3: 45$ & $0.79(10.6)$ & $1.15(8.21)$ & $1.07(38.12)$ \\
\hline & & & & $3: 45-4: 00$ & $1.08(15.03)$ & $1.25(20.33)$ & $1.16(42.67)$ \\
\hline & & & & 4:00-4:15 & $2.57(36.46)$ & $1.37(23.01)$ & $1.19(45.16)$ \\
\hline & & & & 4:15-4:30 & $1.02(9.66)$ & $2.42(27.07)$ & $1.30(32.95)$ \\
\hline F-Statistic & 477.6 & 1022 & 1931 & F-Statistic & 168.50 & 207.60 & 1004 \\
\hline Adjusted $\mathrm{R}^{2}$ & 0.3099 & 0.4903 & 0.6452 & Adjusted $\mathrm{R}^{2}$ & 0.2365 & 0.2707 & 0.6431 \\
\hline Std. Error & 1.637 & 1.15 & 0.819 & Std. Error & 1.962 & 1.693 & 0.7491 \\
\hline
\end{tabular}




\begin{tabular}{|c|c|c|c|c|c|c|c|}
\hline \multicolumn{8}{|c|}{ Panel C: Dual-listed ETFs for the overlapping period (2008) } \\
\hline Time & Volatility & Volume & Depth & Time & Volatility & Volume & Depth \\
\hline 9:30-9:45 & $1.92(27.14)$ & $2.23(56.77)$ & $1.63(55.31)$ & $2: 30-2: 45$ & $1.26(9.04)$ & $1.38(11.94)$ & $1.19(24.34)$ \\
\hline $9: 45-10: 00$ & $1.37(19.06)$ & $1.36(34.11)$ & $1.31(43.87)$ & $2: 45-3: 00$ & $1.54(11.18)$ & $1.39(11.94)$ & $1.11(22.87)$ \\
\hline 10:00-10:15 & $1.26(17.39)$ & $1.25(31.10)$ & $1.26(41.79)$ & $3: 00-3 ; 15$ & $1.23(9.40)$ & $0.97(8.82)$ & $1.06(22.73)$ \\
\hline $10: 15-10: 30$ & $1.13(15.53)$ & $1.08(26.72)$ & $1.10(36.28)$ & $3: 15-3: 30$ & $1.38(10.20)$ & $1.17(10.38)$ & $1.14(23.68)$ \\
\hline $10: 30-10: 45$ & $1.15(15.76)$ & $0.98(24.27)$ & $1.03(33.91)$ & $3: 30-3: 45$ & $1.25(8.96)$ & $0.98(8.50)$ & $1.09(22.29)$ \\
\hline $10: 45-11: 00$ & $0.92(12.62)$ & $0.99(24.44)$ & $1.03(33.74)$ & $3: 45-4: 00$ & $0.90(6.55)$ & $1.29(11.3)$ & $1.10(22.84)$ \\
\hline 11:00-11:15 & $1.00(13.77)$ & $0.97(23.87)$ & $1.01(33.13)$ & $4: 00-4: 15$ & $0.92(7.21)$ & $1.31(12.29)$ & $1.17(25.8)$ \\
\hline $11: 15-11: 30$ & $0.83(11.36)$ & $0.95(23.54)$ & $0.96(31.63)$ & $4: 15-4: 30$ & $1.43(8.86)$ & $1.48(10.87)$ & $1.29(22.43)$ \\
\hline F-Statistic & 296.2 & 1047 & 1554 & F-Statistic & 80.9 & 110.8 & 531.4 \\
\hline Adjusted $\mathrm{R}^{2}$ & 0.3338 & 0.6395 & 0.7247 & Adjusted $\mathrm{R}^{2}$ & 0.2833 & 0.35 & 0.7191 \\
\hline Std. Error & 1.757 & 0.9873 & 0.7333 & Std. Error & 1.97 & 1.66 & 0.7028 \\
\hline \multicolumn{8}{|c|}{ Panel D: Dual-listed ETFs for the overlapping period (2010) } \\
\hline Time & Volatility & Volume & Depth & Time & Volatility & Volume & Depth \\
\hline $9: 30-9: 45$ & $2.30(35.04)$ & $2.61(63.95)$ & $2.39(82.30$ & $2: 30-2: 45$ & $1.12(11.19)$ & $1.06(15.38)$ & $1.07(34.70)$ \\
\hline $9: 45-10: 00$ & $2.14(32.16)$ & $1.48(35.71)$ & $1.50(51.01$ & $2: 45-3: 00$ & $1.58(15.89)$ & $1.18(17.23)$ & $1.08(35.1)$ \\
\hline $10: 00-10: 15$ & $1.66(25.09)$ & $1.55(37.51)$ & $1.55(52.97)$ & $3: 00-3 ; 15$ & $1.50(14.72)$ & $1.21(17.41)$ & $1.16(37.24)$ \\
\hline $10: 15-10: 30$ & $1.43(21.46)$ & $1.18(28.48)$ & $1.18(40.05)$ & $3: 15-3: 30$ & $1.47(14.50)$ & $1.15(16.49)$ & $1.11(35.52)$ \\
\hline $10: 30-10: 45$ & $1.35(20.34)$ & $1.12(27.07)$ & $1.13(28.66)$ & $3: 30-3: 45$ & $0.79(7.89)$ & $1.15(16.78)$ & $1.07(34.65)$ \\
\hline $10: 45-11: 00$ & $1.34(20.14)$ & $1.03(25.01)$ & $1.04(35.19)$ & $3: 45-4: 00$ & $1.08(11.19)$ & $1.25(18.73)$ & $1.16(38.79)$ \\
\hline $11: 00-11: 15$ & $1.03(15.36)$ & $1.07(25.70)$ & $1.08(36.17)$ & $4: 00-4: 15$ & $2.57(27.14)$ & $1.37(21.20)$ & $1.19(41.05)$ \\
\hline $11: 15-11: 30$ & $1.02(15.17)$ & $0.95(22.55)$ & $0.97(32.38)$ & $4: 15-4: 30$ & $1.02(7.19)$ & $2.42(24.94)$ & $1.30(29.95)$ \\
\hline F-Statistic & 579.6 & 1264 & 2359 & F-Statistic & 207.3 & 324.8 & 1235 \\
\hline Adjusted $\mathrm{R}^{2}$ & 0.3462 & 0.5362 & 0.6834 & Adjusted $\mathrm{R}^{2}$ & 0.2385 & 0.3233 & 0.6445 \\
\hline Std. Error & 2.2 & 1.367 & 0.9726 & Std. Error & 2.635 & 1.838 & 0.8242 \\
\hline
\end{tabular}


Table 2-4: Correlations of trade price returns during the overlapping two-hour period

This table contains the auto-correlations and cross-correlations of dual listed iShares ETFs for the two-hour overlapping trading period between New York and London for the periods September through November 2008 and June through November 2010.

\begin{tabular}{|c|c|c|c|c|}
\hline & \multicolumn{2}{|c|}{2008} & \multicolumn{2}{|c|}{2010} \\
\hline & New York & London & New York & London \\
\hline \multicolumn{5}{|l|}{ Auto-correlations } \\
\hline 15 minutes & 0.153 & -0.026 & 0.183 & 0.001 \\
\hline 30 minutes & -0.059 & 0.021 & 0.020 & -0.004 \\
\hline \multicolumn{5}{|l|}{ Cross-correlations } \\
\hline \multicolumn{5}{|l|}{ New York lagged } \\
\hline 15 minutes & -0.021 & & 0.023 & \\
\hline 30 minutes & 0.008 & & -0.009 & \\
\hline \multicolumn{5}{|l|}{ London lagged } \\
\hline 15 minutes & & -0.008 & & 0.004 \\
\hline 30 minutes & & 0.011 & & -0.010 \\
\hline
\end{tabular}


Table 2-5: Vector Error Correction Results

The results from the Vector Error Correction Model are presented here. The t-statistic is shown in parentheses. The model is computed as:

$r_{t}^{L}=\Delta \log \left(P_{t}^{L}\right)$

$r_{t}^{N}=\Delta \log \left(P_{t}^{N}\right)$

$r_{t}^{L}=\alpha^{L}\left(\log \left(P_{t-1}^{L}\right)-\log \left(P_{t-1}^{N}\right)\right)+\sum_{i=1}^{4} \gamma_{i}^{L, L} r_{t-i}^{L}+\sum_{i=1}^{4} \gamma_{i}^{L, N} r_{t-i}^{N}+\varepsilon_{t}^{A}$

$r_{t}^{N}=\alpha^{N}\left(\log \left(P_{t-1}^{L}\right)-\log \left(P_{t-1}^{N}\right)\right)+\sum_{i=1}^{4} \gamma_{i}^{N, L} r_{t-i}^{L}+\sum_{i=1}^{4} \gamma_{i}^{N, N} r_{t-i}^{N}+\varepsilon_{t}^{N}$

\begin{tabular}{|c|c|c|c|c|c|c|c|c|}
\hline \multicolumn{9}{|l|}{ Panel A: 2008} \\
\hline & \multicolumn{3}{|l|}{ New York lags } & \multicolumn{5}{|c|}{ London lags } \\
\hline & $\mathrm{P}_{\mathrm{NY}}-\mathrm{P}_{\mathrm{LN}}$ & -15 & -30 & -15 & -30 & $\mathrm{n}$ & $\operatorname{Adj} R^{2}$ & Std Error \\
\hline New York & -0.0001 & -0.2254 & -0.2469 & 0.0011 & 0.0023 & 3281 & 0.1198 & 0.0044 \\
\hline & $(-1.71)$ & $(-12.908)$ & $(-20.328)$ & $(0.224)$ & $(0.436)$ & & & \\
\hline London & 0.0005 & 0.0846 & 0.0501 & -0.6296 & -0.4974 & 3281 & 0.2981 & 0.0158 \\
\hline & $(1.845)$ & $(1.35)$ & (1.149) & $(-36.382)$ & $(-26.843)$ & & & \\
\hline
\end{tabular}

Panel B: 2010

\begin{tabular}{|c|c|c|c|c|c|c|c|c|}
\hline & \multicolumn{3}{|l|}{ New York lags } & \multicolumn{5}{|c|}{ London lags } \\
\hline & $\mathrm{P}_{\mathrm{NY}}-\mathrm{P}_{\mathrm{LN}}$ & -15 & -30 & -15 & -30 & $\mathrm{n}$ & $\operatorname{Adj~} R^{2}$ & Std Error \\
\hline New York & 0.000009 & -0.2483 & -0.2099 & 0.0002 & 0.0004 & 11363 & 0.11 & 0.0010 \\
\hline & $(0.977)$ & $(-26.461)$ & $(-33.879)$ & $(0.618)$ & $(0.541)$ & & & \\
\hline London & $\begin{array}{r}0.000078 \\
(0.386)\end{array}$ & $\begin{array}{r}0.1556 \\
(0.745)\end{array}$ & $\begin{array}{c}0.2294 \\
(1.664)\end{array}$ & $\begin{array}{r}-1.64 \\
(-184.78)\end{array}$ & $\begin{array}{r}-1.96 \\
(-127.41)\end{array}$ & 11363 & 0.77 & 0.0217 \\
\hline
\end{tabular}




\section{CHAPTER 3: ETF: LEVERAGE AND LIQUIDITY}

\subsection{Introduction}

Liquidity is essential to the efficient functioning of financial markets as investors are assured of timely execution of their trades. Moreover, the increased importance of algorithmic traders has altered the liquidity in many markets, often affecting the quantities available at any time of trading. I examine the liquidity of the ETF market, including leveraged and inverse ETFs, with the leveraged and unleveraged ETFs potentially possessing different types of market microstructure behavior. In addition, I examine the effect of leverage on liquidity by comparing the change in the bid-ask spread and depth for leveraged and unleveraged ETFs. More specifically, does depth diminish and bid-ask spread increase as leverage increases? Thus, this chapter will advance the literature for the understanding of unleveraged and leveraged ETFs by examining their differences with respect to liquidity.

An extremely volatile day should amplify the effects of leverage on liquidity according to Goodhart and O'Hara (1997). Cheng and Madhavan (2009) also allude to the liquidity effects on leveraged ETFs being more pronounced when liquidity is low and volatility is high. However, previous studies have only focused on the long-term performance of leveraged ETFs and their associated path-dependence (Lu, Wang, \& Zhang, 2009; Avellaneda \& Zhang, 2009), instead of the effect of volatility or the intraday profiles of leveraged ETFs. Therefore, here I examine two periods, one of relatively normal volatility and the other of relatively high volatility to see the impact that leverage has on spread and depth when comparing leveraged and unleveraged ETFs. On an aggregate basis, the bid-ask spreads for positive multiples tend to be larger than those of negative multiples, but the double-leveraged ETFs, whether positive or negative, have the largest spreads (Cheng \& Madhavan, 2009). Since hedging demands for leveraged ETFs differ based on the sign and the size of the multiple then do leveraged ETFs differ in liquidity based on the sign 
and the size of the multiple in a linear fashion? In this chapter, I examine the spread and depth of the leveraged ETFs disaggregated by the leverage multiple using 15-minute intervals.

There is a distinct difference in liquidity displayed between leveraged and unleveraged ETFs in periods of normal volatility as well as in periods of high volatility. This difference is noticeable in both spread and depth when looking at leveraged ETFs on an aggregate basis as well as when leveraged ETFS are decomposed by leveraged multiples. When leveraged ETFs are segregated into multiples, this difference is also displayed. This difference is more pronounced in periods of high volatility than in periods of normal volatility.

The rest of the chapter is divided into the following sections: 3.2 - literature survey and hypothesis, 3.3 - data and methodology, 3.4 - results, and 3.5 - conclusion.

\subsection{Literature Survey and Hypothesis}

Leveraged ETFs are a new ETF product approved by the SEC, but relatively little is known about this new breed of ETFs. These ETFs are fashioned as long or short products to produce a return that is a multiple of the underlying benchmark portfolio. This multiple is either +3 times or +2 times the daily return of the underlying benchmark for long leveraged ETFs, whereas short or inverse leveraged ETFs have multiples of $-3,-2$, or -1 times that of the underlying benchmark return. The managers use swaps, derivatives, and rebalancing in order to attain these leveraged returns. ${ }^{3}$ Leveraged ETFs in the USA are originated by three different companies - ProShares, Rydex, and Direxion. ProShares started the leveraged ETF revolution by distributing the first leveraged ETF in 2006. There are about 146 leveraged ETFs being actively traded on US exchanges, with assets of over 30 billion dollars. In the recent downturn in financial markets, these leveraged products have seen great increases in volume, and they account for a substantial part of the overall growth of ETFs.

\footnotetext{
${ }^{3}$ Swaps are often the derivatives chosen to achieve the leveraged multiple, since swaps avoid the strictures and standards associated with the more regularized derivatives (Cheng \& Madhavan, 2009)
} 
Leveraged ETFs have received negative publicity in terms of their associated risks, i.e., the leveraged ETF may not generate the expected multiple of return expected over the long term (Stanley, 2009; Canadian Foundation for Advancement of Investors Rights, 2009; Justice, 2009). These warnings are based on the path-dependence of the leveraged ETFs as well as the leveraged ETFs' ability to magnify the movements of the underlying benchmark. Given that these leveraged products vary so significantly from the previously introduced ETFs, it is important to policymakers, investors, and investment managers to have a clear picture of the liquidity aspects of these funds in both normal and highly volatile times. Thus, generating the expected return of leveraged ETFs involves a major problem in that their exposure is rebalanced on a daily basis in order to maintain the exposure level to the correct multiple. This frequent rebalancing can prove quite costly as rebalancing is initiated based on the upward or downward movement of the index. ${ }^{4}$ However, this issue is outside the scope of this study.

Leverage is an important factor in financial markets, but one that is often ignored or relegated to secondary importance. Financial leverage is important to investors who utilize margin to trade, and it is just as important to companies that utilize leverage in order to maintain their day-to-day operations. ${ }^{5}$ Similarly, leverage (as in leveraged ETFs) is important as it magnifies returns, and therefore it becomes a significant factor to consider when volatility exists. However, just as leverage can exhibit a magnification result, a lack of liquidity can also magnify the effect of other factors. Black (1975) posited that leverage is instrumental for the decisionmaking of investors who choose between option investing and equity investing. These investors

\footnotetext{
${ }^{4}$ This cost shows up as increased commissions for managers of leveraged ETFs compared to managers of unleveraged ETFs. Moreover, the cost is impounded into long-term returns, where compounding shows much divergence in the returns from the leverage multiple.

${ }^{5}$ An investor who uses margin to trade may be required to put an initial margin of $50 \%$ of their own money in order to trade. If the price of the stock increases by $50 \%$, then the investor would have a holding period return of $100 \%$ on his or her initial investment (not accounting for any interest payment). Hence the investor had his or her returns magnified by 2 due to leverage.
} 
tend to make the choice to conduct transactions in the derivatives markets based on the power of leverage. However, unlike the futures market, where the downside loss is theoretically unrestricted, in the leveraged ETF markets investors only end up losing their investment in the leveraged ETF. Thus, investors would be more inclined to invest in leveraged ETFs that can give them leveraged returns, provide some exposure to the derivatives' markets, and also restrict losses to the amount invested, rather than other financial securities without those benefits (Little, 2010). These benefits could help explain the sharp increase in leveraged ETFs' trading activity in the short time since inception.

Factors affecting ETFs include maintaining the leverage multiple by daily rebalancing and the effect of high volatility contributing to the deviation between the returns of the leveraged ETFs and the returns of the underlying benchmark portfolio over time (Cheng \& Madhavan, 2009). These factors impact on the ownership costs of leveraged ETFs versus unleveraged ETFs. Unleveraged ETFs do not need daily rebalancing; therefore, they do not have the transaction costs associated with that activity. ${ }^{6}$ Cheng and Madhavan (2009) illustrate that the volatility of leveraged ETFs is a function of both the leverage multiplier and the volatility of the underlying index. In addition, volatility in the underlying index affects both leveraged and unleveraged ETFs; however, the leverage multiplier inherent in leveraged ETFs affects the leveraged ETFs more than the underlying ETF (Cheng \& Madhavan, 2009; Stanley, 2009; Guiese, 2010). Since leveraged ETFs are designed to match the return of the underlying benchmark to a specified multiple of its value, then it stands to reason that anything that affects the underlying benchmark will also affect a product based on it.

The path-dependence of leveraged ETFs and its effect on return over a period greater than a day has been noted by several authors (Avellaneda \& Zhang, 2009; Cheng \& Madhavan,

\footnotetext{
${ }^{6}$ Expense ratios are the costs to investors, but funds have transaction costs due to daily rebalancing with total return swaps. These transaction costs would diminish the fund's return and cumulate over time.
} 
2009; Guiese, 2010; Liu, 2009). In fact, path-dependence is largely blamed for the deviation between the leveraged ETFs' long-run return and that of its underlying benchmark portfolio. However, liquidity constraints in financial markets and their effect on leveraged returns have not been examined as an alternative solution to this deviation in return. Spread and depth should both be considered as previous research such as Bessembinder and Seguin (1993) show that when depth is high, then volatility is low. Therefore, liquidity changes in the bid-ask spread and depth should also affect the long-run return on leveraged ETFs and factor in the deviation between the leveraged ETF return and the underlying index.

The fact that leveraged ETFs do not perform well in comparison to their underlying benchmarks with large tracking errors has been further noted (Liu, 2009; Lu, Wang, \& Zhang, 2009). Most prospectuses from leveraged ETF issuers caution that these funds should not be held for over a day: "The return of each Fund for periods longer than a single day, especially in periods of market volatility, may be completely uncorrelated to the return of the Fund's benchmark for such longer periods" (Direxion prospectus). However, most investors hold these funds for longer lengths of periods. Therefore, the cumulated volatility gyrations will severely impact these investors since this volatility does not magnify the long-term movements of the leveraged ETFs in their portfolios as assumed by investors. Volatility is one of the reasons given for the resulting path-dependence and variation from the underlying benchmark in the long run (Avellaneda \& Zhang, 2009). The underperformance will be notably higher in high volatility periods, and this trend will be exhibited in a loss of liquidity. ${ }^{7}$

The lack of liquidity in financial markets causes issues such as unmatched trades and poor execution time. Leverage, especially financial leverage, has been shown in both corporate finance and investments to cause magnification. Studying both of these effects together to

\footnotetext{
${ }^{7}$ Bessembinder and Seguin (1993) find a negative relationship between liquidity and volatility.
} 
observe the impact on financial instruments is phenomenal. Leveraged ETFs make a good candidate for this type of study as there is a built-in control group of unleveraged ETFs and thus liquidity and leverage can be analyzed together. The analysis of the impact of leverage on liquidity using leveraged and unleveraged exchange traded funds provides important insights into market microstructure. Leveraged and unleveraged ETF returns can significantly deviate from one another in the long run; however, these dynamics in the short run are not well documented. If there is a significant difference in the spread between leveraged and unleveraged ETFs, then more costs would be incurred by investors. Moreover, a decrease in depth would result in more volatility. In order to examine the effect of leverage on spread and depth, I propose the following hypotheses based on the literature surveyed:

Hypothesis One: During highly volatile markets, the differences in depth between leveraged and unleveraged ETFs will become larger relative to times of normal volatility. More volatile market periods will result in higher bid-ask spreads for all ETFs. In addition, the leveraged ETFs' bid-ask spreads will increase more than the unleveraged ETFs' spreads.

Hypothesis Two: The leveraged ETFs' bid-ask spread is consistent with a multiple of the associated unleveraged ETF on an intra-day basis for periods of normal volatility. Alternatively, in periods of abnormal volatility, the bid-ask spreads between the two types of ETFs are not aligned with the leverage multiple.

Hypothesis Three: The leveraged ETFs' bid-ask spread and depth will differ based on the leveraged multiple and will progress in a linear fashion based on the size and sign of the leveraged multiple.

\subsection{Data and Methodology}

I employ data from the TAQ database for the Direxion, Ryder, and Proshares families of leveraged ETFs and their corresponding unleveraged ETFs. The unleveraged ETF is characterized as $1 \mathrm{x}$, whereas long leveraged ETFs are characterized as $2 \mathrm{x}$ and $3 \mathrm{x}$, depending on 
the leveraged multiple of two or three times the index return. Short leveraged ETFs are characterized as $-1 \mathrm{x},-2 \mathrm{x}$, and $-3 \mathrm{x}$, depending on the inverse leveraged multiple and its relation to the underlying index. For each long leveraged ETF, there is a matching inverse leveraged ETF, except for the leveraged multiplier of $-1 \mathrm{x}$, which has no corresponding long pair (as the group of 1x ETFs encompasses the unleveraged ETFs). The entire universe of unleveraged ETFs is not used as only those unleveraged ETFs that have the same underlying index as the leveraged ETFs are included in the group of $1 \mathrm{x}$.

First, two groups of 15 days each are formed. One group represents 15 days of normal volatility, and the other group represents 15 days of high/abnormal volatility. These groups are determined by finding the Garman-Klass daily volatility estimator for the S\&P 500 index from September 2008 through May 2010..$^{8}$ The Garman and Klass (1980) volatility estimator is computed as:

$$
\sigma_{G K}^{2}=0.5\left(\ln \left(\frac{H_{i}}{L_{i}}\right)\right)^{2}-(2 \ln (2)-1)\left(\ln \left(\frac{C_{i}}{o_{i}}\right)\right)^{2}
$$

$\mathrm{H}_{\mathrm{i}}$ and $\mathrm{L}_{\mathrm{i}}$ represent the daily high price and low price, respectively $\mathrm{C}_{\mathrm{i}}$ and $\mathrm{O}_{\mathrm{i}}$ represent the daily closing price and opening price, respectively

The daily volatility estimators are then sorted from largest to smallest, and the 15 days with the median daily volatility are assigned to the normal volatility group. In contrast, the 15 days with the largest daily volatility estimators (except for the Flash Crash of May 6, 2011) are assigned to the abnormal volatility group. ${ }^{9}$

${ }^{8}$ The Garman-Klass volatility estimator was used as it has been documented as one of the most robust volatility estimators (Daigler \& Wiley, 1999; Chen, Daigler, \& Parhizgari, 2006).

${ }^{9}$ Group Normal consisted of 09/24/08, 01/27/09, 01/29/09, 02/09/09, 02/13/09, 04/27/09, 05/14/09, 05/22/09, 06/24/09, 07/16/09, 08/07/09, 11/04/09, 12/03/09, 01/20/10 and 05/10/10. Group High/Abnormal consisted of $09 / 18 / 08,10 / 06 / 08,10 / 07 / 08,10 / 09 / 08,10 / 10 / 08,10 / 14 / 08,10 / 16 / 08,10 / 17 / 08,10 / 22 / 08$, $10 / 23 / 08,10 / 28 / 08,11 / 13 / 08,11 / 20 / 08,11 / 21 / 08,12 / 05 / 08$. 
In order to eliminate possible errors in the data, we employ the following data tests. If the bid or ask size is negative, the ask is less than the bid, or the depth equals zero, then the quote is deleted. For the remaining data, the inside quote and the cumulated depth are calculated for each second. The inside quotes from each exchange are used to obtain the national best bid and offer (nbbo).The depth, however, is calculated by summing the bid and ask sizes for the quotes at the nbbo price. The characteristics of both the leveraged and unleveraged ETFs are examined to determine the effect of leverage on liquidity. For each group, the characteristics of the average spread and depth are computed and compared for all the ETFs in our sample. The variables explored are the spread, quoted spread, log spread, quote slope, percentage spread, bid size, and ask size. The variables are calculated as follows:

$$
\begin{aligned}
& \text { Spread }(\text { Sit })=\text { Ait }- \text { Bit } \\
& \text { Quoted spread }(\text { QSpit })=(\text { Ait }- \text { Bit }) / 2 \\
& \text { Log spread }(\text { LSit })=\log (\text { Ait } / \text { Bit }) \\
& \text { Quote slope }(\text { QSlit })=(\text { Ait-Bit }) /(\log (\text { ASit })+\log (\text { BSit }) \\
& \text { Percent spread }(\text { PSit })=((\text { Ait }- \text { Bit }) /((\text { Ait }+ \text { Bit }) / 2)) * 100
\end{aligned}
$$

Where $A_{i t}$ is the national best ask for each ETF (i) and time interval (t); $B_{i t}$ is the national best bid for each ETF (i) and time interval (t); $\mathrm{AS}_{\mathrm{it}}$ is the ask size for each ETF (i) and time interval (t); and $\mathrm{BS}_{\mathrm{it}}$ is the bid size for each ETF (i) and time interval l(t).

The nbbo data are aggregated into 15 -minute intervals and then winsorized by $0.5 \%$ at both ends of the daily 15-minute intervals in order to remove outliers. A realistic microstructure picture of the ETFs' characteristics is then obtained for each trade variable. The 15-minute mean for each 15-minute interval for each day for the entire period for volatile and normal days by multiple is calculated and used to represent each interval and to eliminate microstructure issues such as bid-ask bounce. The exploration of relationships between the ETFs is conducted by performing both univariate and multivariate analyses on this dataset. For univariate analysis, a 
difference of means t-test is computed to look at the differences between high and normal volatility for the different groups of ETFs. The t-test is conducted assuming both equal and unequal variances. The hypothesis being test is

$$
\begin{aligned}
& \mathrm{H}_{0}: \mu_{1}-\mu_{2}=\mu_{d}=0 \\
& \mathrm{H}_{1}: \mu_{\mathrm{d}} \neq 0
\end{aligned}
$$

which is estimated by $y_{d}=y_{b a r_{1}}-$ ybar $_{2}$. The estimate for common standard deviation is calculated under both assumptions about the variance. Under the assumption that the variances are equal, the test is carried out by using the following

$$
\begin{aligned}
& \text { Pooled }\left(\mathrm{s}_{\mathrm{p}}\right)=\left(\frac{\left(n_{1-1}\right) s_{1}^{2}+\left(n_{2}-1\right) s_{2}^{2}}{n_{1}+n_{2}-2}\right)^{1 / 2} ; \\
& \text { Pooled standard error }\left(\mathrm{SE}_{\mathrm{p}}\right)=s_{p}\left(\frac{1}{\sum_{i=1}^{n_{1}} f_{1 i} w_{1 i}}+\frac{1}{\sum_{i=1}^{n_{2}} f_{2 i} w_{2 i}}\right)^{1 / 2} \\
& \text { Pooled t-statistic }\left(\mathrm{t}_{\mathrm{p}}\right)=\frac{y_{d}-\mu_{o}}{S E_{p}} \\
& \text { Pooled P-value }=P\left(t_{p}^{2}>F_{1-\alpha, 1, n_{1}+n_{2}-2}\right)
\end{aligned}
$$

Under the assumption that the variances are not equal, the test is carried out using the following

$$
\begin{aligned}
& \text { Unpooled }\left(\mathrm{SE}_{\mathrm{u}}\right)=\left(\frac{s_{1}^{2}}{\sum_{i=1}^{n_{1}} f_{1 i} w_{1 i}}+\frac{s_{2}^{2}}{\sum_{i=1}^{n_{2}} f_{2 i} w_{2 i}}\right)^{1 / 2} \\
& \text { Sattherwaite's estimated } \quad \mathrm{df}_{\mathrm{u}}= \\
& \frac{S E_{u}^{4}}{\frac{s_{1}^{4}}{\left(n_{1}-1\right)\left(\sum_{i=1}^{n_{1}} f_{1 i} w_{1 i}\right)}+\frac{s_{2}^{4}}{\left(n_{2}-1\right)\left(\sum_{i=1}^{n_{2}} f_{2 i} w_{2 i}\right)}} \\
& \text { Unpooled t-statistic }\left(\mathrm{t}_{\mathrm{u}}\right)=\frac{y_{d}-\mu_{0}}{S E_{u}}
\end{aligned}
$$




$$
\text { Unpooled P-value }=P\left(t_{u}^{2}>F_{1-\alpha, 1, d f_{u}}\right)
$$

A test for equality of variance between the two periods for the same multiple is also conducted. Here, we assume that the data are normally distributed and a two-tailed F test is conducted under the null hypothesis that $\sigma_{1}{ }^{2}=\sigma_{2}{ }^{2}$. The test is carried out by using the folded form of the F Statistic, F'.

$$
\mathrm{F}^{\prime}=\frac{\max \left(s_{1}^{2}, s_{2}^{2}\right)}{\min \left(s_{1}^{2}, s_{2}^{2}\right)}
$$

The Jonckheere-Terpstra test for ordered alternatives, a non-parametric test for ordered differences among classes, is also used to test between the different groups. This test is used because no assumptions about the distribution of the quotes have to be made. In other words, it serves as a robustness check to confirm the results of the t-test. It tests the null hypothesis that the distribution of the response variable does not differ among classes and is designed to detect alternatives of ordered class differences, where $\tau_{1} \leq \tau_{2} \leq \ldots \leq \tau_{\mathrm{k}}$. The test is carried out using the following procedure:

$$
\begin{aligned}
& \text { The test-statistic } \mathrm{J}^{*}=\left(J-E_{o}(J)\right) / \sqrt{\operatorname{var}_{o} J} \\
& E_{o}(J)=\left(n^{2}-\sum_{i} n_{i}^{2}\right) / 4 \\
& \operatorname{var}_{o}(J)=\frac{A}{72}+\frac{B}{36 n(n-1)(n-2)}+\frac{C}{8 n(n-1)} \\
& \mathrm{A}=n(n-1)(2 n+5)-\sum_{i} n_{i .}\left(n_{i}-1\right)\left(2 n_{i}+5\right)-\sum_{j} n_{. j}\left(n_{. j}-1\right)\left(2 n_{. j}+5\right) \\
& B=\left(\sum_{i} n_{i .}\left(n_{i .}-1\right)\left(n_{i .}-2\right)\right)\left(\sum_{j} n_{. j}\left(n_{. j}-1\right)\left(n_{. j}-2\right)\right) \\
& \mathrm{C}=\left(\sum_{i} n_{i .}\left(n_{i .}-1\right)\right)\left(\sum_{j} n_{. j}\left(n_{. j}-1\right)\right)
\end{aligned}
$$

where $E_{0}(J)$ is the expected value and $\operatorname{var}_{o}(J)$ is the variance of the test statistic under the null hypothesis.

When the standardized test statistic is greater than the null hypothesis of 0 , the right-sided value is displayed, which is the probability of a larger value of the statistic occurring under the 
null hypothesis. A small right-sided p-value supports the alternative hypothesis of increasing order from row 1 to row $k . P=\operatorname{Prob}\left(Z>J^{*}\right)$ if $J^{*}>0$ or $\operatorname{Prob}\left(Z<J^{*}\right)$ if $J^{*} \leq 0$ or $\operatorname{Prob}\left(|Z|>\left|J^{*}\right|\right)$, where $\mathrm{Z}$ is distributed as standard normal.

Panel regressions are conducted to understand the liquidity components of the ETFs. Intraday patterns for depth and bid-ask spread are estimated using ordinary least squares regression. These regressions are conducted with dummy variables for the leveraged multiple in order to ascertain the effect of leverage. The linear equation used in the regression is

$$
Y_{i t}=\alpha_{i t}+\beta_{1} \sigma_{i t}+\beta_{2} T O_{i t}+\sum_{i=1}^{5} \beta_{i} L_{i t}+C S V_{i t}+T S V_{i t}+E r r_{i t}
$$

where $\sigma_{i t}$ represents the ith volatility (of each trading variable) of the time interval $t$; $\mathrm{TO}_{\mathrm{it}}$ represents the ith turnover of the time interval $\mathrm{t}-\mathrm{TO}_{\mathrm{it}}=$ Volume $_{\mathrm{it}} /$ Shares outstanding; $\mathrm{L}_{\mathrm{it}}$ represents the ith leverage dummy variable for each leverage multiple $-1,-2,-3,2,3$ at each time interval t. The error terms are decomposed into $\mathrm{CSV}_{\text {it }}-$ the variance component attributed to cross section, $\mathrm{TSV}_{\mathrm{it}}$ - the variance component attributed to time series, and $\mathrm{Err}_{\mathrm{it}}$ - the error variance component. The equality of the individual regression coefficients obtained from the leveraged dummy variables is then tested using the Welch test. This test is calculated using a BLUE estimator of $\beta$, $\beta$ hat*.

$\beta$ hat $^{*}=\sum_{i=1}^{n} w_{i} \beta$ hat $t_{i} / \sum_{i=1}^{n} w_{i}$, where the $\mathrm{w}_{\mathrm{i}}$ are the corresponding weights of $\beta$ hat.

The Welch statistic, $\mathrm{W}=\frac{\sum_{i=1}^{n} \frac{\left(\text { Bhat }_{i}-\beta \text { hat }^{*}\right)}{s_{i}^{2}} /(n-1)}{1+\frac{(2 n-2)}{n^{2}-1} \sum_{i=1}^{n} \frac{1}{\left(T_{i}-1\right)}\left(1-\frac{1 / s_{i}^{2}}{\sum_{i=1}^{n} 1 / s_{i}^{2}}\right)}$

In the case where the comparison is only between two betas, this relationship can be shown to reduce to a simplified z statistic where $Z=\frac{\left(\beta_{i}-\beta_{k}\right)}{\sqrt{S E_{i}{ }^{2}+S E_{k}{ }^{2}}}$. 


\subsection{Results}

The three hypotheses require an analysis that compares both the abnormally high and normal volatility time as well as leveraged and unleveraged ETFs. Furthermore, an unaggregated look at leveraged ETFs is required to see the response of different leveraged multiples in abnormally high and normal volatility times. In order to arrive at a conclusion regarding these three hypotheses, we start off with univariate tests to compare the high and normal volatility times. Hypothesis One states that during highly volatile markets, the differences in depth between leveraged and unleveraged ETFs will become larger relative to times of normal volatility while Hypothesis Two states that more volatile market periods will result in higher bid-ask spreads for all ETFs; moreover, the leveraged ETFs' bid-ask spreads will increase more than the unleveraged ETFs' spreads. Hypothesis Three states that the leveraged ETFs' bid-ask spread and depth will differ based on the leveraged multiple and will progress in a linear fashion based on the size and sign of the leveraged multiple.

Table 3-1 provides the descriptive statistics for the liquidity and depth variables: Spread (Panel A), Log Spread (Panel B), Quote Slope (Panel C), Percentage Spread (Panel D), Bid Size (Panel E) and Ask Size (Panel F). They were accumulated over each 15-day period for the normal and abnormally high volatility group. ${ }^{10}$ The results are sequenced into three different groups for comparative purposes: All ETFs, Leveraged ETFs, and Unleveraged ETFs. For the liquidity variables: Spread, Log Spread, Quote Slope. and Percentage Spread, it is apparent that there is a distinct difference when comparing normal volatility to abnormally high volatility for all three groups, where mean liquidity increases substantially in abnormally high volatility when benchmarked against normal volatility regardless of the time of day. This distinct difference is also apparent for the depth variables: Ask size and Bid size. The mean depth decreases in

\footnotetext{
${ }^{10}$ The data are winsorized at .5\% in each 15 -minute interval to remove outliers, and the winsorized mean and standard error are computed for each liquidity and depth variable. The standard errors are small for each 15-minute interval, so they were not reported in the table.
} 
abnormally high volatility in comparison to normal volatility regardless of the time of day. This finding lends support to Hypothesis One and Two.

The graphs depicted in Figures 3-1 and 3-2 confirm these findings and suggest the confirmation of Hypotheses One and Two. Figure 3-1 shows all the liquidity variables in abnormally high volatility while Figure 3-2 shows all the liquidity variables in normal volatility for the three groups : All ETFs, Leveraged ETFs, and Unleveraged ETFs. Both figures show that leveraged ETFs have bigger spreads than the unleveraged ETFs, irrespective of time, throughout the day. The converse is true for depth variables in high volatility as unleveraged ETFs have the bigger size. On the other hand, in normal volatility, the sizes of depth variables for the leveraged and unleveraged ETFs are very similar.

Since there appears a distinct difference of means between leveraged and unleveraged ETFs, it would be interesting to note if there is a difference in the decomposed leveraged ETFs into the different leveraged multiples, $-3,-2,-1,2$ and 3. Table 3-2 reports the summary statistics for the liquidity and depth variables in abnormally high volatility and normal volatility by leveraged multiple. The means for the negative leveraged multiples for the liquidity variables in high volatility are larger than those for the positive leveraged multiples. The largest leverage multiple is that for multiple -2 . There does not seem to be a clear indication of the mean getting bigger as the multiple gets smaller since the multiples -2 and 2 have the biggest means. This finding leads to the suggestion of a humped shaped distribution as one goes from the largest multiple, 3 , to the smallest multiple, -3 . This observation might be due to the relative newness of the leveraged ETFs with a multiple of 3, whereas the leveraged ETFs with a multiple of 2 have been around the longest and have the most ETFs in that category.

Conversely, the depth variables in high volatility exhibit larger means for the positive leveraged multiples as opposed to the negative leveraged multiples. Both the ask size and the bid size tend to be largest for leveraged multiple 3 and smallest for leveraged multiple -3 . Again, 
there seems to be a repeat of the humped distribution exhibited by the liquidity variables when moving from the largest leveraged multiple, positive 3, to the smallest leveraged multiple, negative 3 . The distribution of the variables in normal volatility appears to have a different shape from the distribution shape in high volatility. There does not appear to be much difference between the leveraged multiples of $-3,-1,2$, and 3 with only -2 showing any remarkable deviation from the pack. However, the size of the spread changes considerably compared to that in high volatility. The liquidity variables have a much smaller size in normal volatility. In normal volatility, the size of the depth variables grow with the negative multiples from smallest to largest, where -1 has the smallest size, and -3 has the largest size. The largest size overall is attributed to 2, unlike the liquidity variables that have -2 as the largest size. Figure 3-3 shows all the liquidity variables in abnormally high volatility while Figure 3-4 shows all the liquidity variables in normal volatility for the leveraged ETFs by multiples $-3,-2,-1,2$, and 3 . Figures 3-3 and 3-4 confirm the findings depicted in the tables as the variables have less distinction between multiples in normal volatility versus in high volatility.

There is a need for difference of the means tests to statistically confirm the appearances of the differences between the groups as shown in the tables. The results of the difference of the means test for the liquidity and depth variables by leveraged multiples are shown in Table 3 . The difference of the means tests where normal volatility is subtracted from high volatility confirms the previous findings. All the tests are statistically significant at a $1 \%$ level, indicating there is a difference between the liquidity and depth variables when volatility is a factor. This is consistent with Hypotheses One and Two, which suggest a significant difference to leveraged and unleveraged ETFs based on whether there is a highly volatile period or a relatively normal period. As the difference of the means test assumes a normal distribution, the distribution free test provided by Jonckheere-Terpstra (JT) is conducted to corroborate that of the difference of the means test. The JT test for ordered alternatives, a non-parametric test for ordered differences 
among classes, tests the null hypothesis that the distribution of the response variable does not differ among classes and is designed to detect alternatives of ordered class differences, where $\tau_{1} \leq$ $\tau_{2} \leq \ldots \leq \tau_{\mathrm{k}}$. Table 3-4 reports the results of the JT test. The results illustrate that the JT test is highly significant for the liquidity and depth variables.

Multivariate panel regressions were conducted by looking at the impact that leveraged multiples had on the liquidity variables. Other variables were added into the regression to provide a more complete picture. These variables were Turnover (TO) and Volatility (Vol). The results are presented in Table 3-5. There are distinct differences noted between the leveraged variables with the leveraged multiple -2 having the largest impact. It does not seem that the impact of the leveraged multiples occurs in a linear fashion with -3 having the biggest impact. If that was the case, then the leveraged impact would decrease in a linear fashion commensurate with the leveraged multiple. This result might be related to the number of ETFs in each category as the ETFs with a leveraged multiple of -2 have the most ETFs and have been around the longest. In order to analyze the regression coefficients based on leveraged multiples and compare them to other ETFs, the Welch test is used for comparisons. The results from the Welch test are presented in Table 3-6 for Abnormally High Volatility and in Table 3-7 for Normal Volatility. The Welch test again shows the dominance of the leveraged multiple -2 over all the other multiples. There might also be a weak linear relation in measuring the impact from leveraged multiples as -3 is less than $-2,-1$, and 2 , but it is higher than multiple 3 . Thus, while there might not be a strict linear relationship, there is evidence of a relationship for linear decrease going from leveraged multiple -3 to -2 , to -1 to 2 .

\subsection{Conclusion}

There is a distinct difference displayed between all ETFs as well as leveraged and unleveraged ETFs in periods of normal volatility as well as in periods of high volatility. This difference for mean liquidity is a downward shift in value in periods of high volatility but an 
upward shift in value for mean depth. When leveraged ETFs are disaggreagated into leveraged multiples, $-3,2,-1,2,3$, the difference between periods of normal volatility and high volatility are also exhibited. Additionally, there is a difference in the magnitude between the multiples themselves. 
Table 3-1: Summary Statistics for Trading Variables

Panel A: Summary Statistics of All, Leveraged, and Unleveraged ETFs in High and Normal Volatility for Spread

\begin{tabular}{|c|c|c|c|c|c|c|c|c|c|c|c|c|}
\hline & \multicolumn{6}{|c|}{ Normal Volatility } & \multicolumn{6}{|c|}{ High Volatility } \\
\hline & \multicolumn{2}{|c|}{ All } & \multicolumn{2}{|c|}{ Leveraged } & \multicolumn{2}{|c|}{ Unleveraged } & \multicolumn{2}{|c|}{ All } & \multicolumn{2}{|c|}{ Leveraged } & \multicolumn{2}{|c|}{ Unleveraged } \\
\hline & Mean & Std dev & Mean & Std dev & Mean & Std dev & Mean & Std dev & Mean & Std dev & Mean & Std dev \\
\hline $9: 45$ & 0.074 & 0.166 & 0.102 & 0.229 & 0.026 & 0.032 & 0.596 & 1.323 & 0.841 & 1.543 & 0.076 & 0.161 \\
\hline $10: 45$ & 0.046 & 0.069 & 0.063 & 0.083 & 0.016 & 0.010 & 0.300 & 0.503 & 0.422 & 0.616 & 0.030 & 0.030 \\
\hline $11: 45$ & 0.041 & 0.061 & 0.056 & 0.077 & 0.015 & 0.009 & 0.284 & 0.456 & 0.391 & 0.520 & 0.027 & 0.024 \\
\hline $12: 45$ & 0.039 & 0.059 & 0.054 & 0.075 & 0.015 & 0.009 & 0.276 & 0.489 & 0.388 & 0.590 & 0.026 & 0.024 \\
\hline $13: 45$ & 0.040 & 0.062 & 0.056 & 0.078 & 0.015 & 0.009 & 0.271 & 0.441 & 0.378 & 0.508 & 0.027 & 0.025 \\
\hline $14: 45$ & 0.042 & 0.064 & 0.058 & 0.079 & 0.016 & 0.010 & 0.295 & 0.475 & 0.409 & 0.550 & 0.029 & 0.028 \\
\hline $15: 45$ & 0.045 & 0.070 & 0.062 & 0.085 & 0.015 & 0.010 & 0.388 & 0.674 & 0.530 & 0.798 & 0.037 & 0.046 \\
\hline $16: 00$ & 0.045 & 0.073 & 0.063 & 0.094 & 0.015 & 0.011 & 0.454 & 0.889 & 0.631 & 1.065 & 0.038 & 0.051 \\
\hline
\end{tabular}

Panel B: Summary Statistics of All, Leveraged, and Unleveraged ETFs in High and Normal Volatility for Log Spread

\begin{tabular}{|c|c|c|c|c|c|c|c|c|c|c|c|c|}
\hline & \multicolumn{6}{|c|}{ Normal Volatility } & \multicolumn{6}{|c|}{ High Volatility } \\
\hline & \multicolumn{2}{|c|}{ All } & \multicolumn{2}{|c|}{ Leveraged } & \multicolumn{2}{|c|}{ Unleveraged } & \multicolumn{2}{|c|}{ All } & \multicolumn{2}{|c|}{ Leveraged } & \multicolumn{2}{|c|}{ Unleveraged } \\
\hline & Mean & Std dev & Mean & Std dev & Mean & Std dev & Mean & Std dev & Mean & Std dev & Mean & Std dev \\
\hline $9: 45$ & 0.002 & 0.004 & 0.002 & 0.005 & 0.001 & 0.001 & 0.009 & 0.023 & 0.013 & 0.027 & 0.002 & 0.004 \\
\hline $10: 45$ & 0.001 & 0.002 & 0.002 & 0.002 & 0.000 & 0.000 & 0.004 & 0.008 & 0.006 & 0.010 & 0.001 & 0.001 \\
\hline $11: 45$ & 0.001 & 0.001 & 0.001 & 0.002 & 0.000 & 0.000 & 0.004 & 0.007 & 0.006 & 0.007 & 0.001 & 0.001 \\
\hline $12: 45$ & 0.001 & 0.001 & 0.001 & 0.002 & 0.000 & 0.000 & 0.004 & 0.008 & 0.005 & 0.010 & 0.001 & 0.001 \\
\hline $13: 45$ & 0.001 & 0.001 & 0.001 & 0.002 & 0.000 & 0.000 & 0.004 & 0.006 & 0.005 & 0.007 & 0.001 & 0.001 \\
\hline $14: 45$ & 0.001 & 0.001 & 0.001 & 0.002 & 0.000 & 0.000 & 0.004 & 0.007 & 0.006 & 0.008 & 0.001 & 0.001 \\
\hline $15: 45$ & 0.001 & 0.001 & 0.001 & 0.002 & 0.000 & 0.000 & 0.006 & 0.011 & 0.008 & 0.013 & 0.001 & 0.001 \\
\hline $16: 00$ & 0.001 & 0.003 & 0.001 & 0.003 & 0.000 & 0.000 & 0.007 & 0.014 & 0.009 & 0.017 & 0.001 & 0.001 \\
\hline
\end{tabular}


Panel C: Summary Statistics of All, Leveraged, and Unleveraged ETFs in High and Normal Volatility for Quote Slope

\begin{tabular}{|c|c|c|c|c|c|c|c|c|c|c|c|c|}
\hline & \multicolumn{6}{|c|}{ Normal Volatility } & \multicolumn{6}{|c|}{ High Volatility } \\
\hline & \multicolumn{2}{|l|}{ All } & \multicolumn{2}{|c|}{ Leveraged } & \multicolumn{2}{|c|}{ Unleveraged } & \multicolumn{2}{|l|}{ All } & \multicolumn{2}{|c|}{ Leveraged } & \multicolumn{2}{|c|}{ Unleveraged } \\
\hline & Mean & Std dev & Mean & Std dev & Mean & Std dev & Mean & Std dev & Mean & Std dev & Mean & Std dev \\
\hline $9: 45$ & 0.022 & 0.073 & 0.032 & 0.104 & 0.007 & 0.015 & 0.244 & 0.913 & 0.351 & 1.098 & 0.025 & 0.070 \\
\hline $10: 45$ & 0.012 & 0.026 & 0.017 & 0.031 & 0.003 & 0.004 & 0.087 & 0.198 & 0.124 & 0.270 & 0.009 & 0.014 \\
\hline $11: 45$ & 0.011 & 0.025 & 0.016 & 0.032 & 0.003 & 0.004 & 0.077 & 0.153 & 0.106 & 0.176 & 0.009 & 0.013 \\
\hline $12: 45$ & 0.011 & 0.024 & 0.015 & 0.030 & 0.003 & 0.004 & 0.079 & 0.219 & 0.114 & 0.282 & 0.008 & 0.013 \\
\hline $13: 45$ & 0.011 & 0.026 & 0.016 & 0.031 & 0.003 & 0.004 & 0.072 & 0.130 & 0.100 & 0.153 & 0.008 & 0.013 \\
\hline $14: 45$ & 0.011 & 0.025 & 0.016 & 0.031 & 0.003 & 0.004 & 0.079 & 0.145 & 0.109 & 0.165 & 0.009 & 0.016 \\
\hline $15: 45$ & 0.012 & 0.026 & 0.017 & 0.031 & 0.003 & 0.004 & 0.116 & 0.308 & 0.160 & 0.383 & 0.012 & 0.024 \\
\hline $16: 00$ & 0.013 & 0.029 & 0.018 & 0.037 & 0.003 & 0.005 & 0.146 & 0.452 & 0.211 & 0.585 & 0.013 & 0.028 \\
\hline
\end{tabular}

Panel D: Summary Statistics of All, Leveraged, and Unleveraged ETFs in High and Normal Volatility for Percentage Spread

\begin{tabular}{|c|c|c|c|c|c|c|c|c|c|c|c|c|}
\hline & \multicolumn{6}{|c|}{ Normal Volatility } & \multicolumn{6}{|c|}{ High Volatility } \\
\hline & \multicolumn{2}{|c|}{ All } & \multicolumn{2}{|c|}{ Leveraged } & \multicolumn{2}{|c|}{ Unleveraged } & \multicolumn{2}{|c|}{ All } & \multicolumn{2}{|c|}{ Leveraged } & \multicolumn{2}{|c|}{ Unleveraged } \\
\hline & Mean & Std dev & Mean & Std dev & Mean & Std dev & Mean & Std dev & Mean & Std dev & Mean & Std dev \\
\hline $9: 45$ & 0.178 & 0.378 & 0.243 & 0.487 & 0.058 & 0.068 & 0.913 & 2.255 & 1.256 & 2.652 & 0.179 & 0.429 \\
\hline $10: 45$ & 0.112 & 0.155 & 0.152 & 0.183 & 0.037 & 0.026 & 0.442 & 0.751 & 0.611 & 1.005 & 0.070 & 0.070 \\
\hline $11: 45$ & 0.098 & 0.130 & 0.134 & 0.155 & 0.036 & 0.024 & 0.417 & 0.665 & 0.561 & 0.746 & 0.064 & 0.058 \\
\hline $12: 45$ & 0.094 & 0.129 & 0.130 & 0.156 & 0.035 & 0.024 & 0.403 & 0.815 & 0.550 & 0.949 & 0.062 & 0.057 \\
\hline $13: 45$ & 0.097 & 0.132 & 0.134 & 0.159 & 0.036 & 0.024 & 0.393 & 0.627 & 0.533 & 0.711 & 0.063 & 0.056 \\
\hline $14: 45$ & 0.102 & 0.137 & 0.140 & 0.162 & 0.037 & 0.026 & 0.433 & 0.675 & 0.583 & 0.766 & 0.067 & 0.062 \\
\hline $15: 45$ & 0.107 & 0.143 & 0.145 & 0.167 & 0.036 & 0.027 & 0.586 & 1.089 & 0.785 & 1.267 & 0.082 & 0.094 \\
\hline $16: 00$ & 0.108 & 0.266 & 0.148 & 0.328 & 0.036 & 0.028 & 0.673 & 1.429 & 0.910 & 1.651 & 0.085 & 0.105 \\
\hline
\end{tabular}


Panel E: Summary Statistics of All, Leveraged, and Unleveraged ETFs in High and Normal Volatility for Bid SIze

\begin{tabular}{|c|c|c|c|c|c|c|c|c|c|c|c|c|}
\hline & \multicolumn{6}{|c|}{ Normal Volatility } & \multicolumn{6}{|c|}{ High Volatility } \\
\hline & \multicolumn{2}{|c|}{ All } & \multicolumn{2}{|c|}{ Leveraged } & \multicolumn{2}{|c|}{ Unleveraged } & \multicolumn{2}{|c|}{ All } & \multicolumn{2}{|c|}{ Leveraged } & \multicolumn{2}{|c|}{ Unleveraged } \\
\hline & Mean & Std dev & Mean & Std dev & Mean & Std dev & Mean & Std dev & Mean & Std dev & Mean & Std dev \\
\hline $9: 45$ & 355.123 & 2586.169 & 366.770 & 2966.583 & 323.249 & 1558.674 & 51.021 & 250.015 & 34.383 & 203.010 & 85.533 & 324.554 \\
\hline $10: 45$ & 576.679 & 3915.181 & 603.774 & 4551.580 & 510.095 & 2212.230 & 64.538 & 329.133 & 37.286 & 245.574 & 133.703 & 473.166 \\
\hline $11: 45$ & 642.077 & 4265.399 & 658.236 & 4980.061 & 614.872 & 2551.188 & 67.178 & 338.452 & 41.029 & 265.777 & 130.760 & 463.098 \\
\hline $12: 45$ & 712.381 & 4418. & 705.533 & 5017.023 & 726.346 & 3146.149 & 89.110 & 495.483 & 56.033 & 419.392 & 166.971 & 631.072 \\
\hline $13: 45$ & 700.913 & 4280.296 & 705.494 & 4856.561 & 693.249 & 3022.144 & 76.250 & 456.540 & 52.135 & 421.917 & 136.846 & 530.725 \\
\hline $14: 45$ & 667.535 & 4244.830 & 681.401 & 4891.250 & 643.794 & 2719.838 & 71.287 & 425.464 & 47.868 & 397.658 & 132.576 & 487.024 \\
\hline $15: 45$ & 702.333 & 4297.143 & 668.452 & 4806.999 & 736.176 & 3061.554 & 71.932 & 459.162 & 50.265 & 446.436 & 130.310 & 487.167 \\
\hline $16: 00$ & 749.619 & 4330.948 & 672.223 & 4669.349 & 855.639 & 3503.867 & 92.374 & 598.684 & 66.132 & 605.434 & 161.210 & 574.520 \\
\hline
\end{tabular}

Panel F: Summary Statistics of All, Leveraged, and Unleveraged ETFs in High and Normal Volatility for Ask Size

\begin{tabular}{|c|c|c|c|c|c|c|c|c|c|c|c|c|}
\hline & \multicolumn{6}{|c|}{ Normal Volatility } & \multicolumn{6}{|c|}{ High Volatility } \\
\hline & \multicolumn{2}{|c|}{ All } & \multicolumn{2}{|c|}{ Leveraged } & \multicolumn{2}{|c|}{ Unleveraged } & \multicolumn{2}{|c|}{ All } & \multicolumn{2}{|c|}{ Leveraged } & \multicolumn{2}{|c|}{ Unleveraged } \\
\hline & Mean & Std dev & Mean & Std dev & Mean & Std dev & Mean & Std dev & Mean & Std dev & Mean & Std dev \\
\hline $9: 45$ & 328.934 & 2367.778 & 335.575 & 2691.827 & 307.959 & 1512.539 & 53.253 & 245.981 & 35.269 & 183.171 & 90.724 & 338.874 \\
\hline $10: 45$ & 550.113 & 3648.099 & 543.485 & 4146.074 & 546.024 & 2390.931 & 72.563 & 374.526 & 46.790 & 314.260 & 138.085 & 490.608 \\
\hline 11:45 & 651.791 & 4018.319 & 663.895 & 4631.903 & 631.875 & 2600.850 & 76.891 & 422.338 & 52.793 & 384.491 & 135.265 & 494.871 \\
\hline $12: 45$ & 685.828 & 4022.658 & 677.378 & 4536.672 & 702.379 & 2945.947 & 91.312 & 479.370 & 58.411 & 395.430 & 168.717 & 626.203 \\
\hline $13: 45$ & 683.869 & 4120.232 & 683.786 & 4683.396 & 684.345 & 2885.308 & 77.789 & 450.716 & 56.008 & 431.557 & 132.604 & 493.772 \\
\hline $14: 45$ & 661.948 & 4136.593 & 678.767 & 4755.191 & 632.935 & 2686.871 & 75.536 & 467.551 & 54.693 & 466.011 & 130.315 & 470.304 \\
\hline $15: 45$ & 738.319 & 4380.517 & 704.071 & 4835.051 & 771.601 & 3297.696 & 69.524 & 399.873 & 47.084 & 372.732 & 129.946 & 459.879 \\
\hline 16:00 & 778.626 & 4502.532 & 725.777 & 4963.822 & 838.419 & 3368.575 & 80.796 & 451.160 & 51.448 & 404.464 & 157.628 & 547.913 \\
\hline
\end{tabular}



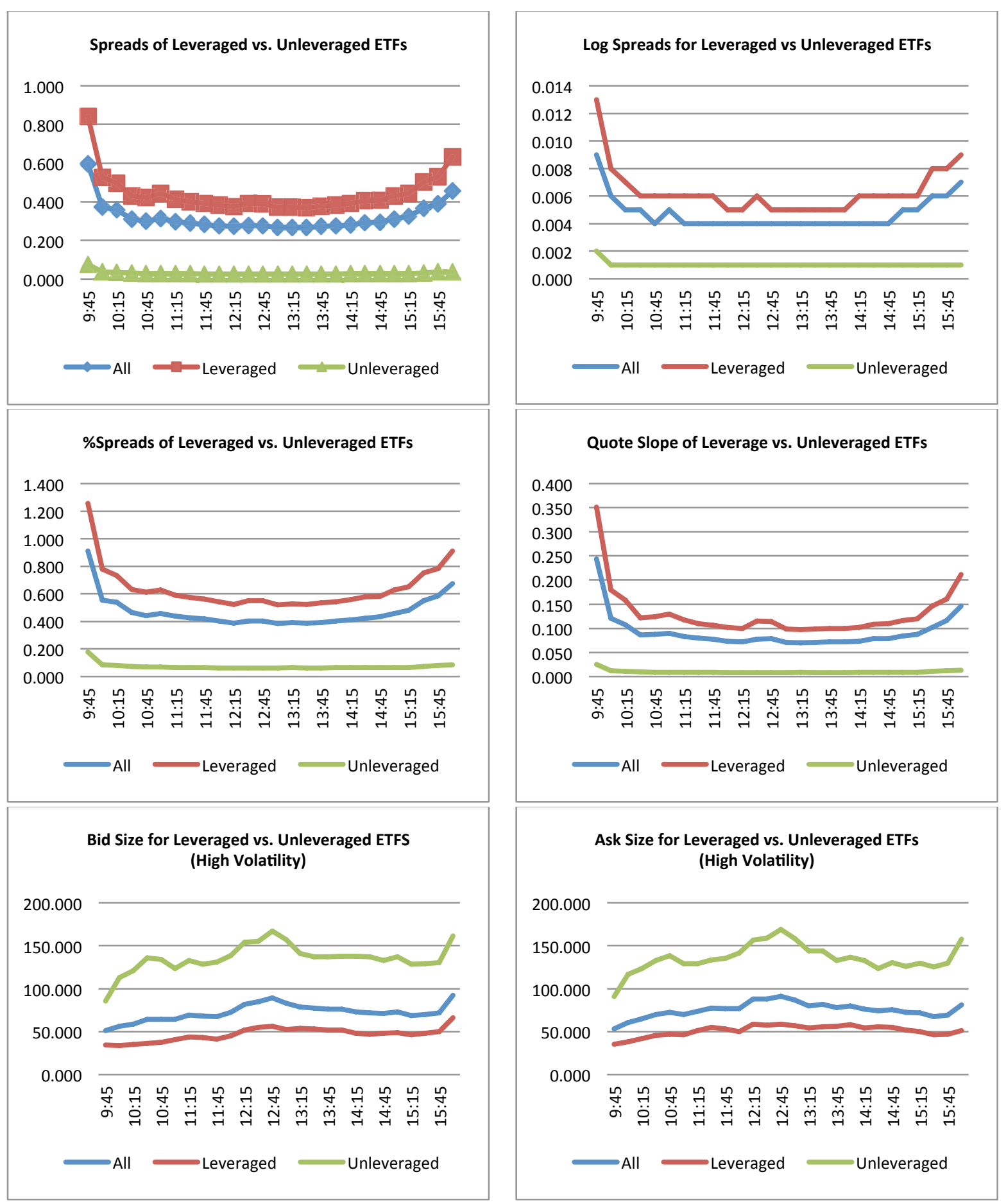

Figure 3-1: All, Leveraged, and Unleveraged ETFs in High Volatility 

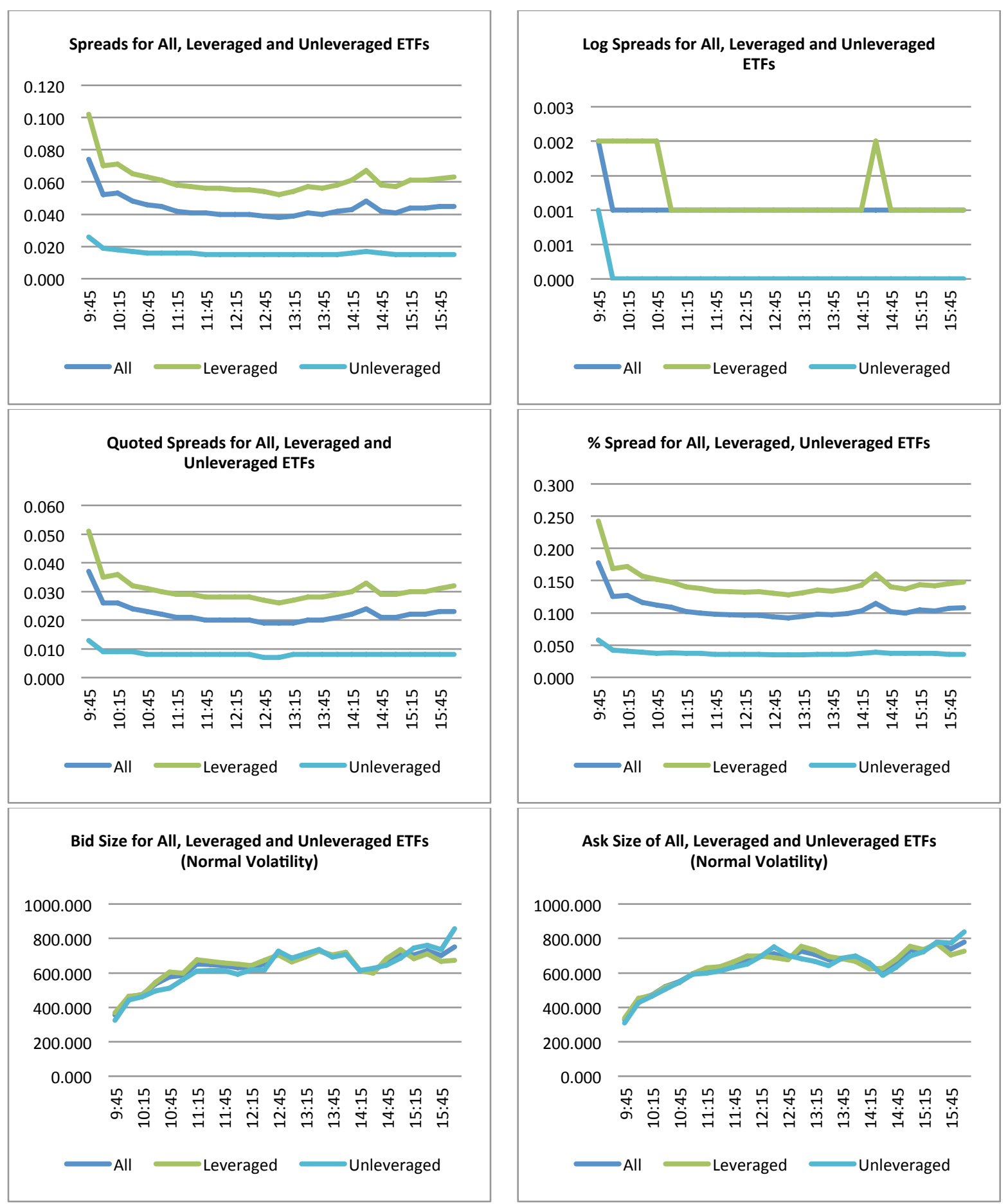

Figure 3-2: All, Leveraged, and Unleveraged ETFs in Normal Volatility 
Table 3-2: Summary Statistics for Trading Variables by Leveraged Multiple

Panel A: Summary Statistics for Spread, in High and Normal Volatility by Leveraged Multiple

\begin{tabular}{|c|c|c|c|c|c|c|c|c|c|c|c|c|c|c|c|c|c|c|c|c|}
\hline & \multicolumn{10}{|c|}{ Normal Volatility } & \multicolumn{10}{|c|}{ High Volatility } \\
\hline & -3 & & -2 & & -1 & & 2 & & 3 & & -3 & & -2 & & -1 & & 2 & & 3 & \\
\hline & Mean & $\begin{array}{l}\text { Std } \\
\text { dev }\end{array}$ & Mean & $\begin{array}{l}\text { Std } \\
\text { dev }\end{array}$ & Mean & $\begin{array}{l}\text { Std } \\
\text { dev }\end{array}$ & Mean & $\begin{array}{l}\text { Std } \\
\text { dev }\end{array}$ & Mean & $\begin{array}{l}\text { Std } \\
\text { dev }\end{array}$ & Mean & $\begin{array}{l}\text { Std } \\
\text { dev }\end{array}$ & Mean & $\begin{array}{l}\text { Std } \\
\text { dev }\end{array}$ & Mean & $\begin{array}{l}\text { Std } \\
\text { dev }\end{array}$ & Mean & $\begin{array}{l}\text { Std } \\
\text { dev }\end{array}$ & Mean & $\begin{array}{l}\text { Std } \\
\text { dev }\end{array}$ \\
\hline $9: 45$ & 0.06 & 0.07 & 0.13 & 0.25 & 0.14 & 0.47 & 0.09 & 0.22 & 0.09 & 0.11 & 0.30 & 0.58 & 1.44 & 2.19 & 0.60 & 1.09 & 0.64 & 1.33 & 0.13 & 0.20 \\
\hline $10: 45$ & 0.05 & 0.05 & 0.09 & 0.11 & 0.05 & 0.06 & 0.06 & 0.08 & 0.06 & 0.06 & 0.17 & 0.19 & 0.70 & 0.89 & 0.26 & 0.22 & 0.25 & 0.33 & 0.08 & 0.09 \\
\hline $11: 45$ & 0.05 & 0.05 & 0.08 & 0.10 & 0.05 & 0.07 & 0.05 & 0.07 & 0.06 & 0.06 & 0.17 & 0.19 & 0.65 & 0.72 & 0.23 & 0.19 & 0.23 & 0.28 & 0.08 & 0.08 \\
\hline $12: 45$ & 0.04 & 0.05 & 0.07 & 0.10 & 0.05 & 0.06 & 0.05 & 0.07 & 0.06 & 0.05 & 0.16 & 0.16 & 0.67 & 0.91 & 0.22 & 0.18 & 0.21 & 0.28 & 0.08 & 0.08 \\
\hline $13: 45$ & 0.05 & 0.05 & 0.07 & 0.11 & 0.05 & 0.05 & 0.05 & 0.07 & 0.06 & 0.05 & 0.16 & 0.16 & 0.63 & 0.69 & 0.22 & 0.17 & 0.21 & 0.26 & 0.08 & 0.09 \\
\hline $14: 45$ & 0.05 & 0.06 & 0.08 & 0.11 & 0.05 & 0.04 & 0.05 & 0.07 & 0.06 & 0.06 & 0.17 & 0.18 & 0.68 & 0.75 & 0.25 & 0.19 & 0.24 & 0.29 & 0.08 & 0.09 \\
\hline $15: 45$ & 0.05 & 0.06 & 0.09 & 0.12 & 0.05 & 0.06 & 0.05 & 0.07 & 0.06 & 0.06 & 0.18 & 0.20 & 0.88 & 1.12 & 0.32 & 0.30 & 0.34 & 0.55 & 0.10 & 0.12 \\
\hline $16: 00$ & 0.05 & 0.05 & 0.08 & 0.12 & 0.06 & 0.07 & 0.06 & 0.09 & 0.06 & 0.06 & 0.20 & 0.28 & 1.06 & 1.44 & 0.35 & 0.35 & 0.40 & 0.79 & 0.11 & 0.14 \\
\hline
\end{tabular}


Panel B: Summary Statistics for Log Spread, in High and Normal Volatility by Leveraged Multipl (x 10^-01)

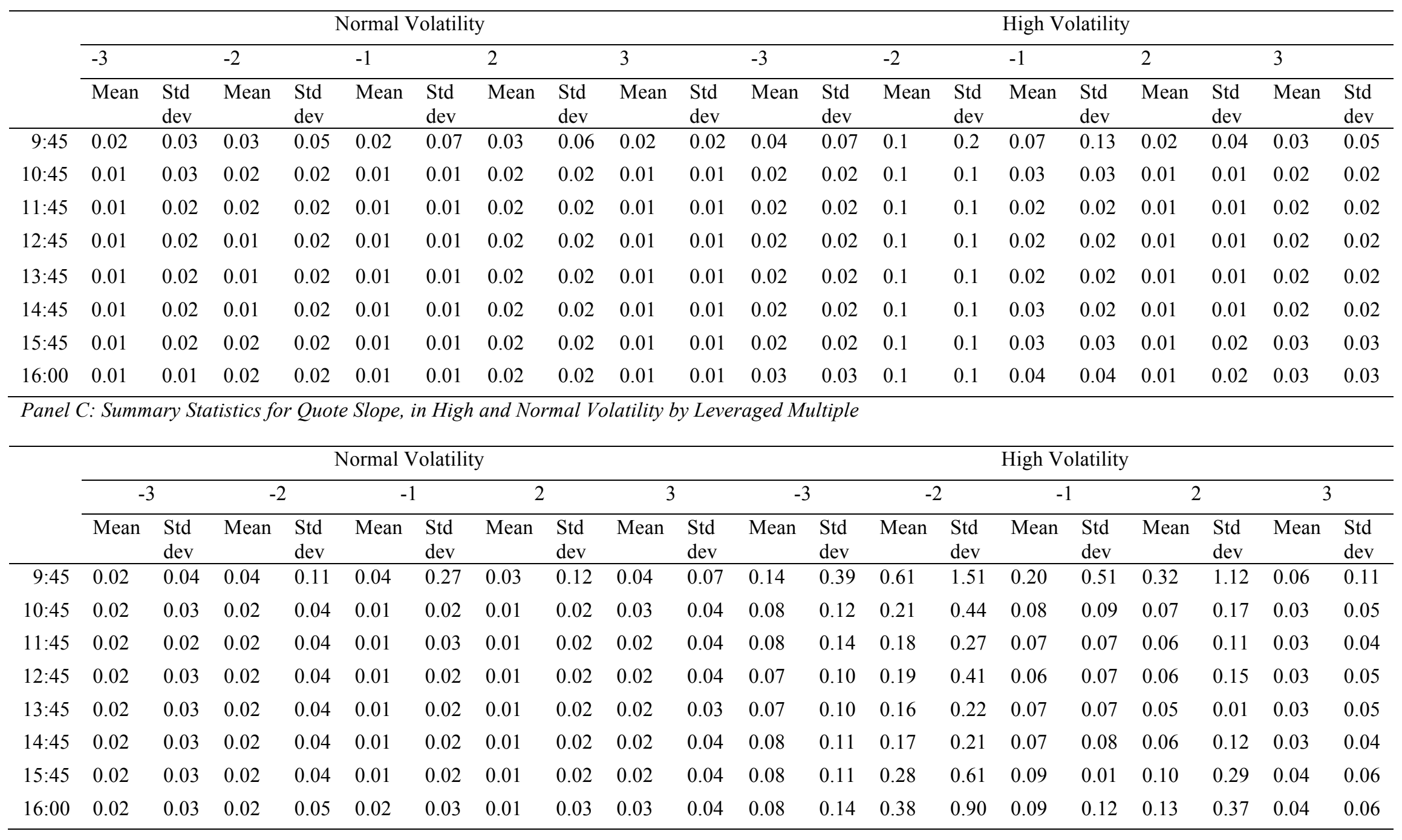


Panel D: Summary Statistics for Percentage Spread, in High and Normal Volatility by Leveraged Multiple

\begin{tabular}{|c|c|c|c|c|c|c|c|c|c|c|c|c|c|c|c|c|c|c|c|c|}
\hline & \multicolumn{10}{|c|}{ Normal Volatility } & \multicolumn{10}{|c|}{ High Volatility } \\
\hline & \multicolumn{2}{|c|}{-3} & \multicolumn{2}{|c|}{-2} & \multicolumn{2}{|c|}{-1} & \multicolumn{2}{|c|}{2} & \multicolumn{2}{|c|}{3} & \multicolumn{2}{|c|}{-3} & \multicolumn{2}{|c|}{-2} & \multicolumn{2}{|c|}{-1} & \multicolumn{2}{|c|}{2} & \multicolumn{2}{|c|}{3} \\
\hline & Mean & $\begin{array}{l}\text { Std } \\
\text { dev }\end{array}$ & Mean & $\begin{array}{l}\text { Std } \\
\text { dev }\end{array}$ & Mean & $\begin{array}{l}\text { Std } \\
\text { dev }\end{array}$ & Mean & $\begin{array}{l}\text { Std } \\
\mathrm{dev}\end{array}$ & Mean & $\begin{array}{l}\text { Std } \\
\text { dev }\end{array}$ & Mean & $\begin{array}{l}\text { Std } \\
\text { dev }\end{array}$ & Mean & $\begin{array}{l}\text { Std } \\
\mathrm{dev}\end{array}$ & Iean & $\begin{array}{l}\text { Std } \\
\text { dev }\end{array}$ & Mean & $\begin{array}{l}\text { Std } \\
\mathrm{dev}\end{array}$ & Mean & $\begin{array}{l}\text { Std } \\
\mathrm{dev}\end{array}$ \\
\hline $9: 45$ & 0.16 & 0.27 & 0.20 & 0.67 & 0.20 & 0.67 & 0.32 & 0.60 & 0.17 & 0.21 & 0.40 & 0.70 & 1.18 & 1.87 & 0.66 & 1.26 & 2.09 & 3.91 & 0.34 & 0.51 \\
\hline $10: 45$ & 0.14 & 0.27 & 0.08 & 0.08 & 0.08 & 0.08 & 0.21 & 0.21 & 0.11 & 0.10 & 0.23 & 0.21 & 0.54 & 0.64 & 0.27 & 0.26 & 0.92 & 1.19 & 0.21 & 0.20 \\
\hline $11: 45$ & 0.13 & 0.20 & 0.08 & 0.09 & 0.08 & 0.09 & 0.18 & 0.18 & 0.11 & 0.09 & 0.23 & 0.21 & 0.51 & 0.53 & 0.24 & 0.22 & 0.85 & 0.99 & 0.21 & 0.17 \\
\hline $12: 45$ & 0.12 & 0.21 & 0.08 & 0.08 & 0.08 & 0.08 & 0.18 & 0.18 & 0.10 & 0.09 & 0.21 & 0.17 & 0.52 & 0.65 & 0.23 & 0.20 & 0.79 & 1.05 & 0.21 & 0.18 \\
\hline $13: 45$ & 0.13 & 0.21 & 0.08 & 0.07 & 0.08 & 0.07 & 0.18 & 0.19 & 0.10 & 0.09 & 0.21 & 0.18 & 0.49 & 0.51 & 0.24 & 0.21 & 0.79 & 0.94 & 0.21 & 0.21 \\
\hline $14: 45$ & 0.13 & 0.20 & 0.08 & 0.06 & 0.08 & 0.06 & 0.19 & 0.20 & 0.11 & 0.10 & 0.23 & 0.20 & 0.52 & 0.54 & 0.26 & 0.23 & 0.89 & 1.04 & 0.21 & 0.18 \\
\hline $15: 45$ & 0.13 & 0.21 & 0.08 & 0.08 & 0.08 & 0.08 & 0.20 & 0.19 & 0.11 & 0.10 & 0.25 & 0.23 & 0.71 & 0.92 & 0.34 & 0.35 & 1.19 & 1.67 & 0.27 & 0.27 \\
\hline $16: 00$ & 0.14 & 0.93 & 0.08 & 0.09 & 0.08 & 0.09 & 0.20 & 0.23 & 0.11 & 0.10 & 0.29 & 0.32 & 0.85 & 1.17 & 0.37 & 0.38 & 1.39 & 2.32 & 0.29 & 0.33 \\
\hline
\end{tabular}

Panel E: Summary Statistics for Bid Size, in High and Normal Volatility by Leveraged Multiple

\begin{tabular}{|c|c|c|c|c|c|c|c|c|c|c|c|c|c|c|c|c|c|c|c|c|}
\hline & \multicolumn{10}{|c|}{ Normal Volatility } & \multicolumn{10}{|c|}{ High Volatility } \\
\hline & \multicolumn{2}{|c|}{-3} & \multicolumn{2}{|c|}{-2} & \multicolumn{2}{|c|}{-1} & \multicolumn{2}{|c|}{2} & \multicolumn{2}{|c|}{3} & \multicolumn{2}{|c|}{-3} & \multicolumn{2}{|c|}{-2} & \multicolumn{2}{|c|}{-1} & \multicolumn{2}{|c|}{2} & \multicolumn{2}{|c|}{3} \\
\hline & Mean & $\begin{array}{l}\text { Std } \\
\text { dev }\end{array}$ & Mean & $\begin{array}{l}\text { Std } \\
\text { dev }\end{array}$ & Mean & $\begin{array}{l}\text { Std } \\
\text { dev }\end{array}$ & Mean & $\begin{array}{l}\text { Std } \\
\text { dev }\end{array}$ & Mean & $\begin{array}{l}\text { Std } \\
\text { dev }\end{array}$ & Mean & $\begin{array}{l}\text { Std } \\
\text { dev }\end{array}$ & Mean & $\begin{array}{l}\text { Std } \\
\text { dev }\end{array}$ & Mean & $\begin{array}{l}\text { Std } \\
\text { dev }\end{array}$ & Mean & $\begin{array}{l}\text { Std } \\
\text { dev }\end{array}$ & Mean & $\begin{array}{l}\text { Std } \\
\text { dev }\end{array}$ \\
\hline $9: 45$ & 171 & 704 & 60 & 222 & 22 & 36 & 1086 & 5409 & 48 & 190 & 10 & 29 & 25 & 56 & 14 & 20 & 41 & 172 & 130 & 665 \\
\hline 10:45 & 284 & 1070 & 84 & 451 & 26 & 37 & 1841 & 8346 & 108 & 571 & 11 & 31 & 18 & 22 & 13 & 18 & 54 & 235 & 163 & 844 \\
\hline 11:45 & 345 & 1436 & 88 & 423 & 27 & 46 & 2113 & 9386 & 110 & 589 & 11 & 28 & 18 & 24 & 15 & 23 & 60 & 274 & 194 & 899 \\
\hline $12: 45$ & 395 & 1444 & 105 & 483 & 29 & 50 & 2241 & 9457 & 152 & 813 & 12 & 36 & 17 & 24 & 15 & 23 & 102 & 574 & 212 & 1065 \\
\hline 13:45 & 419 & 1643 & 92 & 404 & 28 & 44 & 2237 & 9083 & 135 & 594 & 11 & 32 & 19 & 24 & 14 & 22 & 86 & 561 & 226 & 1117 \\
\hline $14: 45$ & 342 & 1441 & 9 & 383 & 26 & 42 & 2164 & 9096 & 127 & 545 & 10 & 22 & 20 & 26 & 15 & 21 & 79 & 548 & 172 & 970 \\
\hline $15: 45$ & 382 & 1644 & 99 & 482 & 28 & 60 & 2087 & 8932 & 111 & 425 & 11 & 25 & 20 & 27 & 16 & 21 & 78 & 603 & 214 & 1116 \\
\hline $16: 00$ & 431 & 1678 & 127 & 633 & 31 & 107 & 2039 & 8693 & 171 & 911 & 12 & 26 & 21 & 35 & 18 & 24 & 101 & 729 & 350 & 1771 \\
\hline
\end{tabular}


Panel F: Summary Statistics for Ask Size, in High and Normal Volatility by Leveraged Multiple

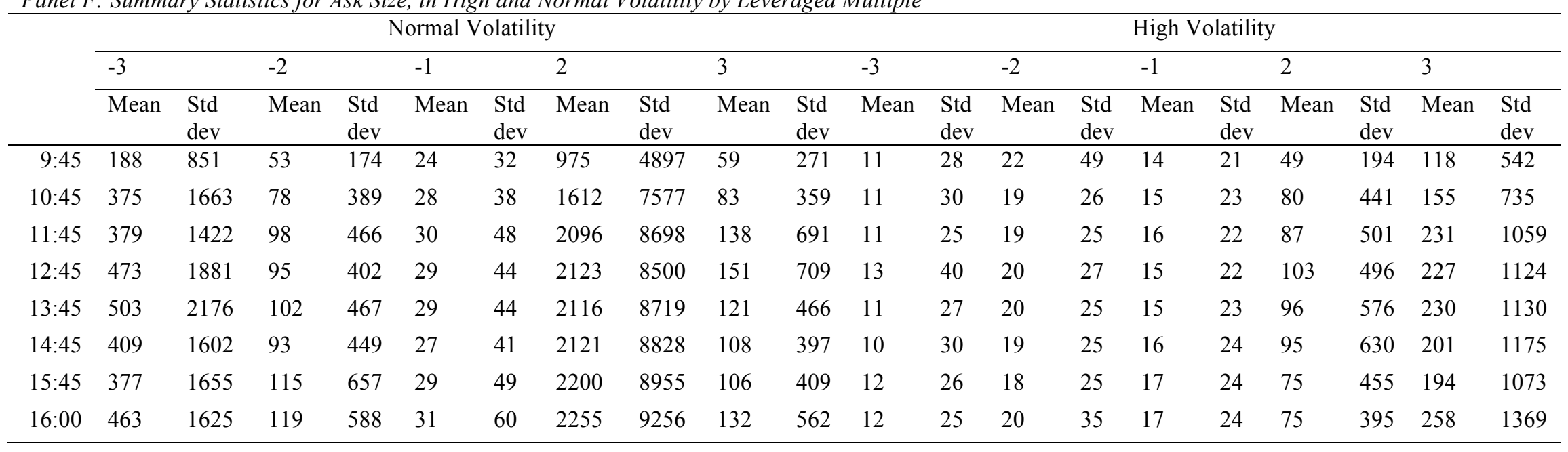



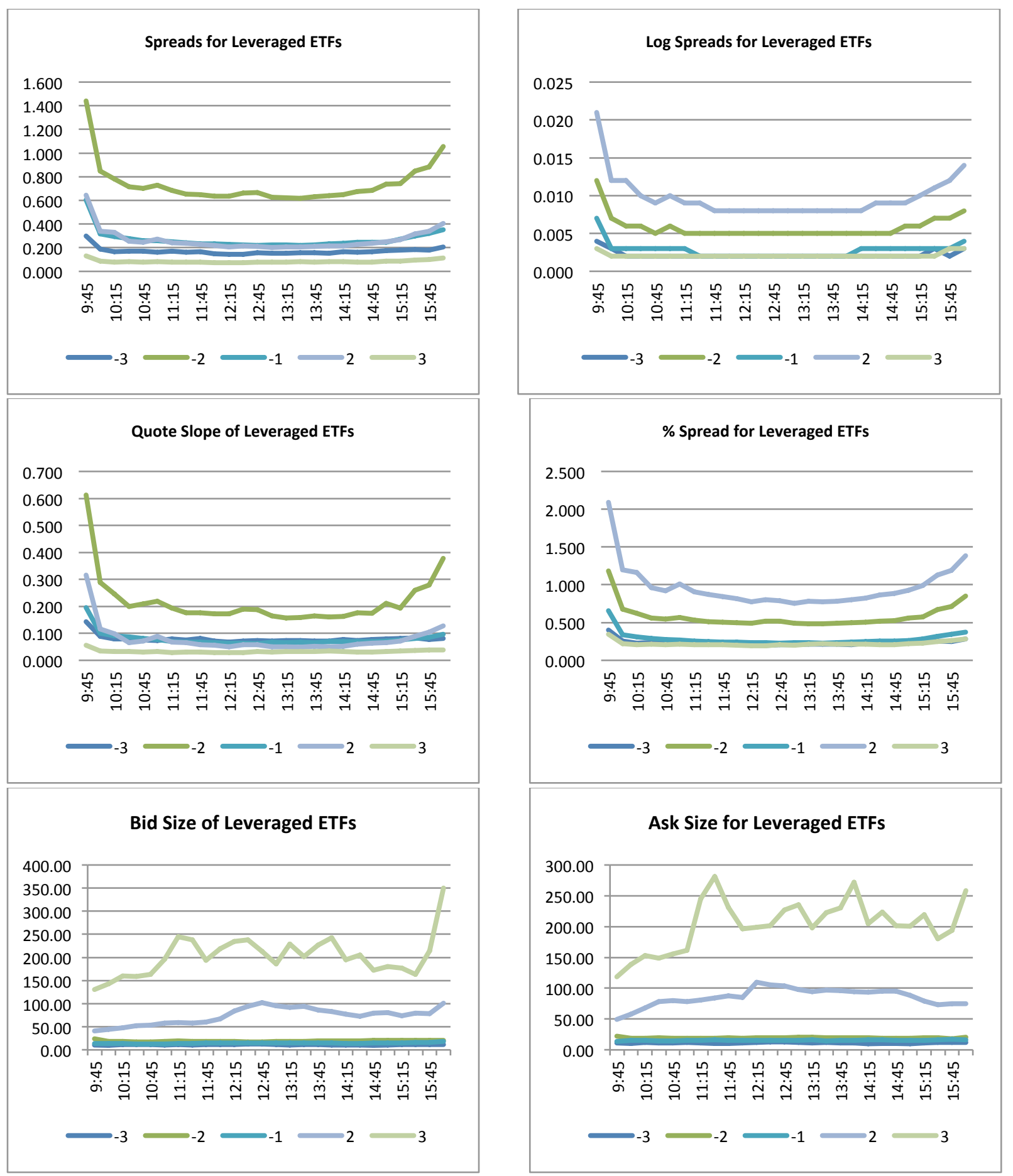

Figure 3-3: Leveraged ETFs by Leverage Multiple in High Volatility 

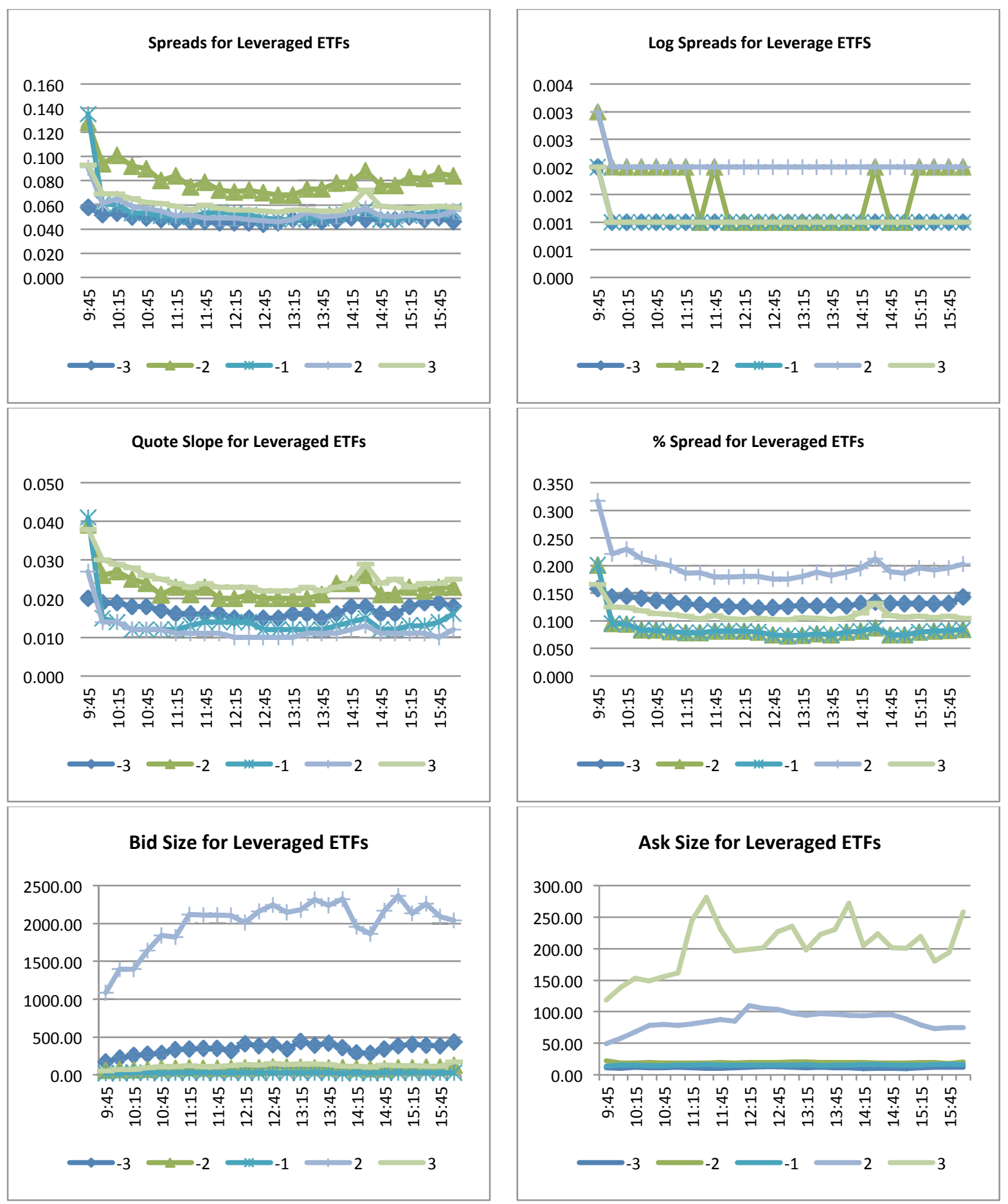

Figure 3-4: Leveraged ETFs by Leveraged Multiple in Normal Volatility 
Table 3-3: Difference of Means Test Results

Panel A: Difference of Means (High-Normal Volatility) for Spread (S) and Percentage Spread (PS)

\begin{tabular}{|c|c|c|c|c|c|c|c|c|c|c|c|c|c|c|c|c|}
\hline & -3 & -2 & -1 & 1 & 2 & 3 & $\mathrm{~L}$ & A & -3 & -2 & -1 & 1 & 2 & 3 & $\mathrm{~L}$ & A \\
\hline Time & $\mathrm{S}$ & $\mathrm{S}$ & $\mathrm{S}$ & $\mathrm{S}$ & $\mathrm{S}$ & $\mathrm{S}$ & $\mathrm{S}$ & $\mathrm{S}$ & PS & PS & PS & PS & PS & PS & PS & PS \\
\hline $9: 45$ & 0.241 & 1.314 & 0.469 & 0.050 & 0.553 & 0.037 & 0.739 & 0.522 & 0.245 & 0.919 & 0.455 & 0.121 & 1.775 & 0.177 & 1.012 & 0.734 \\
\hline $10: 45$ & 0.120 & 0.613 & 0.209 & 0.014 & 0.188 & 0.018 & 0.359 & 0.254 & 0.093 & 0.369 & 0.192 & 0.033 & 0.712 & 0.096 & 0.459 & 0.330 \\
\hline $11: 45$ & 0.122 & 0.570 & 0.180 & 0.012 & 0.178 & 0.017 & 0.335 & 0.243 & 0.098 & 0.353 & 0.162 & 0.028 & 0.668 & 0.096 & 0.426 & 0.319 \\
\hline $12: 45$ & 0.113 & 0.598 & 0.172 & 0.011 & 0.163 & 0.023 & 0.334 & 0.237 & 0.086 & 0.381 & 0.151 & 0.027 & 0.612 & 0.103 & 0.420 & 0.309 \\
\hline $13: 45$ & 0.110 & 0.556 & 0.175 & 0.012 & 0.161 & 0.025 & 0.322 & 0.231 & 0.084 & 0.354 & 0.161 & 0.027 & 0.603 & 0.111 & 0.400 & 0.297 \\
\hline $14: 45$ & 0.119 & 0.605 & 0.198 & 0.013 & 0.184 & 0.021 & 0.351 & 0.253 & 0.096 & 0.378 & 0.182 & 0.030 & 0.697 & 0.100 & 0.443 & 0.330 \\
\hline $15: 45$ & 0.130 & 0.797 & 0.268 & 0.022 & 0.288 & 0.042 & 0.468 & 0.342 & 0.117 & 0.556 & 0.260 & 0.046 & 0.995 & 0.157 & 0.640 & 0.479 \\
\hline $16: 00$ & 0.158 & 0.971 & 0.296 & 0.023 & 0.349 & 0.054 & 0.568 & 0.409 & 0.143 & 0.692 & 0.288 & 0.048 & 1.184 & 0.182 & 0.762 & 0.565 \\
\hline
\end{tabular}

* All differences of means are significant at 1\% level assuming equal and unequal variances

Panel B: Difference of Means (High-Normal Volatility) for Log Spread (LS) and Quote Slope (QS)

\begin{tabular}{|c|c|c|c|c|c|c|c|c|c|c|c|c|c|c|c|c|}
\hline & -3 & -2 & -1 & 1 & 2 & 3 & $\mathrm{~L}$ & A & -3 & -2 & -1 & 1 & 2 & 3 & $\mathrm{~L}$ & A \\
\hline Time & QS1 & QS1 & QS1 & QS1 & QS1 & QS1 & QS1 & QS1 & LS & $\mathrm{LS}$ & $\mathrm{LS}$ & LS & LS & LS & $\mathrm{LS}$ & $\mathrm{LS}$ \\
\hline $9: 45$ & 0.124 & 0.573 & 0.154 & 0.019 & 0.290 & 0.018 & 0.319 & 0.222 & 0.002 & 0.009 & 0.005 & 0.001 & 0.018 & 0.002 & 0.010 & 0.007 \\
\hline $10: 45$ & 0.058 & 0.185 & 0.069 & 0.006 & 0.059 & 0.005 & 0.107 & 0.075 & 0.001 & 0.004 & 0.002 & 0.000 & 0.007 & 0.001 & 0.005 & 0.003 \\
\hline $11: 45$ & 0.066 & 0.154 & 0.053 & 0.006 & 0.048 & 0.006 & 0.090 & 0.066 & 0.001 & 0.004 & 0.002 & 0.000 & 0.007 & 0.001 & 0.004 & 0.003 \\
\hline $12: 45$ & 0.058 & 0.168 & 0.050 & 0.005 & 0.048 & 0.010 & 0.098 & 0.069 & 0.001 & 0.004 & 0.002 & 0.000 & 0.006 & 0.001 & 0.004 & 0.003 \\
\hline $13: 45$ & 0.057 & 0.143 & 0.053 & 0.005 & 0.042 & 0.011 & 0.084 & 0.061 & 0.001 & 0.004 & 0.002 & 0.000 & 0.006 & 0.001 & 0.004 & 0.003 \\
\hline $14: 45$ & 0.060 & 0.153 & 0.058 & 0.006 & 0.052 & 0.006 & 0.092 & 0.068 & 0.001 & 0.004 & 0.002 & 0.000 & 0.007 & 0.001 & 0.004 & 0.003 \\
\hline $15: 45$ & 0.058 & 0.256 & 0.071 & 0.009 & 0.094 & 0.015 & 0.143 & 0.104 & 0.001 & 0.006 & 0.003 & 0.000 & 0.010 & 0.002 & 0.006 & 0.005 \\
\hline $16: 00$ & 0.064 & 0.354 & 0.081 & 0.010 & 0.115 & 0.014 & 0.193 & 0.134 & 0.001 & 0.007 & 0.003 & 0.000 & 0.012 & 0.002 & 0.008 & 0.006 \\
\hline
\end{tabular}

* All differences of means are significant at $1 \%$ level assuming equal and unequal variances 
Panel C: Difference of Means (High-Normal Volatility) for Bid Size(S) and Offer Size (PS)

\begin{tabular}{|c|c|c|c|c|c|c|c|c|c|c|c|c|c|c|c|c|}
\hline & -3 & -2 & -1 & 1 & 2 & 3 & $\mathrm{~L}$ & A & -3 & -2 & -1 & 1 & 2 & 3 & $\mathrm{~L}$ & A \\
\hline Time & BS & BS & BS & BS & BS & BS & BS & BS & AS & AS & AS & AS & AS & AS & AS & AS \\
\hline $9: 45$ & -160.9 & -35.2 & -8.6 & -237.7 & -1045.8 & 81.9 & -332.3 & -304.1 & -177.4 & -31.4 & -10.1 & -217.2 & -926.3 & 58.9 & -300.3 & -275.6 \\
\hline $10: 45$ & -273.5 & -66.1 & -13.3 & -376.3 & -1787.9 & 54.9 & -566.4 & -512.1 & -364.0 & -59.2 & -12.7 & -407.9 & -1532.4 & 72.3 & -496.7 & -477.5 \\
\hline 11:45 & -334.4 & -69.7 & -13.4 & -484.1 & -2052.6 & 83.7 & -617.2 & -574.9 & -368.8 & -78.1 & -14.3 & -496.6 & -2008.7 & 93.1 & -611.1 & -574.9 \\
\hline $12: 45$ & -382.9 & -87.5 & -14.5 & -559.3 & -2139.4 & 59.9 & -649.0 & -623.2 & -460.6 & -75.5 & -13.3 & -533.6 & -2019.5 & 76.2 & -618.9 & -594.5 \\
\hline $13: 45$ & -407.7 & -72.7 & -13.7 & -556.4 & -2151.9 & 90.4 & -653.3 & -624.6 & -491.9 & -82.8 & -13.8 & -551.7 & -2020.1 & 108.6 & -627.7 & -606.1 \\
\hline $14: 45$ & -333.2 & -58.3 & -11.3 & -511.2 & -2085.5 & 44.5 & -633.5 & -596.2 & -399.4 & -73.4 & -11.4 & -502.6 & -2026.1 & 93.1 & -624.1 & -586.4 \\
\hline $15: 45$ & -371.6 & -78.3 & -11.9 & -605.8 & -2009.7 & 103.2 & -618.1 & -630.4 & -365.9 & -97.3 & -12.6 & -641.6 & -2125.2 & 87.7 & -656.9 & -668.7 \\
\hline $16: 00$ & -419.7 & -105.9 & -13.7 & -694.4 & -1938.5 & 178.4 & -606.0 & -657.2 & -450.7 & -99.3 & -14.6 & -680.7 & -2181.1 & 125.5 & -674.3 & -697.8 \\
\hline
\end{tabular}


Table 3-4: Jonckheere-Terpstra Test Results for Spreads, Ask Size (AS) and Bid Size (BS) in High and Normal Volatility

\begin{tabular}{|c|c|c|c|c|c|c|}
\hline & Spreads High & Spreads Normal & AS High & AS Normal & BS High & BS Normal \\
\hline Statistic & $2.90 \mathrm{E}+14$ & $2.68 \mathrm{E}+14$ & $4.84 \mathrm{E}+14$ & $2.78 \mathrm{E}+14$ & $4.60 \mathrm{E}+14$ & $2.80 \mathrm{E}+14$ \\
\hline $\mathrm{Z}$ & -2295.6566 & -55.265 & 1292.6635 & 202.9798 & 849.3866 & 244.1068 \\
\hline $\mathrm{p}$-value & $<.0001$ & $<.0001$ & $<.0001$ & $<.0001$ & $<.0001$ & $<.0001$ \\
\hline $\mathrm{N}$ & 49376492 & 38474836 & 49376492 & 38474836 & 49376492 & 38474836 \\
\hline
\end{tabular}


Table 3-5: Regression Results

Panel A: Multivariate Regression Analysis in High Volatility of Liquidity and Depth Variables $Y_{i t}=\alpha_{i}+\sum_{i=1}^{5} \beta_{i} D_{i t}+\beta_{6} T O_{i t}+\beta_{7} V_{o l} l_{i t}+C S V_{i t}+T S V_{i t}+E r r_{i t}$

\begin{tabular}{|c|c|c|c|c|c|c|c|c|c|c|c|c|c|c|c|}
\hline & \multicolumn{2}{|c|}{-3} & \multicolumn{2}{|c|}{-2} & \multicolumn{2}{|c|}{-1} & \multicolumn{2}{|c|}{2} & \multicolumn{2}{|c|}{3} & \multicolumn{2}{|c|}{ Int } & \multirow[t]{2}{*}{ Vol } & \multirow[t]{2}{*}{ TO } & \multirow[t]{2}{*}{$\mathrm{R}^{2}$} \\
\hline & Beta & $\mathrm{SE}$ & Beta & $\mathrm{SE}$ & Beta & SE & Beta & SE & Beta & $\mathrm{SE}$ & Beta & $\mathrm{SE}$ & & & \\
\hline $\mathrm{S}$ & 0.119 & 0.106 & 0.415 & 0.068 & 0.174 & 0.068 & 0.135 & 0.068 & 0.044 & 0.105 & 0.027 & 0.055 & 0.394 & 0.121 & 0.940 \\
\hline QSp & 0.060 & 0.053 & 0.207 & 0.034 & 0.087 & 0.034 & 0.067 & 0.034 & 0.022 & 0.053 & 0.013 & 0.028 & 0.394 & 0.060 & 0.940 \\
\hline LS & 0.000 & 0.002 & 0.001 & 0.001 & 0.001 & 0.001 & 0.005 & 0.001 & 0.001 & 0.002 & 0.001 & 0.001 & 0.439 & 0.005 & 0.910 \\
\hline PS & 0.107 & 0.110 & 0.166 & 0.070 & 0.100 & 0.071 & 0.369 & 0.071 & 0.109 & 0.109 & 0.049 & 0.056 & 0.523 & 0.143 & 0.882 \\
\hline QS1 & 0.051 & 0.036 & 0.098 & 0.023 & 0.055 & 0.023 & 0.034 & 0.023 & 0.024 & 0.035 & 0.005 & 0.020 & 0.386 & -0.008 & 0.906 \\
\hline BS & -28.483 & 6.639 & -20.603 & 4.330 & -24.042 & 4.334 & -19.832 & 4.291 & -28.156 & 6.636 & 34.304 & 3.111 & 0.217 & 0.511 & 0.922 \\
\hline AS & -25.215 & 5.812 & -16.990 & 3.793 & -20.430 & 3.796 & -14.823 & 3.752 & -23.259 & 5.810 & 30.224 & 2.734 & 0.233 & 3.072 & 0.937 \\
\hline
\end{tabular}

Panel B: Multivariate Regression Analysis in Normal Volatility of Liquidity and Depth Variables $Y_{i t}=\alpha_{i}+\sum_{i=1}^{5} \beta_{i} D_{i t}+\beta_{6} T O_{i t}+\beta_{7} V_{o l}+\operatorname{CSV}_{i t}+T S V_{i t}+\operatorname{Err}_{i t}$

\begin{tabular}{|c|c|c|c|c|c|c|c|c|c|c|c|c|c|c|c|}
\hline & \multicolumn{2}{|c|}{-3} & \multicolumn{2}{|c|}{-2} & \multicolumn{2}{|c|}{-1} & \multicolumn{2}{|c|}{2} & \multicolumn{2}{|c|}{3} & \multicolumn{2}{|c|}{ Int } & \multirow[t]{2}{*}{ Vol } & \multirow[t]{2}{*}{$\mathrm{TO}$} & \multirow[t]{2}{*}{$\mathrm{R}^{2}$} \\
\hline & Beta & SE & Beta & SE & Beta & $\mathrm{SE}$ & Beta & SE & Beta & $\mathrm{SE}$ & Beta & $\mathrm{SE}$ & & & \\
\hline $\mathrm{S}$ & 0.033 & 0.017 & 0.061 & 0.016 & 0.052 & 0.016 & 0.041 & 0.016 & 0.077 & 0.016 & 0.019 & 0.018 & 0.177 & -0.031 & 1.000 \\
\hline QSp & 0.016 & 0.008 & 0.031 & 0.008 & 0.026 & 0.008 & 0.021 & 0.008 & 0.038 & 0.008 & 0.010 & 0.009 & 0.177 & -0.016 & 1.000 \\
\hline LS & 0.001 & 0.000 & 0.001 & 0.000 & 0.001 & 0.000 & 0.002 & 0.000 & 0.001 & 0.000 & 0.000 & 0.000 & 0.221 & -0.006 & 0.892 \\
\hline PS & 0.101 & 0.018 & 0.090 & 0.018 & 0.066 & 0.018 & 0.114 & 0.018 & 0.094 & 0.018 & 0.039 & 0.018 & 0.342 & -0.411 & 0.925 \\
\hline QS1 & 0.019 & 0.005 & 0.020 & 0.005 & 0.018 & 0.005 & 0.014 & 0.005 & 0.030 & 0.005 & 0.005 & 0.006 & 0.183 & -0.075 & 1.000 \\
\hline BS & 209.951 & 40.125 & 130.974 & 39.556 & 118.603 & 39.721 & -29.811 & 41.167 & 125.120 & 40.209 & -100.293 & 28.696 & 0.298 & -15.232 & 0.883 \\
\hline OS & 188.539 & 46.103 & 65.819 & 45.430 & 50.658 & 45.617 & 81.943 & 46.937 & 64.969 & 46.209 & -28.219 & 32.941 & 0.268 & -37.395 & 0.855 \\
\hline
\end{tabular}


Table 3-6: $Z$ statistic for Comparing Regression Coefficients in High Volatility $Z=\frac{\left(\beta_{i}-\beta_{k}\right)}{\sqrt{S E_{i}{ }^{2}+S E_{k}{ }^{2}}}$

\begin{tabular}{|c|c|c|c|c|c|}
\hline Spread Statistic & -3 & -2 & -1 & 2 & 3 \\
\hline-3 & 0.000 & 2.357 & 0.438 & 0.125 & -0.506 \\
\hline-2 & -2.357 & 0.000 & -2.497 & -2.920 & -2.966 \\
\hline-1 & -0.438 & 2.497 & 0.000 & -0.410 & -1.041 \\
\hline 2 & -0.125 & 2.920 & 0.410 & 0.000 & -0.728 \\
\hline 3 & 0.506 & 2.966 & 1.041 & 0.728 & 0.000 \\
\hline Quoted Spread Statistic & -3 & -2 & -1 & 2 & 3 \\
\hline-3 & 0.000 & 2.357 & 0.438 & 0.125 & -0.506 \\
\hline-2 & -2.357 & 0.000 & -2.497 & -2.920 & -2.966 \\
\hline-1 & -0.438 & 2.497 & 0.000 & -0.410 & -1.041 \\
\hline 2 & -0.125 & 2.920 & 0.410 & 0.000 & -0.728 \\
\hline 3 & 0.506 & 2.966 & 1.041 & 0.728 & 0.000 \\
\hline Log Spread Statistic & -3 & -2 & -1 & 2 & 3 \\
\hline-3 & 0.000 & 0.382 & 0.140 & 2.182 & 0.092 \\
\hline-2 & -0.382 & 0.000 & -0.316 & 2.390 & -0.275 \\
\hline-1 & -0.140 & 0.316 & 0.000 & 2.677 & -0.031 \\
\hline 2 & -2.182 & -2.390 & -2.677 & 0.000 & -2.092 \\
\hline 3 & -0.092 & 0.275 & 0.031 & 2.092 & 0.000 \\
\hline Percent Spread Statistic & -3 & -2 & -1 & 2 & 3 \\
\hline-3 & 0.000 & 0.445 & -0.053 & 2.000 & 0.009 \\
\hline-2 & -0.445 & 0.000 & -0.650 & 2.044 & -0.436 \\
\hline-1 & 0.053 & 0.650 & 0.000 & 2.678 & 0.064 \\
\hline 2 & -2.000 & -2.044 & -2.678 & 0.000 & -2.000 \\
\hline 3 & -0.009 & 0.436 & -0.064 & 2.000 & 0.000 \\
\hline Quote Slope Statistic & -3 & -2 & -1 & 2 & 3 \\
\hline-3 & 0.000 & 1.109 & 0.092 & -0.402 & -0.543 \\
\hline-2 & -1.109 & 0.000 & -1.330 & -1.998 & -1.767 \\
\hline-1 & -0.092 & 1.330 & 0.000 & -0.647 & -0.738 \\
\hline 2 & 0.402 & 1.998 & 0.647 & 0.000 & -0.245 \\
\hline 3 & 0.543 & 1.767 & 0.738 & 0.245 & 0.000 \\
\hline Bid Size Statistic & -3 & -2 & -1 & 2 & 3 \\
\hline-3 & 0.000 & 0.994 & 0.560 & 1.094 & 0.035 \\
\hline-2 & -0.994 & 0.000 & -0.561 & 0.126 & -0.953 \\
\hline-1 & -0.560 & 0.561 & 0.000 & 0.690 & -0.519 \\
\hline 2 & -1.094 & -0.126 & -0.690 & 0.000 & -1.053 \\
\hline 3 & -0.035 & 0.953 & 0.519 & 1.053 & 0.000 \\
\hline Offer Size Statistic & -3 & -2 & -1 & 2 & 3 \\
\hline-3 & 0.000 & 1.185 & 0.689 & 1.502 & 0.238 \\
\hline-2 & -1.185 & 0.000 & -0.641 & 0.406 & -0.904 \\
\hline-1 & -0.689 & 0.641 & 0.000 & 1.051 & -0.408 \\
\hline 2 & -1.502 & -0.406 & -1.051 & 0.000 & -1.220 \\
\hline 3 & -0.238 & 0.904 & 0.408 & 1.220 & 0.000 \\
\hline
\end{tabular}


Table 3-7: Z statistic for Comparing Regression Coefficients in Normal Volatility

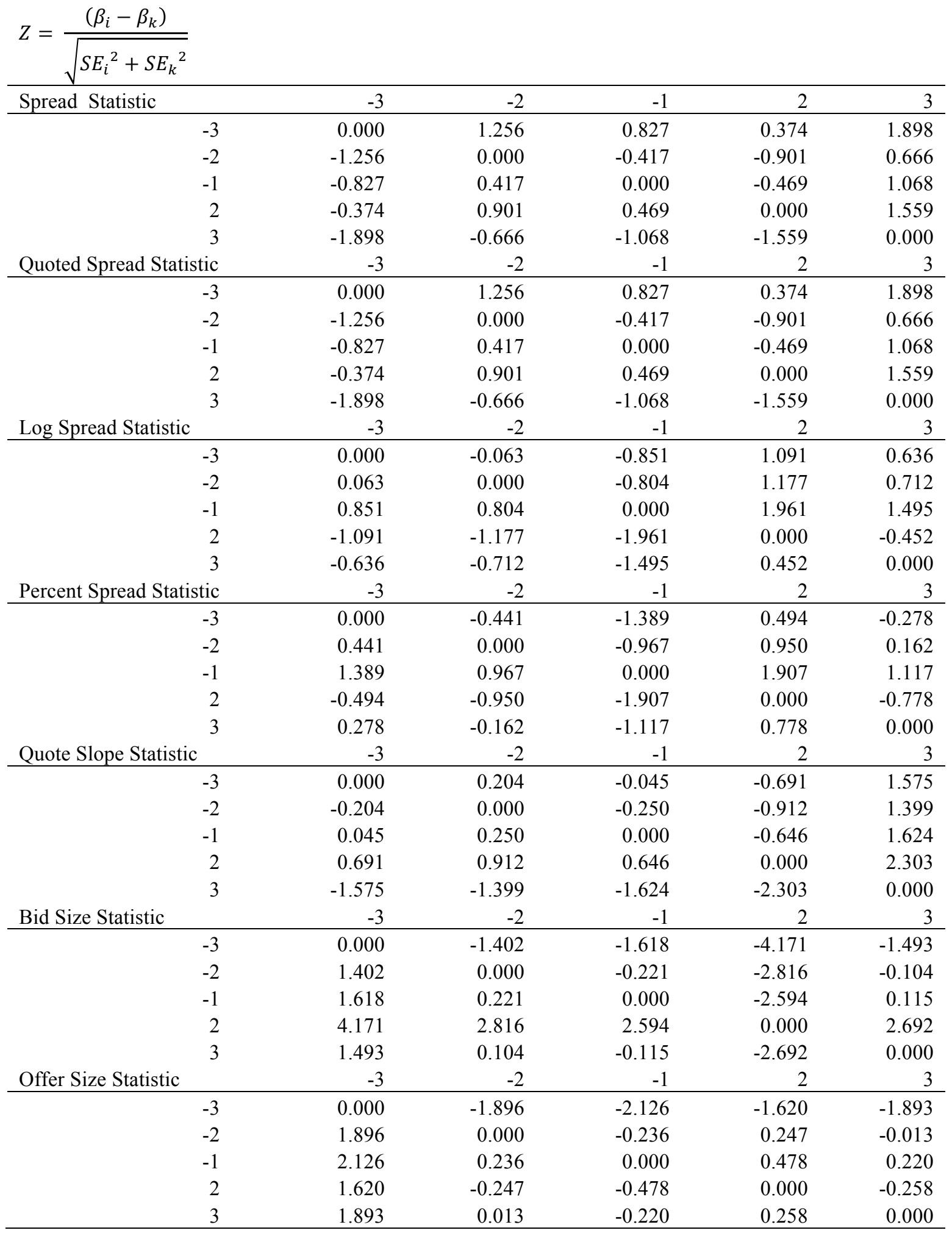




\section{REFERENCES}

Abhyankar, A., Ghosh, D., Levin, E., \& Limmack, R. J. (1997, April). Bid-Ask Spreads, Trading Volume and Volatility: Intra-Day Evidence from the London Stock Exchange. Journal of Business Finance \& Accounting, 24(3 \& 4), 343-362.

Avellaneda, M., \& Zhang, S. (2009, May 15). Path-dependence of Leveraged ETF returns. Working Paper available at http://ssrn.com/abstract=1404708 , 1-25.

Barnhart, S. W., \& Rosenstein, S. (Forthcoming). Exchange-Traded Fund Introduction and Closed-End Fund Discounts and Volume. Financial Review .

Black, F. (1975). Fact and Fantasy in the Use of Options. Financial Analysts Journal, 31, 36-72.

Canadian Foundation for Advancement of Investors Rights. (2009, May 14). Submissions: Heads You Lose, Tails You Lose: The Strange Case of Leveraged ETFs. Retrieved July 1, 2010, from FAIR Canada website: http://faircanada.ca/wp-content/uploads/2008/12/etfs-may-14pm-etf-swfinal-finall.pdf

Cai, C. X., Hudson, R., \& Keasey, K. (2004, June/July). Intra Day Bid-Ask Spreads, Trading Volume and Volatility: Recent Empirical Evidence from the London Stock Exchange. Journal of Business Finance \& Accounting, 31(5 \& 6), 647-676.

Chelley-Steeley, P., \& Park, K. (2008). Evaluating Spread Decomposition Models with a Basket Security. Aston University Working Paper .

Cheng, M., \& Madhavan, A. (2009, April 8). The Dynamics of Leveraged and Inverse-Exchange Traded Funds. Barclays Global Investors .

Choi, J., Salandro, D., \& Shastri, K. (1988). On the Estimation of Bid-Ask Spreads: Theory and Evidence. Journal of Financial and Quantitative Analysis , 23, 219-230.

Clarke, J., \& Shastri, K. (2001, January). Adverse Selection Costs and Closed-End Funds. University of Pittsburgh Working Paper .

Copeland, T. E., \& Galai, D. (1983). Information Effects on the Bid-Ask Spread. The Journal of Finance, 38, 1457-1469.

Daigler, R., \& Wiley, M. (1999). The Impact of Trader Type on the Futures Volatility-Volume Relation. Journal of Finance, 2297-2316.

Easley, D., \& O'Hara, M. (1987). Price, Trade, Size and Information in Securities Markets. Journal of Financial Economics , 19, 69-90.

Easley, D., Kiefer, N. M., \& O'Hara, M. (1996). Liquidity, Information, and Infrequently Traded Stocks. Journal of Finance , 51, 1405-1436.

Engle, R., \& Sarkar, D. (2006). Premiums-Discounts and Exchange Traded Funds. The Journal of Derivatives , 13 (4), 27-45. 
Fama, E. F. (1970). Efficient Capital Markets: A Review of Theory and Empirical Work. The Journal of Finance , 25 (2), 383-417.

Froot, K. A., \& Dabora, E. M. (1999). How Are Stock Prices Affected by the Location of Trade? Journal of Financial Economics, 53, 189-216.

Garman, M., \& Klass, M. (1980). On the Estimation of Security Price Volatility from Historical Data. Journal of Business , 319-331.

George, T. J., Kaul, G., \& Nimalendran, M. (1991). Estimation of the Bid-Ask Spreads and its Components: A New Approach. Review of Financial Studies , 4, 623-656.

Glosten, L. R., \& Harris, L. E. (1988). Estimating the Components of the Bid-Ask Spread. Journal of Financial Economics , 21, 123-142.

Glosten, L., \& Milgrom, P. (1985). Bid, Ask and Transaction Prices in a Specialist Market with Heterogeneously Informed Traders. Journal of Financial Economics , 13, 71-100.

Goodhart, C. A., \& O'Hara, M. (1997). High Frequency Data in Financial Markets: Issues and Applications. Journal of Empirical Finance, 4, 73-114.

Guedj, I., \& Huang, J. (2008, November). Are ETFs Replacing Index Mutual Funds? McCombs School of Business Working Paper.

Guiese, G. (2010, April 18). On the Performance of Leveraged and Optimally Leveraged Investment Funds. Working Paper available at http://ssrn.com/abstract=1510344, 1-21.

Gwilym, O. A., Buckle, M., \& Thomas, S. (1997). The Intraday Behavior of Bid-Ask Spreads, Returns, and Volatility for FTSE-100 Stock Index Options. The Journal of Derivatives, 20-32.

Hasbrouck, J. (1991). Measuring the Information Content of Stock Trades. Journal of Finance, 46, 179-207.

Huang, R. D., \& Stoll, H. R. (1997). The Components of the Bid-Ask Spread: A General Approach. The Review of Financial Studies , 10 (4), 995-1034.

Huang, R., \& Stoll, H. (1994). Market Microstructure and Stock Return Predictions. Review of Financial Studies , 7, 179-213.

Hupperets, C. J., \& Menkveld, A. J. (2002). Intraday Analysis of Market Integration: Dutch Blue Chips Traded in Amsterdam and New York. Journal of Financial Markets, 5, 57-82.

Jain, P. C., \& Joh, G.-H. (1988). The Dependence between Hourly prices and Trading Volume. The Journal of Financial and Quantitative Analysis, 23(3), 269-283.

Justice, P. (2009, January 22). Warning: Leveraged and Inverse ETFs Kill Portfolios. Retrieved July 1, 2010, from Morningstar website: http://news.morningstar.com 
Kyle, A. (1985). Continuous Auctions and Insider Trading. Econometrica , 53 (6), 1315-1335.

Lee, C., \& Ready, M. (1991). Inferring Trade Direction from Intraday Data. The Journal of Finance , 46, 733-746.

Lauricella, T., Pulliam, S., \& Gullapalli, D. (2008, December 15). Are ETFs Driving Late-Day Turns? Leveraged Vehicles Seen Magnifying Other Bets; Last-Hour Volume Surge. The Wall Street Journal , p. C1.

Lin, J. C., Sanger, G., \& Booth, G. (1995). Trade Size and Components of the Bid-Ask Spread. Review of Financial Studies , 8, 1153-1183.

Lin, W.-L., Engle, R. F., \& Ito, T. (1994). Do Bulls and Bears Move across Borders? International Transmission of Stock Returns and Volatility. The Review of Financial Studies, $7(3), 507-538$.

Liu, Q. (2009, November 18). The Jump Risk of Leveraged ETFs and a High-Frequency Volatility Estimator. Working Paper available at http://ssrn.com/abstract=1571003 , 1-47.

Lu, L., Wang, J., \& Zhang, G. (2009, August). Long Term Performance of Leveraged ETFs. Working Paper available at http://ssrn.com/abstract=134133 , 1-29.

Madhavan, A., Richardson, M., \& Roomans, M. (1997). Why Do Security Prices Change? A Transaction Level Analysis of NYSE Stocks. Review of Financial Studies , 10 (4), 1035-1064.

Malkiel, B. G. (2003). The Efficient Market Hypothesis and Its Critics. Journal of Economic Perspectives , 17 (1), 59-82.

McInnish, T. H., \& Wood, R. A. (1992). An Analysis of Intraday Patterns in Bid/Ask Spreads for NYSE Stocks. The Journal of Finance, 47(2), 753-764.

Neal, R., \& Wheatley, S. M. (1998). Adverse Selection and Bid-Ask Spreads: Evidence from Closed-End Funds. Journal of Financial Markets , 121-149.

Roll, R. (1984). A Simple Implicit Measure of the Effective Bid-Ask Spread in an Efficient Market. The Journal of Finance, 39, 1127-39.

Ross, S. M. (1996). Stochastic Processes. New York: John Wiley.

Stanley, D. (2009, June). Leveraged Exchange Traded Funds. Canadian MoneySaver, pp. 9-11.

Stoll, H. R. (1989). Inferring the Components of the Bid-Ask Spread: Theory and Empirical Tests. The Journal of Finance , 44 (1), 115-134.

Van Ness, B. F., Van Ness, R. A., \& Warr, R. S. (2001). How Well Do Adverse Selection Components Measure Adverse Selection? Financial Management, 5-30.

Werner, I. M., \& Kleidon, A. W. (1996). U.K. and U.S. Trading of British Cross-Listed Stocks: An Intraday Analysis of Market Integration. The Review of Financial Studies, 9(2), 619-664. 
VITA

\section{SAMIQUE MARCH}

Born, St. Catherine, Jamaica

2000-2005

B.S., Mathematical Sciences

Certificate, Actuarial Studies

Florida International University

Miami, Florida

2006-2007

M.S., Finance

Florida International University

Miami, Florida

2008-2011

Instructor

Florida International University

Miami, Florida

2007-2013

Doctoral Candidate

Florida International University

Miami, Florida

\section{PRESENTATIONS}

Turn of the Month Effect Across Equity Markets, Across Industries, and Across Extreme Market Conditions, with Shahid Hamid, presented at the 2010 Southern Finance Association meetings in Asheville, North Carolina.

Corporate Spin-offs: Examining the effects on the Entrepreneurial Orientation InheritanceFinancial Performance Relationship. with Derek Holloman and Leslie Klieb, presented at the 2012 IABPAD Conference in Dallas, Texas 